\title{
The Glacial History of Rocky Top Cirque, Southeast Fiordland, New Zealand
}

\author{
Emily Mary McKirdy Moore
}

A thesis submitted to Victoria University of Wellington in partial fulfilment of requirements for the degree of Master of Science in Physical Geography

School of Geography, Environment and Earth Sciences Victoria University of Wellington 



\section{ABSTRACT}

Understanding natural climate variability is a fundamental goal of paleoclimate science. Temperate mountain glaciers are sensitive to climate variability, changing volume, and thus thickness and length, in response to changes in temperature and precipitation. Glaciers deposit moraines at their margins, which if well-preserved may provide evidence of glacier length fluctuations following glacial retreat. Therefore mountain glaciers can be used as proxies to investigate past climatic changes, offering the potential to reconstruct the timing and magnitude of natural climate variability and paleoclimate for the former glacier extent(s).

This study applies methods of detailed geomorphological mapping and cosmogenic ${ }^{10} \mathrm{Be}$ surface exposure dating to establish a high-precision moraine chronology and examine the timing and magnitude of glacier length changes at Rocky Top cirque. A quantitative reconstruction of paleoclimate for the identified former glacier extents was produced using an equilibrium-line altitude (ELA) reconstruction method and application of a temperature lapse rate. Findings show a clear pattern of glacial retreat at the end of the Last Glacial Maximum, with exposure ages from moraine boulders successfully constraining the timing of five distinct periods of glacier readvance or standstills. The most recent glacial event at Rocky Top cirque occurred between $17342 \pm 172$ yrs BP and during this period the ELA was depressed by $611 \mathrm{~m}$. The second innermost moraine produced an indistinguishable age of $17196 \pm 220 \mathrm{yrs}$ BP and had an ELA depression of $616 \mathrm{~m}$, indicating rapid glacial retreat. Progressively older moraines produced surface exposure ages of $18709 \pm 237$ and $19629 \pm 308$ yrs BP, with ELA depressions of 618 and $626 \mathrm{~m}$ respectively. The oldest moraine of $34608 \pm 8437 \mathrm{yrs}$ BP had insufficient geomorphic constraint to produce an ELA. Paleoclimate reconstruction results suggest that a best estimate of paleotemperature at the time of moraine formation ( $\sim 19-17 \mathrm{ka})$ was between $3.2 \pm 0.8$ to $3.3 \pm 0.8^{\circ} \mathrm{C}$ cooler than presentday.

Net retreat of the former glacier is consistent with other similar moraine chronologies from the Southern Alps, which supports the regional trend and suggests that glaciers in the Southern Alps responded to common climatic forcings between $\sim 19-17 \mathrm{ka}$. 



\section{ACKNOWLEDGEMENTS}

I have truly enjoyed the undertaking of this research, but it wouldn't have been possible without the support of many people. Firstly, I would like to thank my supervisor Shaun Eaves. Thank you for all of your helpful and prompt advice - I couldn't have asked for a better supervisor! I thank Kevin Norton for his input to my project and many hours spent helping in the cosmogenic nuclide lab. I also thank the Cosmo Lab technician Luisa Ashworth for her support in the lab (also I'm sorry I melted your oven!). Thank you to the VUW Cosmo group, in particular to Jamey Stutz and Claire Lukens who were always happy to volunteer to be my HF buddy. Thanks to Meah Taylor and Richard Jones for assisting with fieldwork at Rocky Top cirque in December 2018, it was a great trip!

Thank you to my fellow MSc students, I am grateful for your support and friendship over the past two years. In particular I would like to thank Sam Treweek, Josh Lee, Brenton Tozer and Marcel Lanz - thanks for making me smile and putting up with my pranks on your desks. I would also like to thank my family, Pamela, Stephen and Edward, for their love and encouragement.

Finally, I would like to acknowledge Andrew Mackintosh for his involvement in the initial stages of designing this project. This study was funded by a Marsden Grant. Sample analyses were processed at the Lawrence Livermore National Laboratory (LLNL) Center for Accelerator Mass Spectrometry (CAMS). 


\section{TABLE OF CONTENTS}

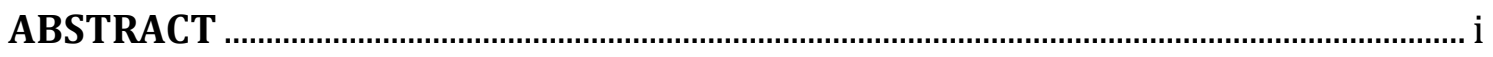

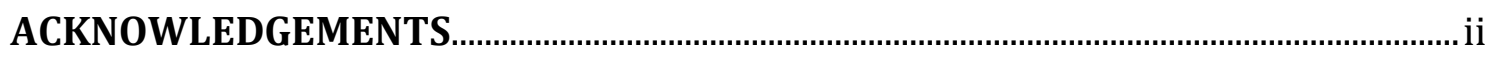

TABLE OF CONTENTS

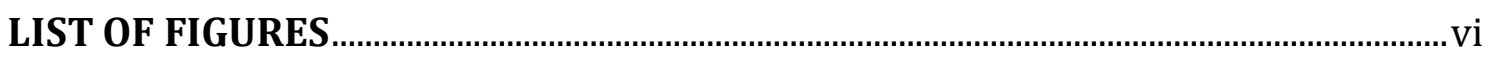

LIST OF TABLES ................................................................................................................... viii

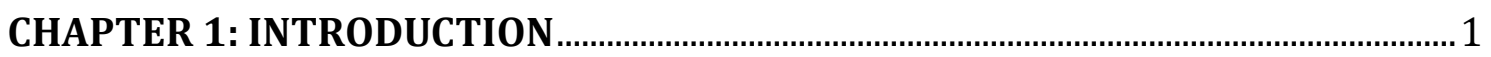

CHAPTER 2: BACKGROUND .................................................................................... 5

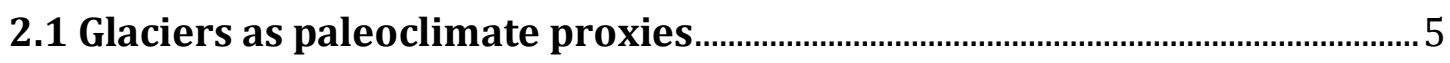

2.1.1 Glacier mass balance and climate ........................................................................ 5

2.1.2 Moraine formation and preservation................................................................. 11

2.1.3 Moraines and their paleoclimatic significance ................................................. 13

2.2 Cosmogenic nuclide surface exposure dating …….......................................... 16

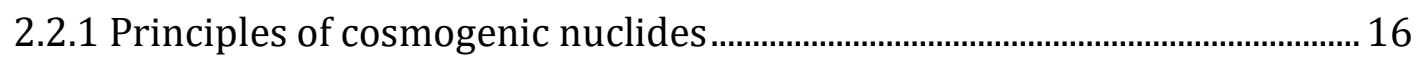

2.2.2 Cosmic ray flux variation with latitude, altitude and depth ........................... 19

2.2.3 Cosmogenic nuclide production rates .............................................................. 25

2.2.4 Applications of the ${ }^{10} \mathrm{Be}$ cosmogenic nuclide ................................................. 27

2.3 Existing moraine chronologies in the Southern Alps ..................................... 30

2.3.1 Glacier retreat since the Last Glacial Maximum ............................................... 30

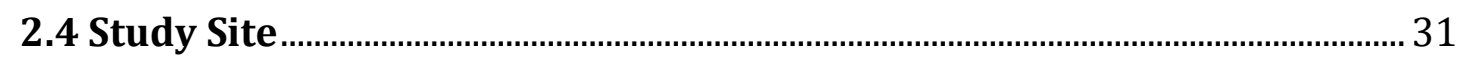

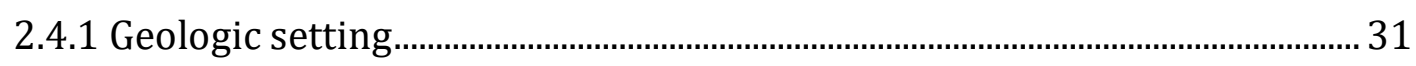

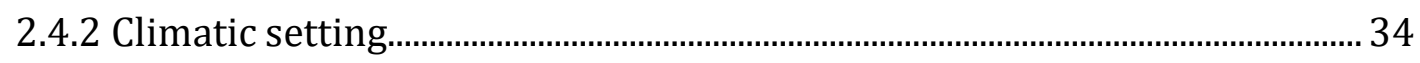

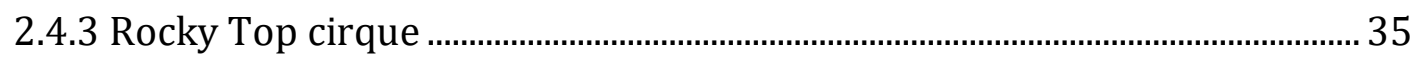

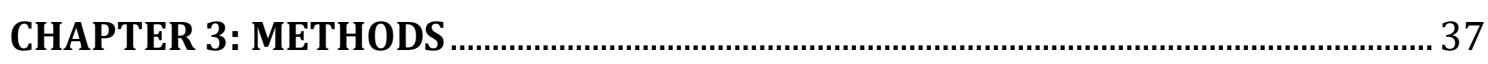

3.1 Geomorphological mapping of landforms at Rocky Top cirque................. 37

3.1.1 General approach and classification of landform type .................................... 37

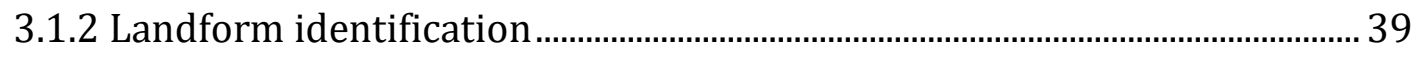

3.2 Cosmogenic ${ }^{10}$ Be surface exposure dating …….................................................. 41

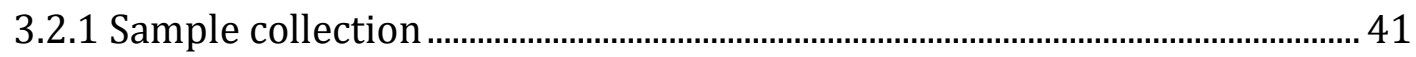

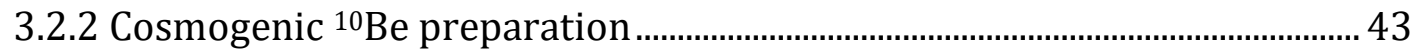

3.2.3 Cosmogenic ${ }^{10} \mathrm{Be}$ measurement and exposure age calculation .................... 48

3.3 Paleoclimate reconstruction ................................................................................ 51

3.3.1 Equilibrium-line altitude reconstruction ......................................................... 51

3.3.2 Paleotemperature reconstruction ................................................................ 54 
4.1 Glacial geomorphology of the Rocky Top cirque ................................................59

4.1.1 Lower cirque geomorphology …………..........................................................60

4.1.2 Upper cirque geomorphology............................................................................62

4.2 Cosmogenic ${ }^{10} \mathrm{Be}$ surface exposure ages........................................................67

4.3 Paleoclimate reconstruction ..................................................................................

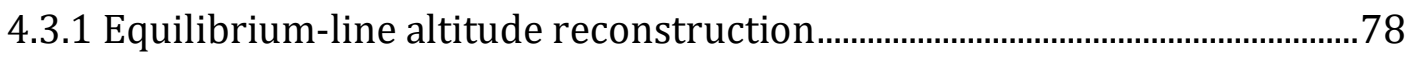

4.3.2 Paleotemperature reconstruction .......................................................................83

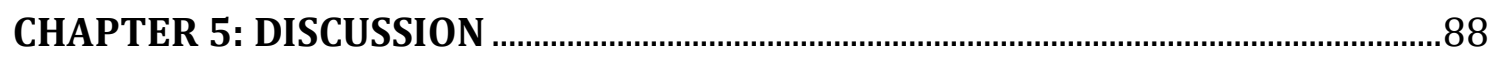

5.1 The chronology of glacier length changes at Rocky Top cirque.................88

5.2 Glacier length changes in the Southern Alps .....................................................95

5.3 Paleoclimatic implications of glacier length changes at Rocky Top

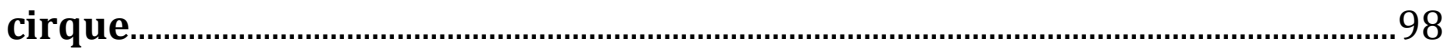

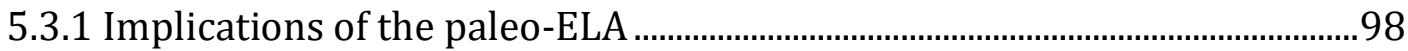

5.3.2 Implications of the present-day ELA............................................................100

5.3.3 Investigation into paleotemperature dissimilarities ....................................106

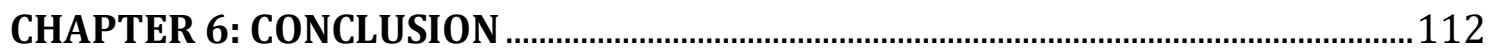

REFERENCES 


\section{LIST OF FIGURES}

Figure 2.1: Schematic cross section of a glacier ............................................................. 7

Figure 2.2: Modelled response time of individual glaciers.............................................. 9

Figure 2.3: Glacier length changes since the 1860's for selected glaciers around the world

Figure 2.4: The nuclear cascade of cosmic ray particles

Figure 2.5: The Earth's geomagnetic field and its effect on incoming primary cosmic rays.

Figure 2.6: Normalised neutron flux at sea level as a function of cut-off rigidity 21

Figure 2.7: Attentuation length as a function of cut-off rigidity. 23

Figure 2.8: ${ }^{10} \mathrm{Be}$ production rates in quartz with depth below the surface 24

Figure 2.9: Model showing the relationship between exposure time and nuclide concentration

Figure 2.10: Possible relationships between surface exposure ages of boulders and the true depositional age of moraines.

Figure 2.11: Location of Rocky Top cirque in the Southern Alps, NZ.

Figure 2.12: Interpreted distribution of ice and vegetation at the height of the LGM. 33

Figure 2.13: Oblique photograph of the Rocky Top cirque 36

Figure 3.1: 3D model of Rocky Top cirque. 40

Figure 3.2: Locations of the twenty processed boulder samples. 43

Figure 3.3: Flow chart of steps used for quartz separation and cosmogenic ${ }^{10} \mathrm{Be}$ preparation. 44

Figure 3.4: ELA calculation using the accumulation-area ratio (AAR) method.... 52 Figure 3.5: Example of a cumulative curve graph, showing area/altitude distribution. 54

Figure 3.6: Distribution of index glaciers in the Southern Alps. 57

Figure 4.1: Map showing the "lower cirque" and "upper cirque" areas 59

Figure 4.2: Moraines identified and labelled for reference 60

Figure 4.3: Photographs of geomorphic features at the study site 64

Figure 4.4: Geomorphological map of the Rocky Top cirque. 65

Figure 4.5: Glacial geomorphology mapping comparison 66

Figure 4.6: Sample exposure ages overlaid on the geomorphic map .73 
Figure 4.7: Camel diagrams of arithmetic mean ages for individual moraines........74 Figure 4.8: Photographs of some sampled boulders and their associated exposure ages 75

Figure 4.9: Camel diagrams of error weighted ages for individual moraines...........77

Figure 4.10: Manual glacier surface and equilibrium-line altitude reconstruction79

Figure 4.11: Cumulative curve graphs, showing altitude-area distribution. .81

Figure 4.12: Cumulative probability graphs of temperature anomaly, produced using a present-day ELA of $2907.7 \pm 602.4 \mathrm{~m}$

Figure 4.13: Cumulative probability graphs of temperature anomaly, produced using a present-day ELA of $1800 \pm 100 \mathrm{~m}$ .85

Figure 5.1: Photographs of boulders that were identified as outliers 91

Figure 5.2: Photographs of sampled boulders on Moraine R4 93

Figure 5.3: Map showing the location of the Green Lake landslide relative to Rocky Top cirque .99

Figure 5.4: Distribution of index glaciers in the Southern Alps 101

Figure 5.5: Annual index glacier survey results from 1977-2016 102

Figure 5.6: Major regions of New Zealand, as referred to by Drost et al. (2007).107

Figure 5.7: Photographs of the three index glaciers closest to Rocky Top 111 


\section{LIST OF TABLES}

Table 3.1: Summary descriptions of landform types.

Table 3.2: Description of inputs and values used for the online exposure-age calculator

Table 4.1: Inputs to the exposure age calculator for Rocky Top moraine landforms 70

Table 4.2: Cosmogenic ${ }^{10} \mathrm{Be}$ exposure ages for the Rocky Top cirque moraines 71

Table 4.3: Process blank ${ }^{10} \mathrm{Be} /{ }^{9} \mathrm{Be}$ ratios and number of ${ }^{10} \mathrm{Be}$ atoms. 72

Table 4.4: Summary statistics for each moraine landform at Rocky Top cirque 76 Table 4.5: Altitude-area distribution of each moraine landform at Rocky Top cirque 80

Table 4.6: Paleo-ELAs for each moraine-constrained glacier extent 82

Table 4.7: Temperature anomalies for the former glacier terminating at each moraine extent 86

Table 5.1: Summarised results of cosmogenic ${ }^{10}$ Be surface exposure dating ....... 89

Table 5.2: Summary of paleo-ELAs derived using the AAR method 98

Table 5.3: Summary of temperature anomalies for the former glacier terminating at each moraine extent 


\section{CHAPTER 1: INTRODUCTION}

Climate varies naturally on a range of timescales due to the combined influence of different climate forcings (Denton et al., 2010). Over the past $\sim 1$ million years there has been a global pattern of natural, cyclical changes between glacial and interglacial climate. Late Quaternary glacial cycles are characterised by a period of 80-120 kyr and an asymmetric signature, featuring a long cooling interval followed by a relatively short warming period (Denton et al., 2010). These natural cycles are paced by astronomically-induced variation and associated feedbacks of the seasonal and latitudinal distribution of insolation, known as 'Milankovich cycles' (Milankovich, 1941). Superimposed on the long-term trend of ice-sheet growth and decay, climate varies on relatively short-term (annual to millennial) timescales as a result of natural climate variability associated with factors that influence Earth's radiative balance, such as greenhouse gas, volcanic and solar forcings (Ciais et al., 2013). In addition to these external forcings, climate varies due to natural internal climate variability. Large-scale climate phenomena such as the El Nino Southern Oscillation (ENSO) work to redistribute heat and energy by oceanatmosphere interactions, which can create significant regional differences in climatic conditions on interannual to decadal timescales (Ummenhofer \& England, 2007).

Since the $18^{\text {th }}$ century Industrial Revolution, human activities have increased greenhouse gas concentrations by over $36 \%$ relative to pre-industrial levels (Forster et al., 2007). The anthropogenic change to atmosphere composition continues to impact the Earth's radiative balance, affecting Earth's energy budget and thus modifying the climate system (IPCC, 2013). The ability to directly attribute modern climate changes to anthropogenic influence is difficult, due to the spatial and temporal variation of climate caused by natural climate variability. In order to detect the extent of anthropogenic influence, there is a need for longer, more highly resolved records of natural climate variability. Comprehensive records provide a baseline for assessing anthropogenic climate change, by comparison of the pre-industrial or 'natural' and modern climatic conditions. 
To investigate pre-industrial climate prior to instrumental records, paleoclimate proxies may offer insight to past variability of the atmospheric and oceanic systems, which are considered to play significant roles in driving global climate change on short- to long-term timescales (Denton et al., 2010). Types of paleoclimate proxies include tree rings, lake and ocean deposits, speleothems and mountain glacier deposits. The Northern Hemisphere has significantly more detailed instrumental and paleoclimate records relative to the Southern Hemisphere, where climate records are generally much shorter and discontinuous. The gaps in the Southern Hemisphere climate record limit the ability to understand natural climate variability and detect the extent of anthropogenic impact on the climate system. The Southern Hemisphere records must be extended to assess the nature and drivers of natural climate variability.

One method to extend Southern Hemisphere records is the use of mountain glacier deposits as paleoclimate proxies. Temperate mountain glaciers are highly sensitive to changes in climate, particularly to changes in temperature and precipitation. Temperature and precipitation determine the amount of accumulation relative to ablation, thus impacting glacier mass balance. New Zealand glaciers are considered to be most sensitive to temperature, with a $\sim 37 \%$ increase in precipitation required to offset a $1^{\circ} \mathrm{C}$ increase in temperature (Anderson and Mackintosh, 2006). Sustained positive glacier mass balance increases glacier volume, typically resulting in advance of the glacier terminus. Conversely, sustained negative glacier mass balance may cause glacier retreat. Moraines are deposited around glacier margins, thus recording glacier length fluctuations. As such, moraine sequences can be used to reconstruct the magnitude and timing of past climate change, affording insight into past, natural climate fluctuations

New Zealand is a suitable location for glacier-climate reconstructions. In the Southern Alps the temperate climate, high relief topography and high precipitation levels cause glaciers to be very responsive to small changes in atmospheric and oceanic conditions (Willsman, 2017). The tectonically active setting contributes to an ample flux of debris, allowing glaciers to form sizeable moraines. The compilation of moraine chronologies from a variety of locations in the Southern Alps is required to examine the regional trend of climate changes associated with 
glacier length fluctuations. Despite recent progress, precisely-dated, quantitative paleoclimate reconstructions in New Zealand remain relatively limited. Records tend to be focused in the central Southern Alps (Barrell et al., 2013a). It is important to extend the spatial range of paleoclimate records, to better examine past climate in different settings and the variation in natural climate variability.

Cosmogenic ${ }^{10} \mathrm{Be}$ surface exposure dating is a commonly applied tool for establishing a high-precision moraine chronology. The basic principle of in situ cosmogenic nuclide exposure dating is that the cosmogenic-nuclide concentration in a rock sample is proportional to the length of time that the sample has been exposed at the Earth's surface (Dunai and Lifton, 2014). With the exception of rocks with complex exposure histories, the surface exposure age represents the age of glacier retreat from a period of standstill or readvance (Putnam et al., 2012). Compilation of a number of moraine chronologies can be used to produce a regional chronological framework of past climate change.

The former moraine-constrained glacier extent can be used to model paleoclimate. Manual glacier surface reconstruction can be used to identify the former equilibrium-line altitude (ELA), which can be translated to temperature change relative to the present-day ELA using temperature lapse rates. The usefulness of the derived paleotemperature estimate depends on the assumption that glacier length change is climatically-driven. Paleotemperature estimates may help to anticipate possible glacier length changes that could result from sustained current global warming.

In this study, a moraine chronology is established at Rocky Top cirque, situated in eastern Fiordland, Southern Alps. As most moraine sequences records are in the central Southern Alps, this previously undated location will help to fill a gap in data in the far south region of New Zealand. Overall, Rocky Top cirque is an ideal site for assessing glacier-climate fluctuations in New Zealand. Moraines are wellpreserved with distinct crests, clearly delineating former ice geometries. The site is unaffected by the presence of current or former pro-glacial lakes, or by significant surface debris cover, which may complicate the glacier-climate response (Mackintosh et al., 2017b). 
The central aims of this study are: (i) to constrain the timing and magnitude of glacier length changes at Rocky Top cirque; and (ii) to make a quantitative reconstruction of paleoclimate for former glacier extents at Rocky Top. To achieve these aims, I complete the following objectives:

1. Identify the distribution of glacial landforms at Rocky Top cirque by detailed geomorphological mapping.

2. Establish a moraine chronology at Rocky Top cirque by surface exposure dating of the in situ cosmogenic ${ }^{10}$ Be nuclide.

3. Provide quantitative estimates of past temperature change at former glacier extents at Rocky Top cirque, using manual glacier surface reconstruction and a Monte Carlo algorithm. 


\section{CHAPTER 2: BACKGROUND}

\subsection{Glaciers as paleoclimate proxies}

\subsubsection{Glacier mass balance and climate}

New Zealand has a temperate climate, where glaciers have high accumulation and ablation rates (Anderson and Mackintosh, 2006). Glaciers in the South Island are sensitive to small climatic changes and respond relatively quickly to variations in temperature and precipitation (Oerlemans, 1997). This makes them ideal for investigating climate variability over short- and long-term timescales.

Mass balance refers to the total net gain (accumulation) and net loss (ablation) of a glacier on a typically annual timescale. For a glacier in a steady-state, net accumulation equals net ablation (Mackintosh et al., 2017b). When glacier mass balance is not in equilibrium, a glacier with negative mass balance has ablation exceeding accumulation and vice versa for a glacier with positive mass balance. Over time a changing mass balance, or changing glacier volume, results in fluctuations of glacier length. Temperature and precipitation exert a strong influence on glacier mass balance. Temperature determines the amount of surface melt and whether precipitation falls as rain or snow, while precipitation as snow can cause the glacier to gain mass (Oerlemans and Fortuin, 1992; Mackintosh et al., 2017b).

For temperate glaciers, accumulation is greatest in the higher-elevation portion of the glacier and mainly occurs by precipitation of snow, though mass is also gained by refreezing of meltwater, avalanching from above, and wind-blown sources (Mackintosh et al., 2017b). In the Southern Alps precipitation rates are typically high (on the order of 5000-10,000 mm/yr in the central Southern Alps; Macara, 2013) and precipitation as snow on mountain glaciers tends to occur at temperatures below $0^{\circ} \mathrm{C}$, meaning that minor fluctuations in air temperature can potentially result in large changes in the amount of snow accumulation (Cullen and Conway, 2015; Mackintosh et al., 2017b). Ablation is typically greatest in the lower-elevation portion of the glacier and is dominated by surface melt processes. 
Other ablation processes include sublimation, evaporation, and calving of icebergs at the glacier terminus (Figure 2.1) (Mackintosh et al. 2017b).

Ablation at the glacier surface is controlled by the energy balance which incorporates incoming and outgoing shortwave and longwave radiation, as well as rain, surface and latent heat fluxes (Figure 2.1). Albedo affects the amount of shortwave radiation absorbed by a glacier, as ice $(\propto=0.3-0.6$; Gardener and Sharp, $2010)$ has the capacity to absorb $2-3 \mathrm{x}$ as much radiation as fresh snow $(\sim \propto=0.0 .6$ 0.95; Gardner and Sharp, 2010) (Oerlemans \& Knap, 1998; Mackintosh et al., 2017b). Cloud cover reduces incoming shortwave radiation, but tends to result in higher levels of incoming longwave radiation. Rain and surface heat fluxes have a relatively minor impact on the energy balance. Outgoing longwave radiation is dependent on the surface temperature. For air temperatures above freezing, each additional degree of air temperature is sufficient to cause an additional 30 $\mathrm{cm} /$ month (water equivalent) of melt, based on the latent heat of melting of ice (Mackintosh et al., 2017b). Air temperature has a dominant influence on the surface energy budget, so many mass balance modelling studies prefer to rely on the relationship between air temperature and ablation and do not calculate the full surface energy balance (Mackintosh et al., 2017b). 


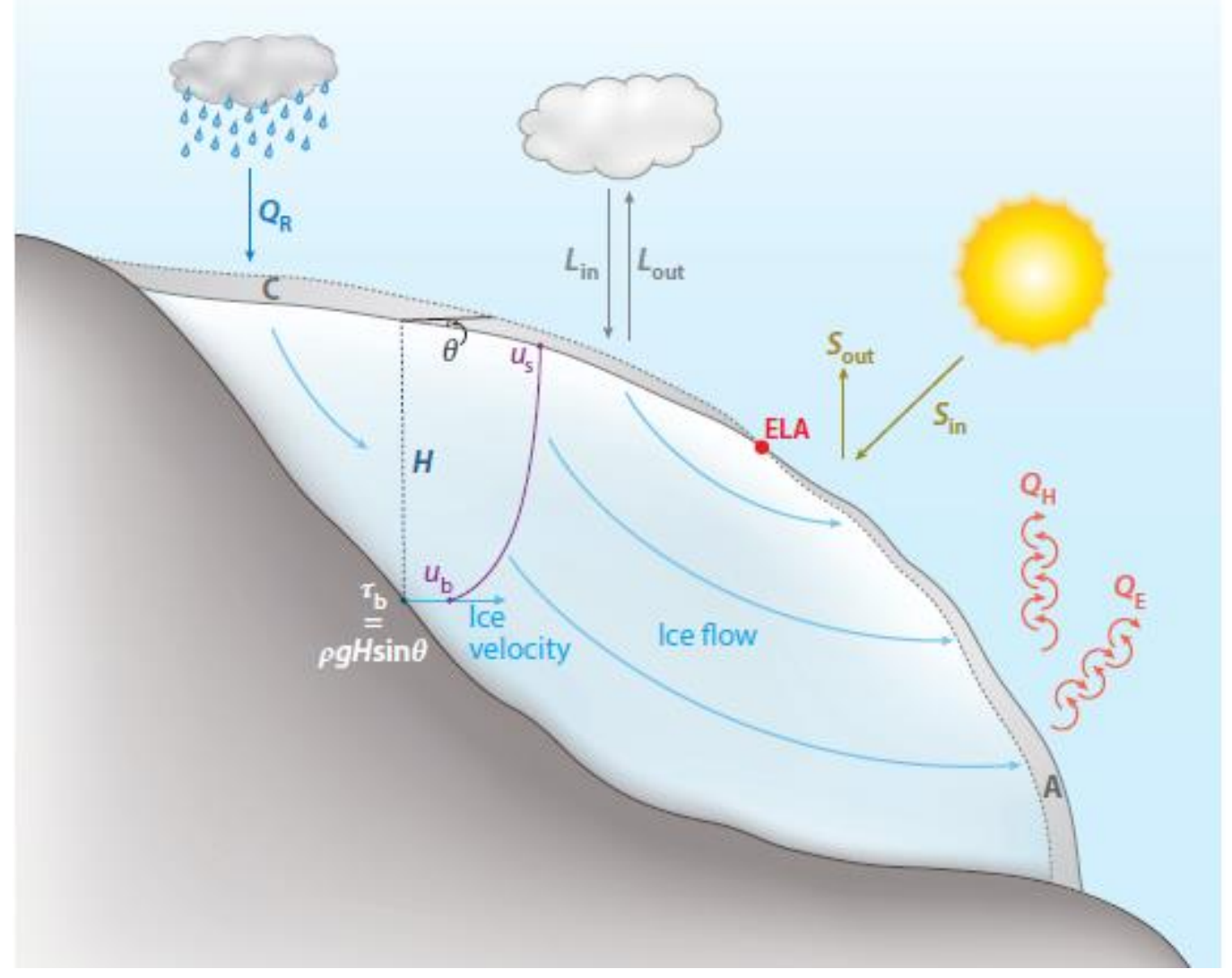

Figure 2.1: Schematic cross section of a glacier showing the equilibrium line altitude (ELA, red dot) and the major surface energy balance fluxed. Abbreviations: $A$, ablation; $C$, accumulation; $S_{\text {in }} / S_{\text {out }}$ incoming/outgoing shortwave radiation; $L_{\text {in }} / L_{\text {out }}$, incoming/outgoing longwave radiation; $Q_{E} / Q_{H} / Q_{R}$ latent/sensible/rain heat flux; $\theta$, surface slope; $H$, ice thickness; $u_{b}$, basal sliding; $u_{s}$, surface velocity. Figure from Mackintosh et al. (2017b).

The equilibrium-line altitude (ELA) marks the transition between zones of accumulation and ablation and has a net mass balance of zero (Figure 2.1) (Mackintosh et al., 2017b). As glacier mass balance fluctuates, the changing dimensions of accumulation and ablation zones causes the ELA to either increase or decrease in altitude. A glacier with positive mass balance experiences accumulation exceeding ablation, so the glacier increases in mass and the ELA decreases (Porter, 1975). Conversely, a glacier with negative mass balance experiences decreases in glacier mass, causing the ELA to increase. Therefore climate variability may cause glacier mass balance change over time, directly resulting in changes to glacier volume and length.

The relative importance of temperature and precipitation as drivers of glacier advance and retreat has been researched by a number of recent studies, the 
majority of which tend to agree that New Zealand glacier mass balance fluctuations are driven more by air temperature than precipitation on timescales of decades or longer (Oerlemans and Fortuin, 1992; Anderson and Mackintosh, 2006; Eaves et al., 2017; Mackintosh et al., 2017a). Anderson and Mackintosh (2006) modelled the Franz Josef Glacier and found that it could not have advanced to its late-glacial position in the absence of temperature change without requiring unrealistic precipitation values. Precipitation has a subsidiary role in mass balance fluctuations, where in New Zealand large precipitation changes of $\sim 37 \%$ are required to offset small temperature changes of $\sim 1^{\circ} \mathrm{C}$, depending on the setting and geometry of the glacier (Anderson \& Mackintosh, 2006; Mackintosh et al., 2017b).

Glacier response time refers to how quickly glacier mass balance changes following fluctuation in climatic conditions (Oerlemans, 2001). In other words, response time reflects how sensitive the mass balance is to external changes. Glacier response time is mostly influenced by flow, which is primarily controlled by the glacier surface slope and ice thickness (Figure 2.1) (Mackintosh et al., 2017b). Slope and thickness determine the driving stress, which controls the internal deformation of ice. Driving stress is assumed to be locally balanced by the shear stress, causing sliding and determining the surface velocity (Mackintosh et al., 2017b). As such, glaciers with steep slopes transfer mass to the ablation zone quickly, responding more promptly to climate perturbations that glaciers with gentler slopes (Figure 2.2). Glacier size also has some influence on response time, with larger glaciers tending to have longer response times due to their greater ice thickness and stability (Bahr et al., 1998). However, glacier slope exerts a dominant influence, meaning that relatively large but steeply sloping glaciers can have shorter response times than smaller, gently sloping glaciers (Figure 2.2) (Bahr et al., 1998; Mackintosh et al., 2017b; Zekollari et al., 2020). The variable response times mean that neighbouring glaciers may exhibit different length responses despite experiencing the same climatic perturbations. This is most important for high-frequency climate fluctuations and may explain why moraine records of the Last Glacial Maximum (LGM) can vary significantly between adjacent glaciers (Anderson et al., 2013). 

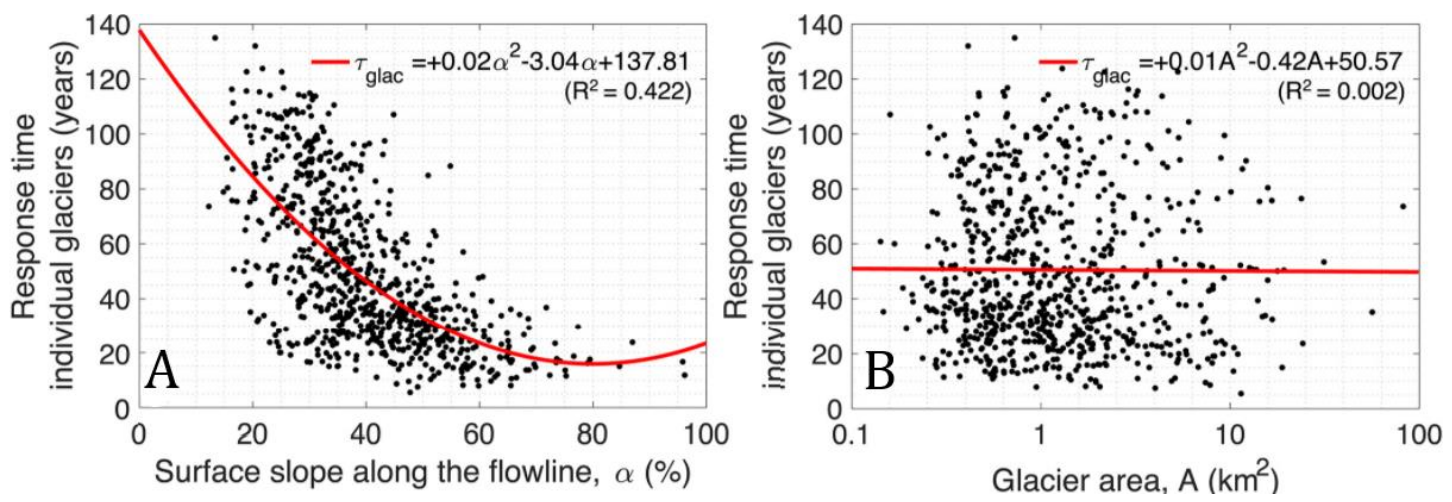

Figure 2.2: Modelled response time of individual glaciers ( $\tau$ glac) as a function of surface slope along the (a) flowline and (b) glacier area. Figure from Zekollari et al. (2020).

Glaciers tend to remain in a transient state as climatic conditions are constantly changing, so response time cannot be directly calculated from field data and is best estimated by numerical models which incorporate the climatic history (Oerlemans, 2001). Historic length changes of glaciers provide examples of variations in behaviour of glaciers with different response times (Figure 2.3). Between 19401980, glaciers with shorter response times (e.g., Franz Josef Glacier, NZ) exhibited repeated sharp length fluctuations within an overall trend of glacier retreat, whereas glaciers with longer response times (e.g., Vernagtferner, Austria) showed a relatively smoothed trend of retreat. In the 1990's a number of glaciers increased in length, most notably in Iceland and New Zealand (Figure 2.3), reflecting variability in atmospheric and oceanic circulation (Dowdeswell et al., 1997; Mackintosh et al., 2017b). Due to variable glacier response times, the increase in length was not ubiquitous (e.g., Rhonegletscher, Switzerland). It is difficult to conclude whether any differences in glacier behaviour between regions are asynchronous because two very different climate regions may experience different rates and magnitudes of temperature change. Variations in glacier response time are clearer when glaciers are in close proximity (have experienced the same climatic changes) but exhibit different length responses. 


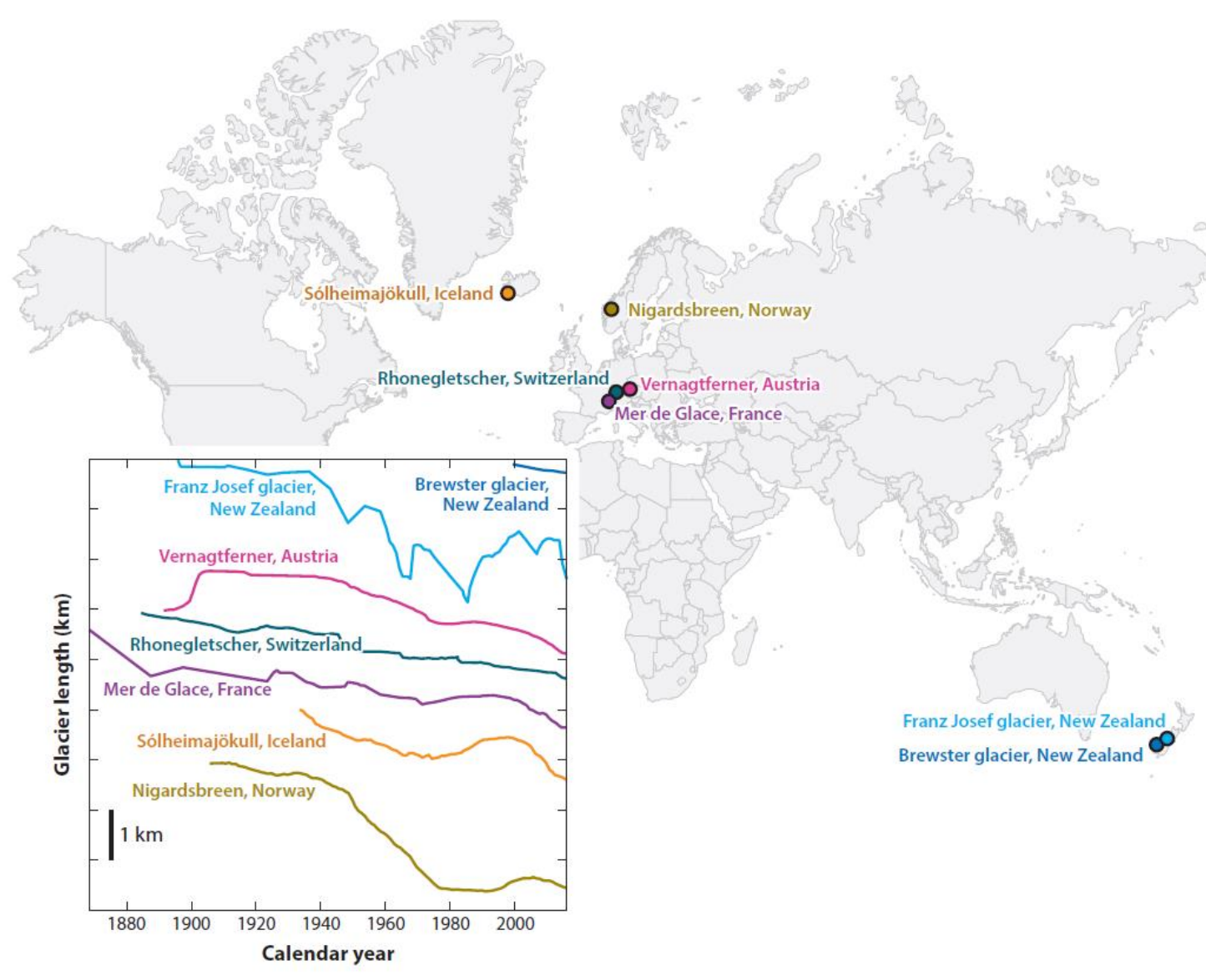

Figure 2.3: Glacier length changes since the 1860's for selected glaciers around the world. Data from the World Glacier Monitoring Service archive (http://wgms.ch). Figure from Mackintosh et al. (2017b).

On interannual to multidecadal timescales, temperature and precipitation are influenced by large-scale atmospheric and oceanic circulation patterns, as well as external factors (e.g. greenhouse gases, insolation). Climate oscillation patterns that are important in the New Zealand region include the El Nino Southern Oscillation (ENSO), Southern Annular Mode (SAM) and the Interdecadal Pacific Oscillation (IPO) (Jiang et al., 2013). Most precipitation to New Zealand glaciers is associated with fronts and low-pressure systems, combined with orographic processes in the Southern Alps (Mackintosh et al., 2017b). Circulation changes may influence temperature and precipitation by temporarily altering the location of fronts, and if a circulation type persists the glacier mass balance may fluctuate (Jiang et al., 2013). Mass balance increase leading to glacier advance in New Zealand is linked to negative phases of SAM, the IPO and El Nino events, which enhance westerly and southerly wind flow, lowering atmospheric pressure and sea surface temperatures (Fitzharris et al., 1997). Conversely, mass balance decrease is linked to positive phases of SAM, the IPO and La Nina events, which enhance 
northerly and easterly flow, increasing air pressure and sea surface temperatures in the Southern Alps (Fitzharris et al., 1997).

\subsubsection{Moraine formation and preservation}

Glaciers produce and transport debris, which is eventually deposited the margins of the glacier ablation area. The accumulation of debris forms moraines, typically defined as discrete ridges of unconsolidated, unstratified sediment (IvyOchs and Briner, 2014; Nesje and Dahl, 2000). Following glacial retreat moraines may remain indefinitely, marking the former extent of the glacier. If a chronology can be established moraines may be used to reconstruct the timing of past climate changes that caused glacier retreat.

Glaciers generate debris though a variety of processes including abrasion, plucking, scouring by meltwater and chemical denudation (Wirsig et al., 2017). Factors that influence subglacial debris production include bedrock lithology, the volume and pressure of meltwater, and variations in ice flux (Wirsig et al., 2017). Debris may also originate from glacier surroundings, such as via mass-movement processes on rock walls above the accumulation area. As the glacier flows downslope, the debris entrained is transported en- (within the glacier), sub- (at the glacier bed) and supra-glacially (at the glacier surface). Eventually the debris is deposited at the glacier front and sides, allowing moraines to form over time (Ivy Ochs et al., 2007). Glacially-produced debris generally has fresh, previously unexposed surfaces, which are suitable for cosmogenic nuclide surface exposure dating (see Section 2.3) (Putnam et al., 2010a).

Moraine size is mainly related to glacier debris flux and the duration the glacier terminus remains at a single location (Barr and Lovell, 2014). Greater debris flux provides more material to form moraines. Debris flux is influenced by ice velocity, the efficiency of sediment transport through the glacier, and the volume of debris within/upon a glacier (Barr and Lovell, 2014; Kirkbride and Winkler, 2012). Conditions that favour large debris flux are often found at temperate glaciers, which tend to be dynamic and erosive (Barr and Lovell, 2014). Active tectonic settings also tend to generate high debris flux due to steep slopes and frequent rockfall (e.g., the Southern Alps, Himalaya). The longer the duration that a glacier 
occupies a single location, the more time there is for moraines to continuously accumulate debris and grow in height. Mass balance fluctuations, and therefore climate, is the dominant control of the duration of glacier occupancy at a given moraine extent (Kirkbride and Winkler, 2012; Barr and Lovell, 2014; Macintosh et al., 2017b). Other controls on moraine size include local topography and glacier response time (Barr and Lovell, 2014).

Moraines may be classified by their location in a glacial setting. The two main types are terminal and lateral moraines (Nesje and Dahl, 2000). Terminal moraines are deposited at the terminus, or end, of a glacier, and usually take the form of a convex down-valley shape (Nesje and Dahl, 2000). Lateral moraines form along the lateral glacier margins, somewhat parallel to the direction of ice flow (Nesje and Dahl, 2000). As moraines outline the glacier margins, they may be assumed to represent the extent of a former glacier following glacial retreat. Consequently, moraine preservation is important to consider when inferring former glaciermargin positions for climate reconstructions. Post-depositional alteration of moraines may be caused by fluvial processes such as flooding, erosion, undercutting and burial by alluvial deposition. Moraine degradation may also be caused by mass-movement processes such as landslides. Landscape instability is particularly relevant for moraines located in tectonically active regions and those in proximity to steep slopes (Barr and Lovell, 2014). In some cases, moraines may be removed from the landscape completely. This often occurs when large glacial advances extend past moraines deposited during earlier advances, a process called 'obliterative overlap' (Gibbons et al., 1984). Moraines can also be removed by significant meltwater outwash during glacial retreat (Barr and Lovell, 2014). Terminal moraines are frequently removed by the large volume of meltwater outwash of large valley glaciers, so lateral moraines are thus more likely to be preserved. Small glaciers, such as cirques, have low fluvial discharge potential so terminal moraines are less likely to be removed from the landscape (Gibbons et al., 1984).

Successive episodes of glacial advance and retreat can form moraine sequences. Investigation of the magnitude and timing of each set of moraines within a sequence may provide insight into climate variability (Mackintosh et al., 2017b). The formation and spatial arrangement of moraine sequences is influenced by glacier response time and glacier length sensitivity. Glaciers with fast response 
times respond to both high-frequency (e.g. interannual to decadal) and lowfrequency (e.g. multidecadal to centennial) climate change, so glacier length fluctuates frequently. Older moraines are likely to be destroyed by obliterative overlap and the remaining moraine sequence may be complex and tightly nested (Kirkbride and Winkler, 2012; Gibbons et al., 1984). In contrast, glaciers with slow response times may only respond to low-frequency climate change, behaving somewhat monotically (Mackintosh et al., 2017b). Glacier length sensitivity is expressed similarly. Glaciers with high length sensitivity exhibit large fluctuations in terminus location, so the resulting moraine sequence tends to be relatively spread out over a great distance (Oerlemans, 1997). Glaciers with low length sensitivity, such as those that terminate at a break in slope, tend to deposit compound moraine sequences due to repeated occupation of the same location (Oerlemans, 1997). As such, moraine sequences may be expressed differently so it is important to take into account the role of individual glacier response times and length sensitivity during paleoclimatic interpretation.

\subsubsection{Moraines and their paleoclimatic significance}

The mass balance of temperate mountain glaciers is highly sensitive to climate change, so reconstruction of past glacier extent fluctuations may be used to investigate past climate variability. Robust estimation of past climate variability based on glacier reconstruction requires well-preserved moraines and highprecision dating methods, and assumes that glacier mass balance fluctuations were climatically-driven (Putnam et al., 2013).

Comparison of extensive chronological moraine data on regional and global scales offers potential for investigation of past climate variability, such as the timing, spatial extent, and potential drivers of past climatic changes (Balco, 2020). The mid-latitudes of the Southern Hemisphere, particularly New Zealand and South America, possess present-day glaciers and moraine sequences that support evidence of past glaciation (Barrell et al., 2011a; Kaplan et al., 2010). Comparison with glaciation patterns in the Northern Hemisphere offers clues as to the possible mechanisms of past climate change (Schaefer et al., 2009; Kaplan et al., 2010; Putnam et al., 2010a). The regional or global extent of climate signals may be confirmed by use of non-glacial continuous palaeoclimate records, such as tree- 
ring, speleothem and lake records (e.g. Lorrey et al., 2016; Koltai et al., 2018). Modelling offers additional opportunity to reconstruct paleoclimate using moraine data. Models based on the physics of glacier-climate interaction allow different hypotheses to be tested regarding past climate and/or glacier behaviour (e.g., Drost et al., 2007; Balco, 2020). In particular, glacier modelling of equilibrium-line altitude (ELA) reconstruction (see Section 3.3) can reconstruct past climate from moraine evidence of former glacial extent (Porter, 1975; Eaves et al., 2017).

Glacier mass balance change that is not climatically-driven threatens the robustness of moraine-based paleoclimate interpretations. Glacier-bed erosion can lead to a progressive decrease in glacier extent over time (Kaplan et al., 2009). Fast-flowing glaciers can erode their bed as much as $10-100 \mathrm{~mm} \mathrm{yr}^{-1}$, depending on bed topography and composition (Mckinnon et al., 2012), resulting in significant erosion on timescales as short as a thousand years. Lowering of the glacial bed by erosion can cause glacial retreat by affecting glacial dynamics, the mass balance profile and the glacier surface longitudinal profile (Kaplan et al., 2009). In particular, changes to glacier bed slope influences the sensitivity of glacier length to climate change and lowering elevation of the glacier surface increases temperature slightly by means of the negative atmospheric lapse rate (Mckinnon et al., 2012).

Debris cover can significantly alter glacier mass balance by either increasing or reducing the rate of ice melt, potentially resulting in nonclimatic behaviour (Shulmeister et al., 2009; Vacco et al., 2010). A thin (<0.03m thickness; Vacco et al., 2010) layer of debris increases ablation due to heat absorption by the low-albedo material (Shulmeister et al., 2009). Conversely a thick layer ( $>0.03 \mathrm{~m}$ thickness; Vacco et al., 2010) of debris cover insulates the glacier from climatic conditions, severely reducing ablation due to low thermal conductivity of debris. Additionally, large rock avalanches contribute significant amounts of material to glacial deposits. This can potentially cause rock avalanches to be interpreted as moraines, as was debatably the case with the Waiho Loop moraine in New Zealand (Tovar et al., 2008; Shulmeister et al., 2009). 
Surging glaciers experience episodes of exceptionally high flow speeds which are unrelated to climatic changes (Meier and Post, 1969; Sharp, 1988). Surge periods may recur periodically, followed by periods of quiescence. The distribution of surge glaciers is non-random, with clusters found in locations including Alaska, Iceland and the Pamirs. There are several theories of why glacial surges occur, such as (i) hydrological control, where meltwater supply from sources such as geothermal heating is increased, reducing basal friction; (ii) deformation of the glacier bed, where the underlying geology fails under stress causing subglacial sliding; and (iii) critical mass theory, which argues that once mass accumulation reaches a critical point, basal melting and thus basal sliding begins to occur (Meier and Post, 1969; Sharp, 1988). Other glacier types that may exhibit non-climatic glacier length behaviour include tidewater glaciers and avalanche-fed glaciers (Mackintosh et al., 2017b). Consequently, geomorphic maps, direct chronological data and other palaeoclimate records should be used to clarify the landscape history and avoid misinterpretation of paleoclimate variability (Mckinnon et al., 2012).

For glaciers that are climatically-driven, the timing and magnitude of past glacier variability can be constrained by the use of high-precision dating methods (Balco, 2020). Cosmogenic ${ }^{10} \mathrm{Be}$ surface exposure dating methods can directly determine the timing of moraine formation. Section 2.3 details an overview of ${ }^{10} \mathrm{Be}$ surface exposure dating and its applications for paleoclimate reconstruction. 


\subsection{Cosmogenic nuclide surface exposure dating}

Cosmogenic nuclides are isotopes, such as ${ }^{10} \mathrm{Be}$, that are produced by nuclear reactions from cosmic rays and may accumulate in the atmosphere (meteoric) or in minerals situated at Earth's surface (in situ). The basic principle of in situ cosmogenic nuclide surface exposure dating is that the nuclide concentration in a rock sample is proportional to the length of time that the sample has been exposed at the Earth's surface (Dunai and Lifton, 2014). Surface exposure dating is applicable to a variety of earth surface processes, including paleoclimate reconstruction from glacial geomorphology (e.g. Putnam et al., 2012). This section discusses the theory of in situ cosmogenic nuclide surface exposure dating and its associated limitations.

\subsubsection{Principles of cosmogenic nuclides}

Cosmic rays originate from extraterrestrial sources such as supernova explosions and constantly impinge on the Earth from all directions (Dunai and Lifton, 2014; Lal, 1991; Ivy-Ochs and Kober, 2008). The galactic cosmic ray flux is the most significant contributor to cosmogenic nuclide production (Dunai and Lifton, 2014). Flux varies on timescales of thousands to millions of years, but time-dependent scaling models exist (e.g. Lifton et al., 2014; see Section 2.3.3) that account for this variation.

Cosmic rays consist of positively charged particles, with energies typically ranging from $\sim 0.1$ to $10 \mathrm{GeV}$ (Gosse and Phillips, 2001). Primary cosmic rays enter the Earth's atmosphere and are comprised mostly of atomic nuclei, namely protons $(\sim 87 \%)$, alpha particles $(\sim 12 \%)$ and heavier nuclei $(\sim 1 \%)$ (Masarik and Reedy, 1995). Following entry, primary cosmic rays interact with atoms in the atmosphere to produce secondary cosmic rays (Figure 2.4). Secondary cosmic rays are responsible for the majority $(98 \%+)$ of in situ cosmogenic nuclide production (Dunai and Lifton, 2014).

In the upper atmosphere, secondary cosmic ray particles can be divided into three main components, as defined by their relative energies. The components are 
nucleonic (protons, alpha particles, and neutrons), mesonic (pions, muons, antimuons, kaons, neutrinos, electrons, and positrons), and electromagnetic (electrons, positrons, and photons) (Figure 2.4) (Dunai, 2010; Dunai \& Lifton, 2014). The nucleonic component has high energy nuclear reactions, so dominates the total secondary cosmic ray flux and is responsible for the majority of the production of in situ cosmogenic nuclides at Earth's surface (Gosse and Phillips, 2001).

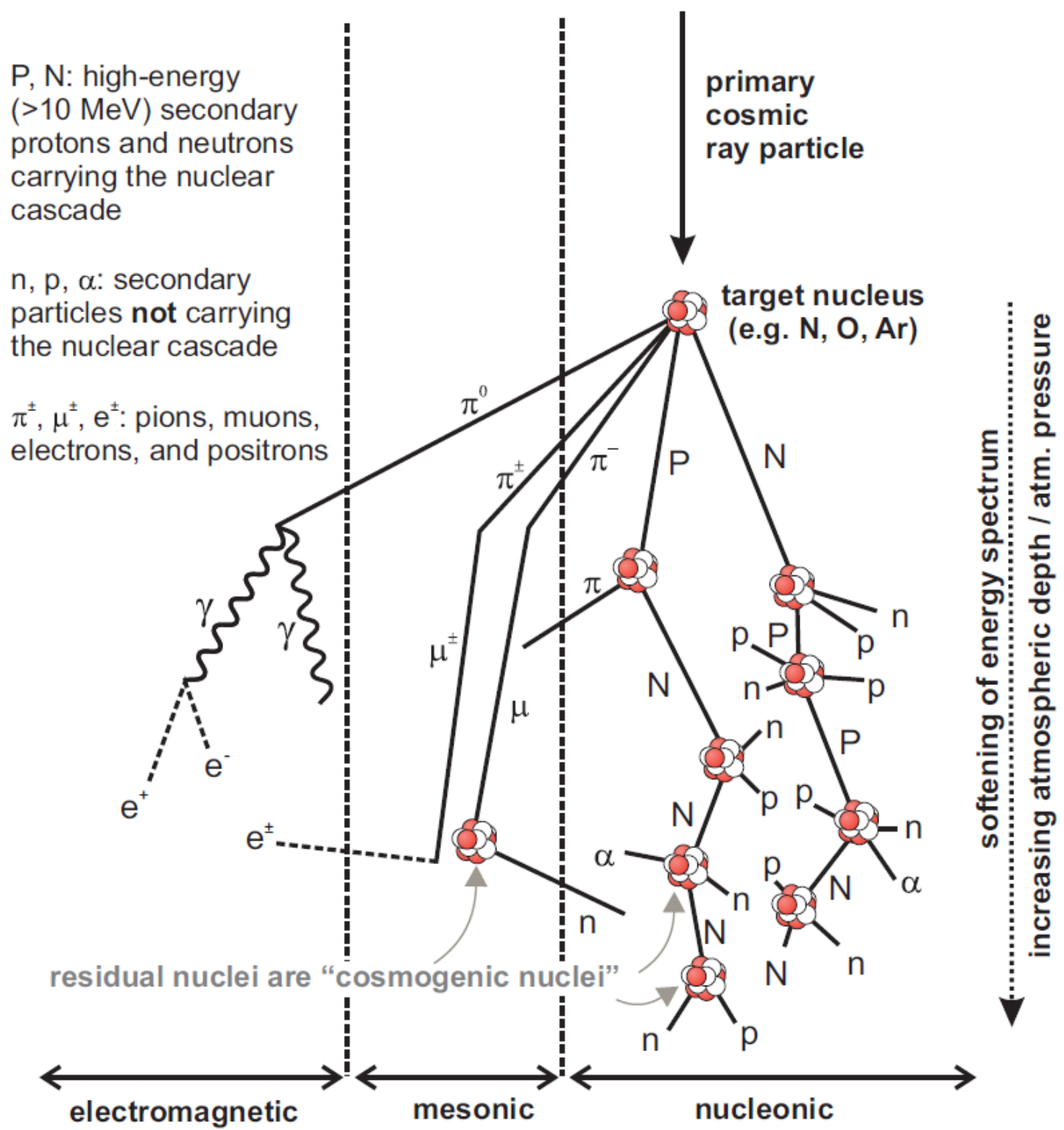

Figure 2.4: The nuclear cascade of cosmic ray particles. Secondary cosmic ray particles, particularly the nucleonic component, are responsible for the majority of in situ cosmogenic nuclide production. Figure from Dunai and Lifton (2014). 
Cosmogenic nuclides are produced when cosmic rays enter Earth's atmosphere and collide with atoms, initiating a cascade of nuclear reactions (Dunai and Lifton, 2014). The relative energy of the cosmic ray particles determines the amount and type of reactions that occur. The predominant nuclear reaction that produces cosmogenic nuclides in the atmosphere is spallation (Figure 2.4). Spallation occurs when high-energy nucleons collide with atomic nuclei, ejecting particle(s) from the nucleus and resulting in a lighter residual nucleus, or isotope (Ivy-Ochs and Kober, 2008). The products of these collisions continue in the trajectory of the incoming cosmic ray and may eventually undergo further spallation with other nuclei, producing a cascade of secondary cosmic rays (Gosse and Phillips, 2001). Consequently the composition of the nuclear cascade is proton-dominated at the top of the atmosphere, becoming neutron-dominated at sea level (Gosse and Phillips, 2001). Spallation requires the cosmic ray to possess sufficiently high energy at a minimum of 7-9 MeV per nucleon, in excess of the binding energies of atomic nuclei (Dunai and Lifton, 2014). Other nuclear reactions that produce cosmogenic nuclides are neutron capture and muon reactions but these are less relevant regarding cosmogenic ${ }^{10} \mathrm{Be}$ surface exposure dating (Dunai 2010).

Cosmogenic nuclides are either 'in situ' or 'meteoric', depending on whether they were produced in the lithosphere or atmosphere respectively. Primary cosmic rays enter the atmosphere and interact with nitrogen, oxygen and rare gases, producing atmospheric nuclides (Gosse and Phillips, 2001). Some primary and secondary cosmic rays retain sufficient energy to continue undergoing nuclear reactions, eventually reaching Earth's surface and penetrating rock. In situ cosmogenic nuclides are produced in the minerals of the surface layer of the rock (von Blankenburg and Willenbring, 2014). Due to attenuation of particle energy within the atmospheric nuclear cascade, the production rate of in situ cosmogenic nuclides is lower than production rates in the atmosphere (Blard. et al., 2008). Accumulation of in situ nuclides makes them useful for surface exposure dating. 


\subsubsection{Cosmic ray flux variation with latitude, altitude and depth}

The energy and intensity of cosmic rays, and therefore nuclide production, varies spatially as a function of latitude, altitude and depth.

\section{Cosmic ray flux variation with latitude}

Cosmic rays are charged particles, so they are affected by interactions with the Earth's magnetic field. The geomagnetic field is dominated by its dipole component which modulates nuclide production by shielding and deflecting primary cosmic rays, sending them on different trajectories. As such, the cosmic ray flux varies with latitude (Darvill, 2013). The deflection of cosmic rays by the geomagnetic field is related to the incident angle and rigidity of the incoming cosmic ray and is defined as:

$$
r=p c / q
$$

Where $\mathrm{r}$ is the rigidity of the incoming cosmic ray, $\mathrm{p}$ is momentum, $\mathrm{c}$ is the velocity of light, and $q$ is the charge of the particle (Cerling \& Craig, 1994).

Cosmic ray particles must have kinetic energy above a certain threshold, referred to as the 'cut-off rigidity' (RC), in order to penetrate the magnetic field and not be deflected. The cut-off rigidity is defined as the momentum of a particle per unit charge (gigavolts, GV) and varies with latitude according to the angle of incidence of the cosmic rays and their location relative to geomagnetic field lines (Dunai, 2010). Cut-off rigidity values are lower at the magnetic poles and higher at the equator. At the poles, particle trajectories are subparallel to magnetic field lines (Figure 2.5), so RC values are approximately zero and virtually all the charged primary cosmic radiation particles are able to penetrate the magnetic field (Gosse and Phillips, 2001). Near the equator, cosmic ray trajectories are near perpendicular to the magnetic field (Figure 2.5) so a significant portion of primary particles are deflected (von Blankenburg and Willenbring, 2014). At the equator $\mathrm{RC}$ values of approximately $17 \mathrm{GV}$ are required for cosmic rays to penetrate the field (Dunai, 2010). Therefore fewer cosmic ray particles are deflected at the poles, resulting in greater cosmic ray flux and cosmogenic nuclide production rates at higher latitudes (Gosse and Phillips, 2001). 


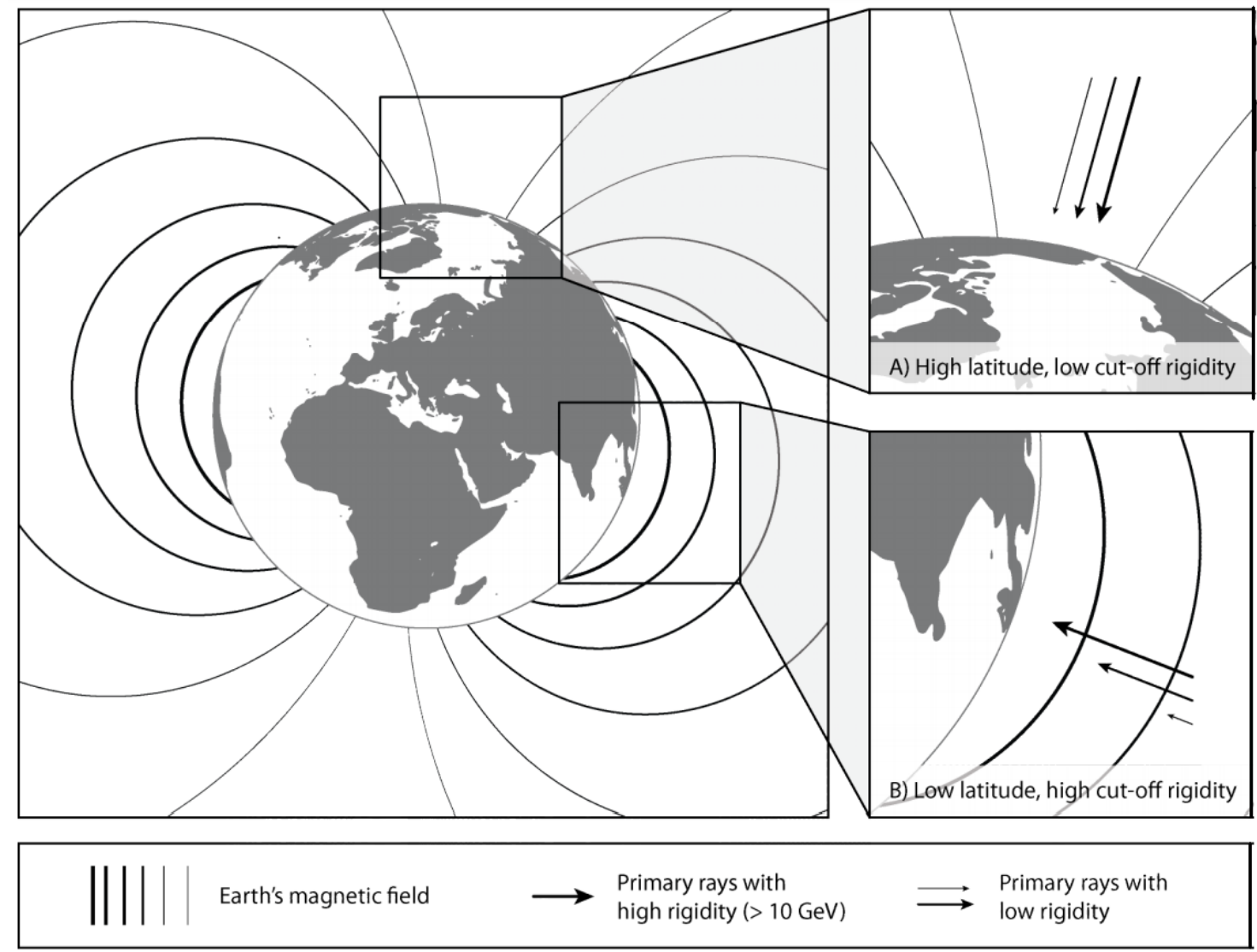

Figure 2.5: The Earth's geomagnetic field and its effect on incoming primary cosmic rays. Cosmic rays must exceed the cut-off rigidity at a particular latitude ( $A$ and $B$ ), which is higher nearer the equator $(B)$ and lower towards the poles (A). Consequently, the poles have higher production rates of cosmogenic nuclides (Figure from Darvill, 2013).

The relationship between latitude and cosmic ray flux is not linear. Figure 2.6 shows a 'latitude knee' at RC $<2 \mathrm{GV}\left(\geq 50-60^{\circ}\right.$ geomagnetic latitude). Beyond the latitude knee ( $\sim 50$-90 degrees latitude) the lowest-energy cosmic ray particles have cut-off rigidities sufficient to enter the atmosphere, but not to generate an atmospheric nuclear cascade. Consequently the increase in the number of cosmic rays that enter the atmosphere at high latitudes does not yield corresponding increases in cosmogenic nuclide flux (Dunai and Lifton, 2014). 


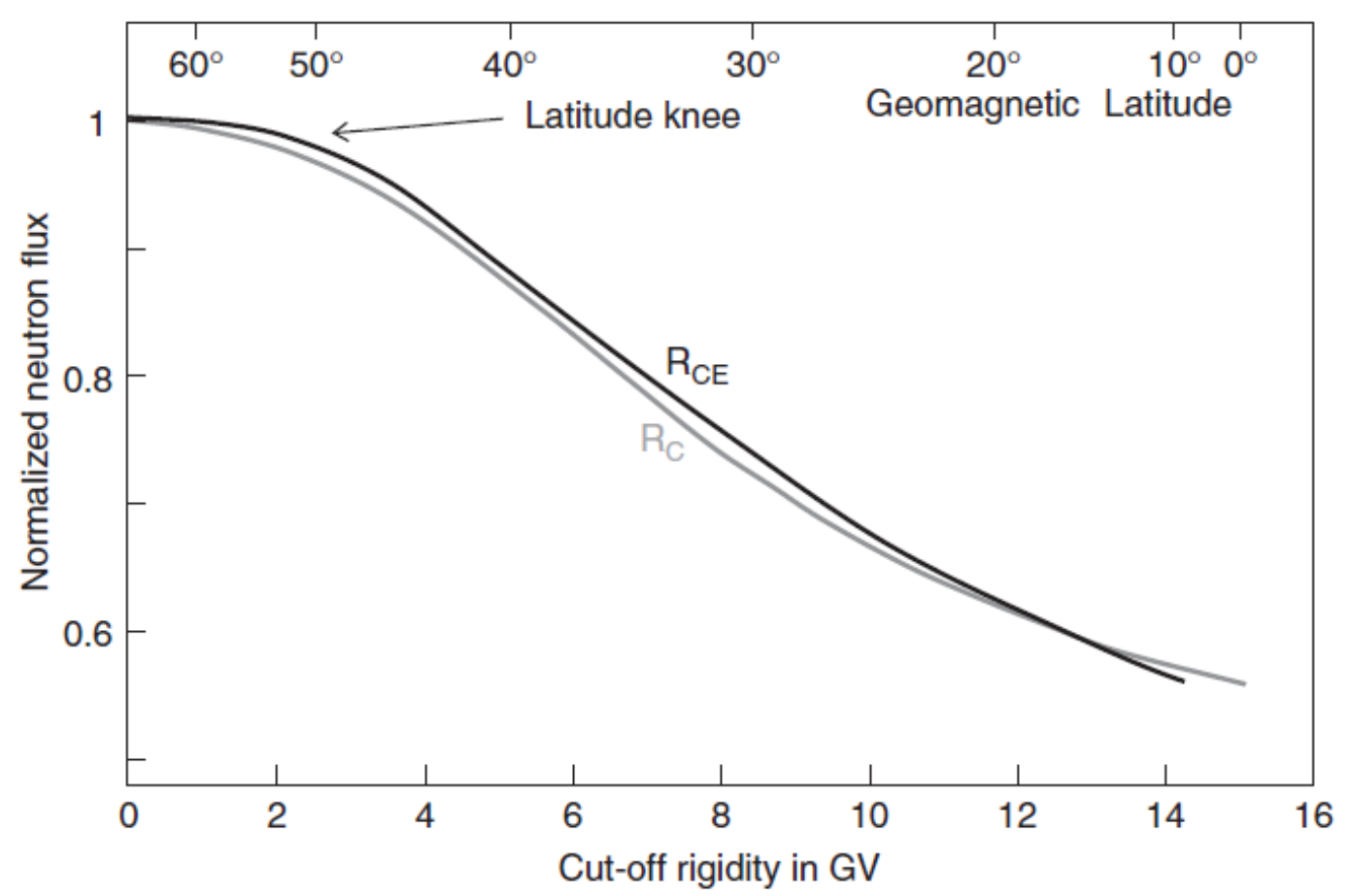

Figure 2.6: Normalised neutron flux at sea level as a function of cut-off rigidity $\left(R_{c}\right)$, calculated for present-day magnetic field strength (Figure from Dunai, 2010).

Temporal variability in geomagnetic field strength is important to consider when considering cosmogenic nuclide production, particularly for geological dating applications. The influence of temporal variability of the geomagnetic field on cosmogenic nuclide production is most relevant for locations at high altitude and/or low latitude (Dunai and Lifton, 2014). Cosmic ray flux is greatest at times when the Earth's magnetic field is weak, as cut-off rigidities are lower and more cosmic rays can enter the atmosphere (von Blankenburg and Willenbring, 2014). Temporal variations in the geomagnetic field may be accounted for by scaling schemes (see Section 2.3.3).

\section{Cosmic ray flux variation with altitude}

The production of in situ cosmogenic nuclides varies with altitude as a result of cosmic ray attenuation (Stone, 2000). As described previously (Section 2.2.1), secondary cosmic ray particles are produced by nuclear reactions in the atmospheric cascade and as they travel through the atmosphere they are attenuated (Dunai, 2010). Due to attenuation the nucleonic cosmic ray flux 
decreases exponentially with increasing atmospheric depth, roughly halving with every 1500m decrease in altitude (Lal, 1991; Cerling and Craig, 1994; Stone, 2000; Dunai, 2010). Consequently the highest cosmic ray flux occurs in the upper atmosphere, resulting in larger cosmogenic nuclide production rates at higher altitudes (Balco, et al., 2008).

The production rate can be represented by the following equation (Lal, 1991):

$$
N(d)=N_{0} e^{-d / \wedge}
$$

Where $\mathrm{N}$ is secondary neutron abundance, $\mathrm{d}$ is atmospheric depth $\left(\mathrm{g} \mathrm{cm}^{-2}\right), \mathrm{N}_{0}$ is the number of nucleons at the top of the atmosphere, and $\wedge$ is the attenuation length $\left(\mathrm{g} \mathrm{cm}^{-2}\right)$.

Attenuation length is defined as the thickness of mass required to attenuate the cosmic ray flux by $1 / \mathrm{e}$. The attenuation length, and therefore in situ cosmogenic nuclide production, varies with altitude and latitude (Stone, 2000).

The cosmic ray flux is greatest at higher altitudes as air pressure and the shielding effect of the atmosphere are low (Stone, 2000). Air pressure, related to the total mass of atmosphere in the overlying air column, corresponds to air mass through which travelling secondary cosmic rays must attenuate (von Blankenburg and Willenbring, 2014). Cosmic rays on an incident angle closer to the horizon have relatively more atmospheric depth to travel (and therefore attenuate) through. As such, the cosmic ray flux at Earth's surface is greatest from the zenith (Dunai, 2010).

Attenuation length also varies with latitude, as the energy of the incoming primary cosmic rays is controlled by cut-off rigidity (Figure 2.7) (Gosse \& Phillips, 2001). Particles entering at low-latitudes must have relatively high energies to penetrate the magnetic field. As a result of the higher energies, particles at low-latitudes have greater attenuation lengths $\left(150 \mathrm{~g} / \mathrm{cm}^{2}\right)$ than the average particle at higher latitudes (130 g/ $\mathrm{cm}^{2}$ ) (Darvill, 2013). Consequently cosmic ray particles penetrate Earth's surface more frequently, increasing in situ cosmogenic nuclide production at low-latitudes (Stone, 2000). 


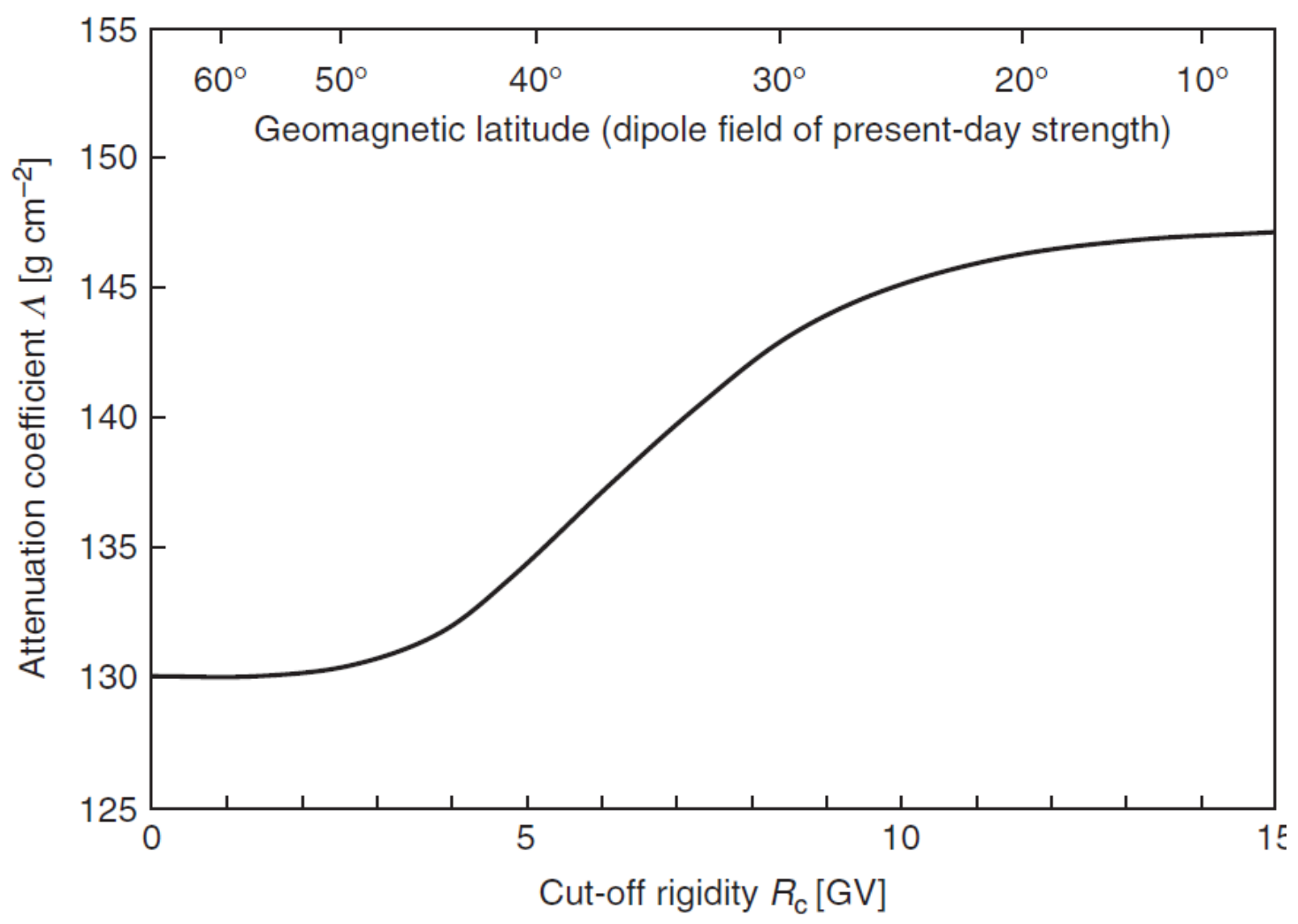

Figure 2.7: Attentuation length as a function of cut-off rigidity, as related to geomagnetic latitude. The attenuation length is longer at low-latitudes (Figure from Dunai, 2010).

\section{Cosmic ray flux variation with depth}

Cosmic rays attenuate with depth below the Earth's surface by similar principles to that of atmospheric attenuation. However, rock is denser than the atmosphere. The production of in situ cosmogenic nuclides decreases rapidly with depth in the lithosphere as secondary cosmic rays are attenuated (Figure 2.8) (Lal, 1991, Dunai 2010).

Cosmic rays interact with elements in minerals, causing changes to mean atomic mass and charge per nucleus (Dunai, 2010). The ${ }^{10} \mathrm{Be}$ cosmogenic isotope is produced by cosmic ray interactions with oxygen and silicon in quartz $\left(\mathrm{SiO}_{2}\right)$. As Figure 2.8 illustrates, cosmogenic isotopes are produced by different nuclear reactions, such as spallogenic and muon reactions (Section 2.3.1), depending on the energy of the incoming particle. Spallogenic reactions are generally the dominant source of nuclide production in surface rocks. The spallation production rate decreases by a factor of two with every $\sim 40 \mathrm{~cm}$ depth below the surface, resulting in a negligible nuclide concentration below 2-3 m depth (Figure 2.8) 
(Dunne et al, 1999, Balco, et al., 2008). The surface concentration of cosmogenic nuclides forms the basis for surface exposure dating (Dunai, 2010). Surface exposure dating can be used to quantify the rate of Earth surface processes and will be discussed further in Section 2.3.4. Muons are produced along with neutrons in the nuclear cascade and produce cosmogenic nuclides by 'fast muon' reactions and muon capture (Figure 2.8). Muons interact weakly with matter so do not produce many cosmogenic nuclides at or above the Earth's surface. However, this allows them to penetrate deeper than nucleons into the subsurface. As such, muoninduced reactions become increasingly relevant with depth into the lithosphere, but have little importance for most surface exposure dating applications (Figure 2.8) (Dunai \& Lifton, 2014; Dunai, 2010).

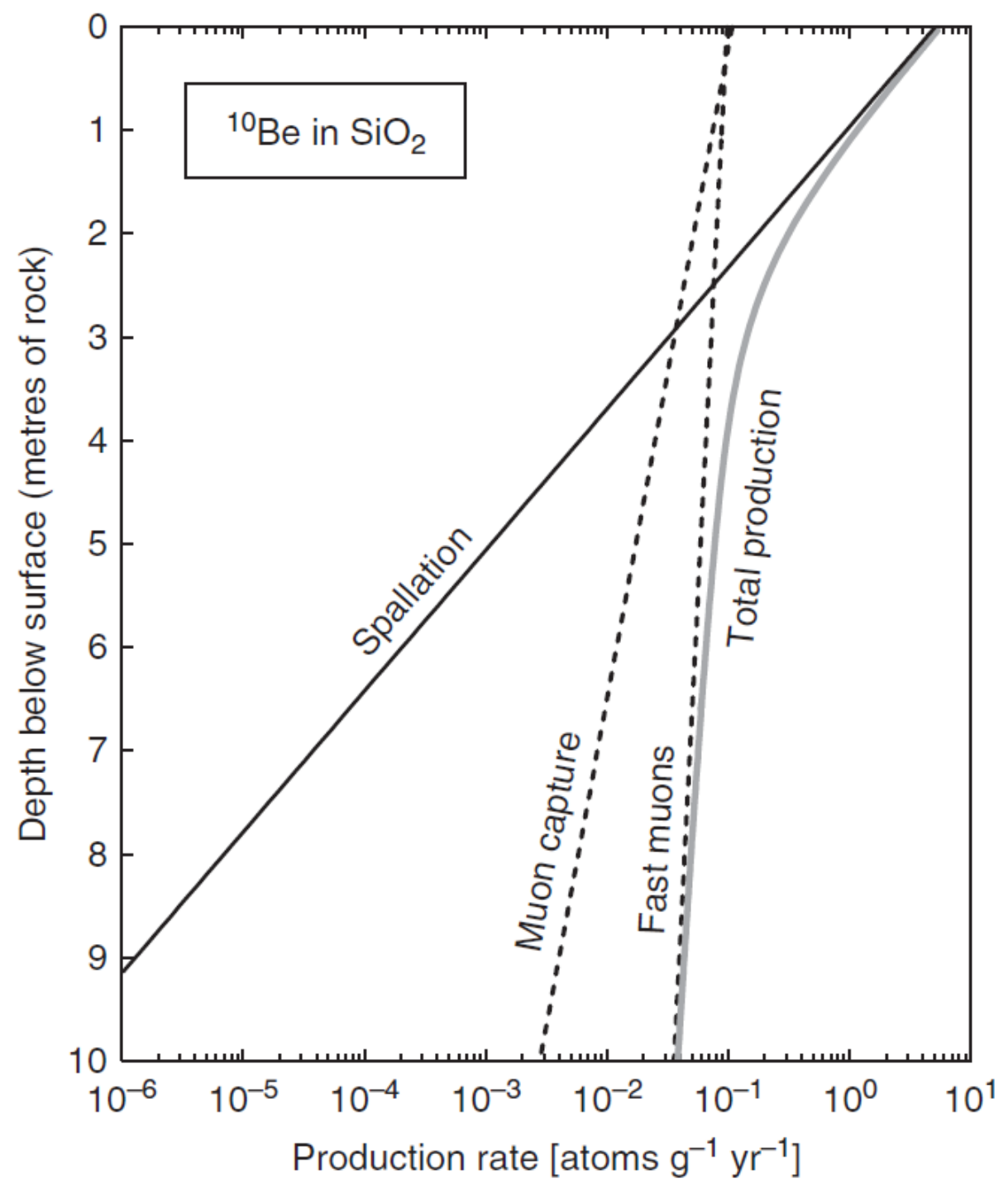

Figure 2.8: ${ }^{10}$ Be production rates in quartz with depth below the surface (at sea level and high latitude for a rock density of $2.7 \mathrm{~g} \mathrm{~cm}^{-3}$ ) (Figure from Dunai, 2010). 


\subsubsection{Cosmogenic nuclide production rates}

The production rate is the rate at which an in situ cosmogenic nuclide is produced in a mineral (Dunai, 2010). The use of cosmogenic nuclides for surface exposure age dating applications is dependent on the accuracy of nuclide production rates. The process to establish production rates typically involves calibration of nuclide concentration with a geological site (e.g. rock avalanche, lava flow) of independently known age, followed by use of a scaling factor to translate the local production rates obtained to values valid elsewhere on the globe. Exposure ages obtained are only as accurate as the production rates and scaling factors they rely on (Dunai 2010).

Calibration of in situ cosmogenic nuclide production rates involves the comparison of cosmogenic nuclide concentration at the sample site with the concentration at a local site of independently determined age. In situ cosmogenic nuclides tend to be produced at a low rate on the order of a few atoms per gram of the target mineral per year (Gosse and Phillips, 2001), so the accuracy of the production rate obtained is heavily sensitive to the independent age constraint used (von Blankenburg and Willenbring, 2014). Common calibration surfaces used include lava flows and moraines and the age of the calibration site may be constrained by techniques including radiocarbon dating and Ar/Ar-dating (Dunai, 2010). These calibration surfaces are generally suitable because a robust calibration site requires a well-constrained exposure history of stable, continuous exposure. Since initial exposure of the site, the surface used for calibration should not have been subject to significant erosion, burial, prior exposure or other disturbance that might impact the natural accumulation of cosmogenic nuclides (Gosse and Phillips 2001; Dunai 2010; Dunai and Lifton, 2014). An example of a suitable calibration site is a landslide deposit in the central Southern Alps (Putnam et al. $2010 \mathrm{~b}$ ). The landslide initiated surface exposure of boulders that contained quartz, allowing cosmogenic ${ }^{10} \mathrm{Be}$ to accumulate on the surface of the deposit. Vegetation was killed and incorporated in the landslide event, offering a source of radiocarbon dating for calibration (Putnam et al., 2010b). For the production rate at a calibration site to be applicable to a sample site, a scaling factor is required to compensate for differences in site-specific factors such as latitude and altitude (Balco et al., 2008). 
A scaling factor is used to apply the local production rates obtained at calibration sites to sample sites located elsewhere. Scaling factors account for differences in cosmic ray intensity, and therefore nuclide production, across locations (Dunai and Lifton, 2014). The scaling factor normalises the local production rates to sitespecific variables and accounts for temporal variation in geomagnetic and atmospheric shielding (Balco et al., 2008). Existing scaling models describe the relative flux of cosmic rays as a function of altitude, latitude (Stone, 2000; Dunai, 2001; Desilets and Zreda, 2003; Balco et al., 2008; Lifton et al., 2008), variations in geomagnetic field strength (Dunai, 2001; Desilets and Zreda, 2003; Lifton et al., 2008), and changes in solar activity (Lifton et al., 2005, 2008). There is much debate over which scaling factor is most appropriate. Scaling factors that are commonly used and perform well include St (Stone, 2000), Lm (Balco et al., 2008), and LSDn (Lifton et al., 2014). Different scaling schemes tend to produce similar exposure age results for sites at latitudes greater than $30^{\circ}$ and elevations below 3 $\mathrm{km}$ a.s.l., through results may differ by up to $30 \%$ at lower latitudes and higher elevations (Balco et al., 2008; Lifton et al., 2014, Dunai and Lifton, 2014). Variation arises primarily from the data on which the scaling models are based. Models vary in the different neutron flux proxies used, such as neutron monitors and photographic emulsions (Lifton et al., 2014; Dunai and Lifton, 2014). A combination of scaling models may be used for cross-calibration and to assess consistency (Dunai, 2010). The application of a scaling factor is computationally complex, but online calculators (e.g. Balco et al., 2008; https://hess.ess.washington.edu/) may be used by non-specialists to obtain exposure ages (see Section 3.2). Online calculator output generally allows for comparisons of surface exposure ages produced using different scaling models (Balco et al., 2008). 


\subsubsection{Applications of the ${ }^{10} \mathrm{Be}$ cosmogenic nuclide}

There are many types of cosmogenic nuclides, including ${ }^{3} \mathrm{He},{ }^{10} \mathrm{Be},{ }^{26} \mathrm{Al}$ and ${ }^{36} \mathrm{Cl}$ (Dunai, 2010). The nuclide produced depends on the target element and the energy of the incoming cosmic ray (Gosse and Phillips, 2001). The ${ }^{10} \mathrm{Be}$ cosmogenic nuclide is widely applicable for surface exposure dating and has been used by many recent studies (e.g., Putnam et al., 2010b; Barrows et al., 2013; Schaefer et al., 2009). The main target mineral of ${ }^{10} \mathrm{Be}$ is quartz, which has a simple molecular composition and can be found in sufficient quantities in a wide range of geologic settings. Despite the abundance of quartz, the ${ }^{10} \mathrm{Be}$ isotope itself rarely occurs naturally in geologic material. The ${ }^{10} \mathrm{Be}$ nuclide is appropriate for chronologic analysis on timescales shorter than its half-life of $1.36 \pm 0.07 \mathrm{Ma}$ (Nishiizumi et al., 2007; Dunai, 2010).

The basic principle of surface exposure dating is that the higher the concentration of cosmogenic nuclides, the longer the surface has been exposed to cosmic radiation (Figure 2.9) (Lal, 1991; Gosse and Phillips, 2001; von Blankenburg and Willenbring, 2014).

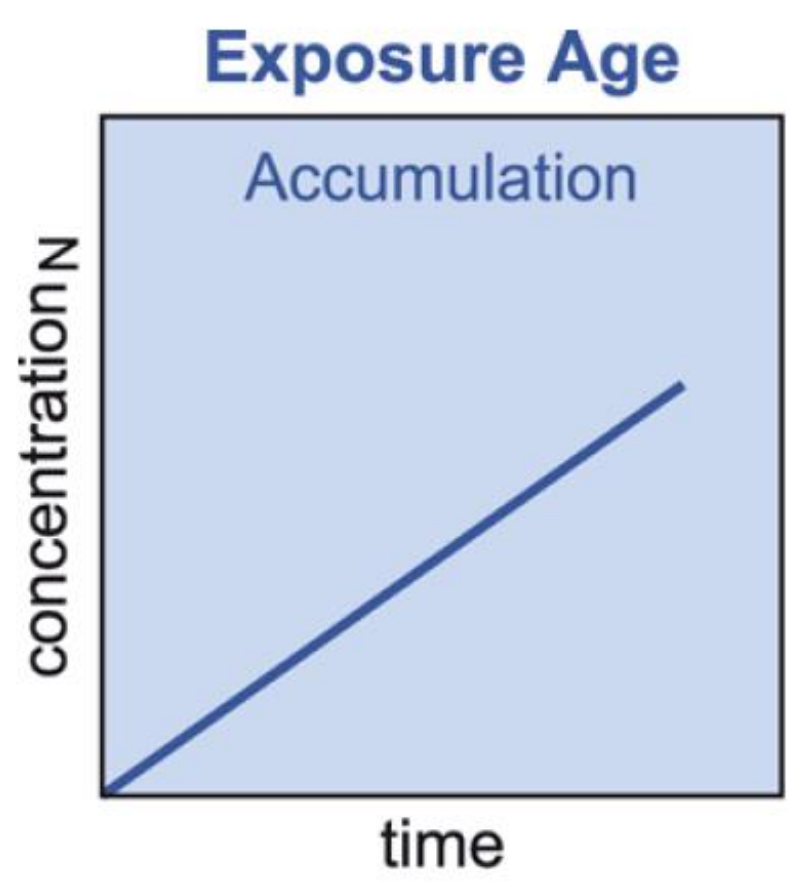

Figure 2.9: Simplified conceptual model showing the positive relationship between exposure time and nuclide concentration. Ignores complex exposure histories such as inheritance and nuclide decay (Figure from von Blankenburg and Willenbring, 2014). 
The surface exposure dating principle relies on the assumption that cosmogenic nuclides could not have existed in the minerals prior to exposure by cosmic radiation (von Blankenburg and Willenbring, 2014). This assumption is generally well-suited to glacial landforms in the Southern Alps, as glacial processes in a temperate environment tend to produce fresh rocks surfaces with virtually nil nuclide concentration. Fresh surfaces are produced by generation of rock that has not previously been exposed (e.g. sub-glacial plucking) and glacial erosion of transported debris (Ivy-Ochs and Briner, 2014). However, the linear trend in Figure 2.9 of cosmogenic nuclide accumulation with time is an over-generalisation, ignoring processes such as nuclide decay and inheritance (non-zero nuclide concentration) in rock surfaces (Figure 2.10, see accompanying discussion).

Rock that is transported by glacial processes is eventually deposited as moraines. When the glacier begins to retreat, the newly exposed moraine surface begins accumulation of cosmogenic nuclides. Therefore, the concentration of cosmogenic nuclides in the moraine material can approximate the time of exposure of the moraine, such as following glacial advance or retreat (Ivy-Ochs and Briner, 2014). Aside from moraines, surface exposure dating is also applicable to a variety of surfaces such as glacially polished bedrock.

Surface exposure dating is limited by the assumption that the cosmogenic nuclide concentration is only representative of the true age of exposure. Inaccuracies may be introduced by cosmogenic nuclide inheritance, burial or disturbance of the surface (Figure 2.10) (Ivy Ochs and Briner, 2014). Inheritance is the retention in a rock surface of cosmogenic nuclides from a period of prior exposure (Figure 2.10B). This may occur when a previously exposed surface has been insufficiently eroded at the time of moraine deposition. There is more nuclide accumulation than reflects the time of moraine deposition, so inheritance leads to the overestimation of exposure age (Ivy-Ochs and Briner, 2014). Burial occurs when rock is shielded (e.g. by significant amounts of soil, snow or vegetation) following deposition on the moraine, creating a rate decrease or pause in accumulation of nuclides (Figure 2.10C). In such situations nuclide concentrations underestimate the true duration of time elapsed since deposition. Underestimation of exposure age may also be caused by post-depositional modification or disturbance of boulders on moraines. As moraines degrade over time, the exhumation or toppling of boulders may cause parts of the boulder that were shielded for some time to become exposed, 
misrepresenting the age of moraine deposition (Ivy-Ochs and Briner, 2014; Dunai, 2010).
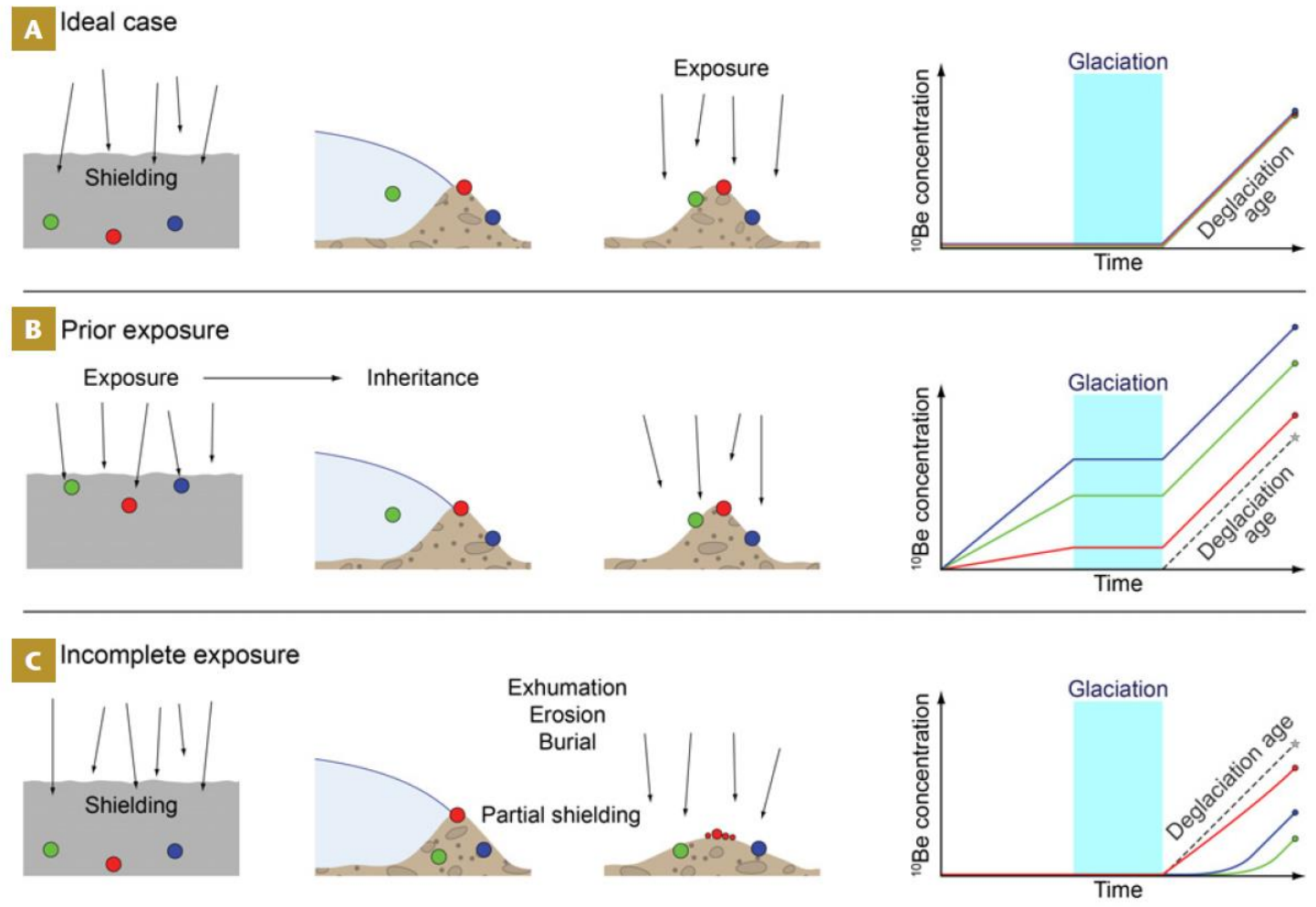

Figure 2.10: Three possible relationships between the surface exposure ages of boulders and the true depositional age of moraines: $(A)$ the exposure age reflects the 'true' age of moraine deposition; (B) inheritance caused by prior exposure results in overestimation of depositional age; (C) incomplete exposure leads to underestimation of depositional age (Figure from Ivy-Ochs and Briner, 2014).

Erosion can impose an additional control on the concentration of cosmogenic nuclides. Erosional processes remove the surface layer of rock, containing the cosmogenic nuclides that have accumulated since initial exposure (Ivy-Ochs and Briner, 2014; Kaplan et al., 2004). Due to removal of nuclides the measured nuclide concentration then underestimates the true age of exposure. As such, assessment during boulder sampling of the degree of surface erosion is essential to avoid sampling a heavily eroded surface. A moraine boulder may erode by processes including spallation, splitting and granular disintegration. Kaplan et al. (2004) sampled boulders that eroded only by granular disintegration, rather than splitting or spallation, to better constrain the erosion rate. 


\subsection{Existing moraine chronologies in the Southern Alps}

In New Zealand, many studies have successfully produced high-precision moraine chronologies using cosmogenic ${ }^{10}$ Be surface exposure dating techniques. Existing Southern Alps chronologies are on timescales ranging from 130 ka (e.g. Putnam et al., 2013a) to 100-200 yrs BP (e.g. Schaefer et al., 2009). Many ${ }^{10}$ Be moraine studies have focused on constraining the timing of glaciation and understanding glacier-climate fluctuations in the Southern Alps. However, there is a need to improve the spatial extent of high-precision moraine chronologies in order to constrain the timing and magnitude of glacier length changes in New Zealand.

\subsubsection{Glacier retreat since the Last Glacial Maximum}

Glaciers exhibited an overall pattern of retreat since the Last Glacial Maximum (LGM; 26-19 ka (Clark et al., 2009)). Moraine sequences demonstrate that during the LGM glaciers in the Southern Hemisphere occupied maximum extents between $\sim 30-18 \mathrm{ka}$, when temperatures were $6-7^{\circ} \mathrm{C}$ cooler than present day (Golledge et al., 2012; Barrell et al., 2013b). The LGM was followed by the Last Glacial-Interglacial Transition (LGIT; 18-11 ka), a transitional period of deglaciation during which global mean temperatures increased by $\sim 5^{\circ} \mathrm{C}$, atmospheric carbon dioxide $\left(\mathrm{CO}_{2}\right)$ increased by 80-100 ppmv and global mean sea level rose $\sim 60-80 \mathrm{~m}$ (Eaves et al., 2017; Denton, 2010). During the LGIT the Southern Alps experienced widespread glacial retreat. Recent studies have suggested that rapid retreat commenced around 17-18 ka, followed by numerous short-term still-stands and/or minor readvances over the ensuing 3-4 kyr (Barrows et al., 2013; Putnam et al., 2013a; Putnam et al., 2013b). One such period of re-advance was the Antarctic Cold Reversal (14.5-12.5 ka), a cool interval with a temperature reduction of $2-3^{\circ} \mathrm{C}$ relative to present-day (Putnam et al., 2010a; Kaplan et al., 2013). By the Holocene $(\sim 11,700 \mathrm{ka})$ temperatures in New Zealand had risen to similar levels as preindustrial and glaciers had significantly retreated into the Southern Alps (Barrell et al., 2013a). Glaciers experienced episodic mass balance fluctuations during the Holocene in response to (sub)millennial-scale climatic events such as the Little Ice Age (Carrivick et al., 2020). The overall pattern of glacier retreat and episodic glacier fluctuations since the LGM provides context for the moraine chronology 
produced at Rocky Top cirque.

\subsection{Study Site}

\subsubsection{Geologic setting}

The Rocky Top cirque ( $45^{\circ} 49^{\prime} \mathrm{S}, 167^{\circ} 24^{\prime} \mathrm{E}$ ) is located in the Hunter Mountains, in the southernmost region of the Southern Alps, New Zealand. The Hunter Mountains are located along the eastern margin of Southern Fiordland. Rocky Top cirque is in close proximity to Green Lake and Lake Monowai (Figure 2.11).

The historical record of the study area is very brief. In 1861-1862 the surveyor James McKerrow named many geographical features within the Hunter Mountains region (Byrnes, 2015). The most notable research in proximity to Rocky Top cirque is the Green Lake landslide deposit (Hancox and Perrin, 2009). The Green Lake landslide occurred approximately $\sim 12-13,000$ yrs BP, shifting a great volume of debris $\left(\sim 27 \mathrm{~km}^{3}\right)$ that formed a dam and consequent lake. The landslide was likely triggered by a large earthquake ( $\geq$ M 7.5-8) associated with the Alpine Fault. The Green Lake landslide has some implications for paleoclimate reconstruction at Rocky Top cirque (see Section 5.3).

Barrell et al. (2013b) made some inferences of the distribution of glacial occupation during the LGM (specifically between $\sim 20,000-22,000$ years ago). As shown in Figure 2.12, the Southern Alps were extensively glaciated during the LGM with an extensive ice cap covering the central mountains of Fiordland. To the southeast many glaciers terminated on land, some of which deposited wellreserved sequences of moraines (e.g. Lake Pukaki; Barrell et al., 2013b). The Hunter Mountains blocked ice flow to the east, directing much of the flowing ice southwards along Grebe Valley which carved the glacial trough that is now occupied by Lake Monowai (Figure 2.11) (Hancox and Perrin, 2009). Other icecarved lakes such as Manapouri and Te Anau provide further evidence for glacial erosion in southeastern Fiordland (Hancox and Perrin, 2009). 


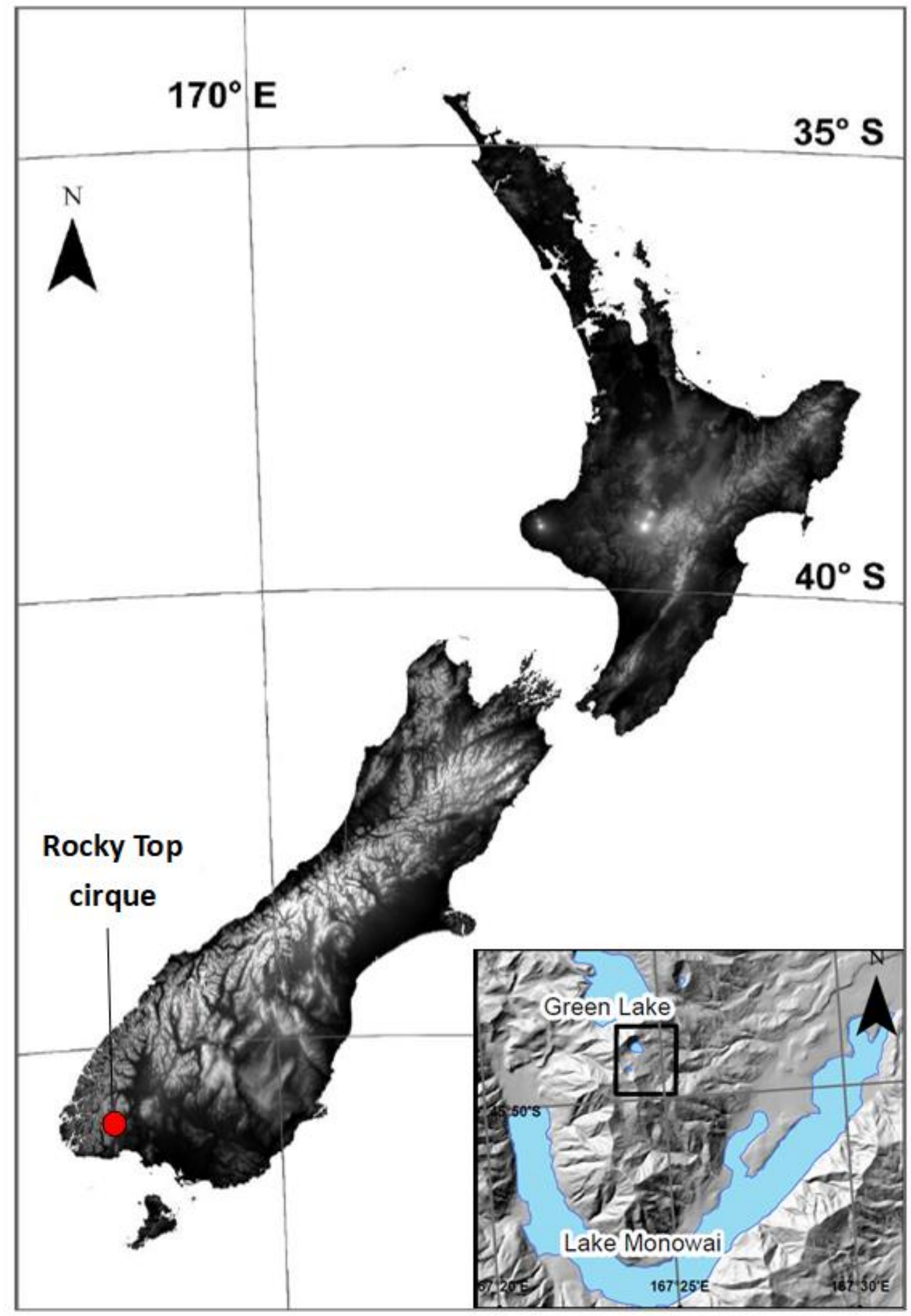

Figure 2.11: Location of Rocky Top cirque in the Southern Alps, NZ. 


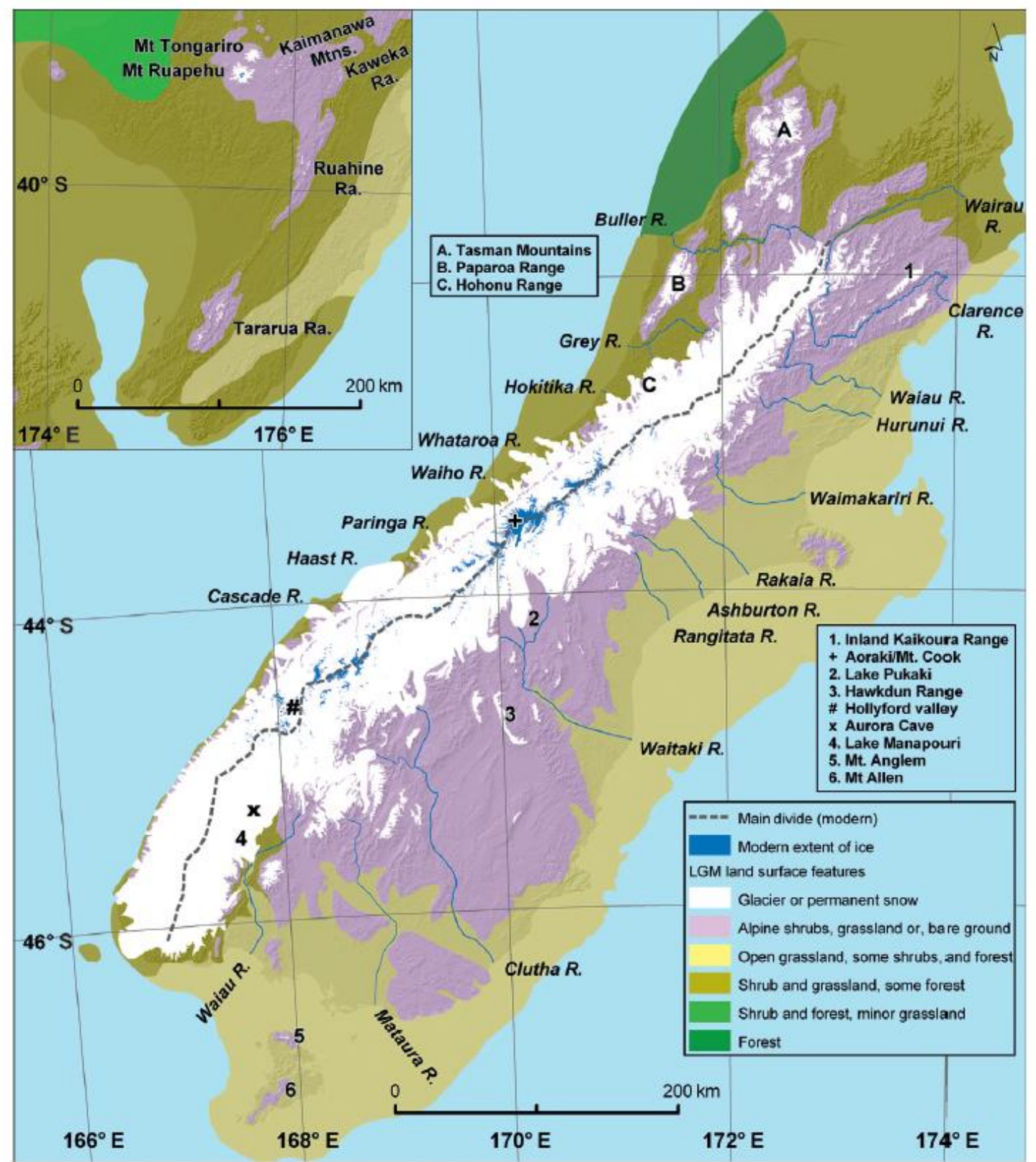

Figure 2.12: An interpretation of the distribution of ice and the main vegetation zones at the height of the LGM (between $20,000-22,000$ years ago). The land extent approximates the $120 \mathrm{~m}$ isobaths on the modern sea floor, reflecting lower global sea level during the LGM. Figure from Barrell (2013b). 


\subsubsection{Climatic setting}

New Zealand has a temperate maritime climate, a result of its location in the midlatitudes where subtropical and sub-Antarctic air and water masses interact (Salinger \& Mullan, 1999). Atmospheric circulation is dominated by prevailing westerlies, generated by the circumpolar westerly current.

In the South Island local climate is influenced by the orographic effect of the Southern Alps, a $\sim 500 \mathrm{~km}$ long mountain range with many peaks exceeding 2500 $m$ a.s.l. The Southern Alps are created by the Alpine Fault, where ongoing oblique plate convergence between the Pacific and Australian plates causes uplift on the order of 0.5-8 mm/yr (Batt and Braun, 1999). The resulting orographic precipitation regime creates a pattern of extremely high precipitation on the west coast (typically $\sim 12,000 \mathrm{~mm} / \mathrm{yr}$ ), steadily decreasing to the east of the main divide (Macara, 2013). As such, high uplift rates are matched by similarly high denudation rates, generating ample debris for moraine formation.

Rocky Top cirque is located in south-eastern Fiordland, where mountain ranges to the west act as a barrier to the prevailing westerlies. The orographic effect creates a local climate that is relatively dry with annual rainfall between 800-1200 mm/yr (Macara, 2013). Precipitation that falls as snow during winter months is fully melted during the summer months, hence there are no present-day glaciers at Rocky Top (Macara, 2013).

On interannual-decadal timescales, large-scale climatic phenomena cause changes to the intensity and location of the westerly wind belt across New Zealand, influencing temperature and precipitation, especially in the South Island (Salinger \& Mullan, 1999). The circumpolar westerlies are predominantly modulated by the Southern Annular Mode (SAM), a climate phenomenon that is characterised by latitudinal movement of the westerly wind belt on an interannual-annual timescale. During a positive SAM phase the westerly wind belt contracts towards Antarctica, decreasing westerlies in the South Island. Conversely, during negative SAM phases the westerlies are shifted equatorwards and the South Island experiences stronger winds (Ummenhofer et al., 2009). The El Niño-Southern Oscillation (ENSO) is a large-scale fluctuation of sea surface temperature and air pressure in the Pacific Ocean, recurring every 2-7 years. In New Zealand, the El 
Niño phase is associated with more intense westerlies and precipitation, with precipitation in Fiordland increasing by up to $400 \mathrm{~mm} / \mathrm{yr}$ greater than average (Ummenhofer et al., 2009). La Niña phases bring warmer, less turbulent weather to New Zealand (Ummenhofer et al., 2009). The variability of precipitation and temperature in New Zealand caused by a combination of SAM and ENSO impacts landscape development, influencing glacier mass balance and thus glacier length (Willsman, 2017).

\subsubsection{Rocky Top cirque}

Rocky Top cirque is not currently glaciated, but the presence of landforms such as moraines provide evidence of past glaciation. Despite regional mapping, the geomorphology of the study site has not been previously researched in detail.

Similar to the majority of central and eastern Fiordland, the geology of the catchment is comprised of plutonic granitoid material (Turnbull et al., 2010; Allibone et al., 2009). The underlying bedrock consists of the Cleughearn Pluton, a NNE-trending belt that was emplaced at 153.8 $\pm 2.3 \mathrm{Ma}$ and crops out over $30 \mathrm{~km}^{2}$ in the southern Hunter Mountains (Turnbull et al., 2010; Allibone et al., 2009). The composition is largely granodiorite, which has greater than $20 \%$ quartz by volume (Streckeisen, 1974) so is suitable for cosmogenic ${ }^{10}$ Be surface exposure dating.

The cirque itself has a diameter of $0.75 \mathrm{~km}$. Rocky Top peak is at $1450 \mathrm{~m}$ elevation, situated about $\sim 1 \mathrm{~km}$ northwest of the 1578 m Cleughearn Peak. The unnamed peak is at $1430 \mathrm{~m}$, below which steep walls of exposed bedrock extend down to a roughly circular-shaped tarn with an area of $0.12 \mathrm{~km}^{2}$. A stream originates from the tarn and travels $~ 8 \mathrm{~km}$ SE before reaching Lake Monowai (Figure 2.13).

The study site focuses on the upper $1.25 \mathrm{~km}$ of the cirque valley, in an attempt to achieve the first research aim, 'to constrain the timing and magnitude of glacier length changes at Rocky Top'. The study site has well-preserved evidence of past glaciation, including terminal and lateral moraines and glaciofluvial outwash plains (Section 4.1). Though the former glacier likely extended further downvalley, the evidence is less well-preserved. 


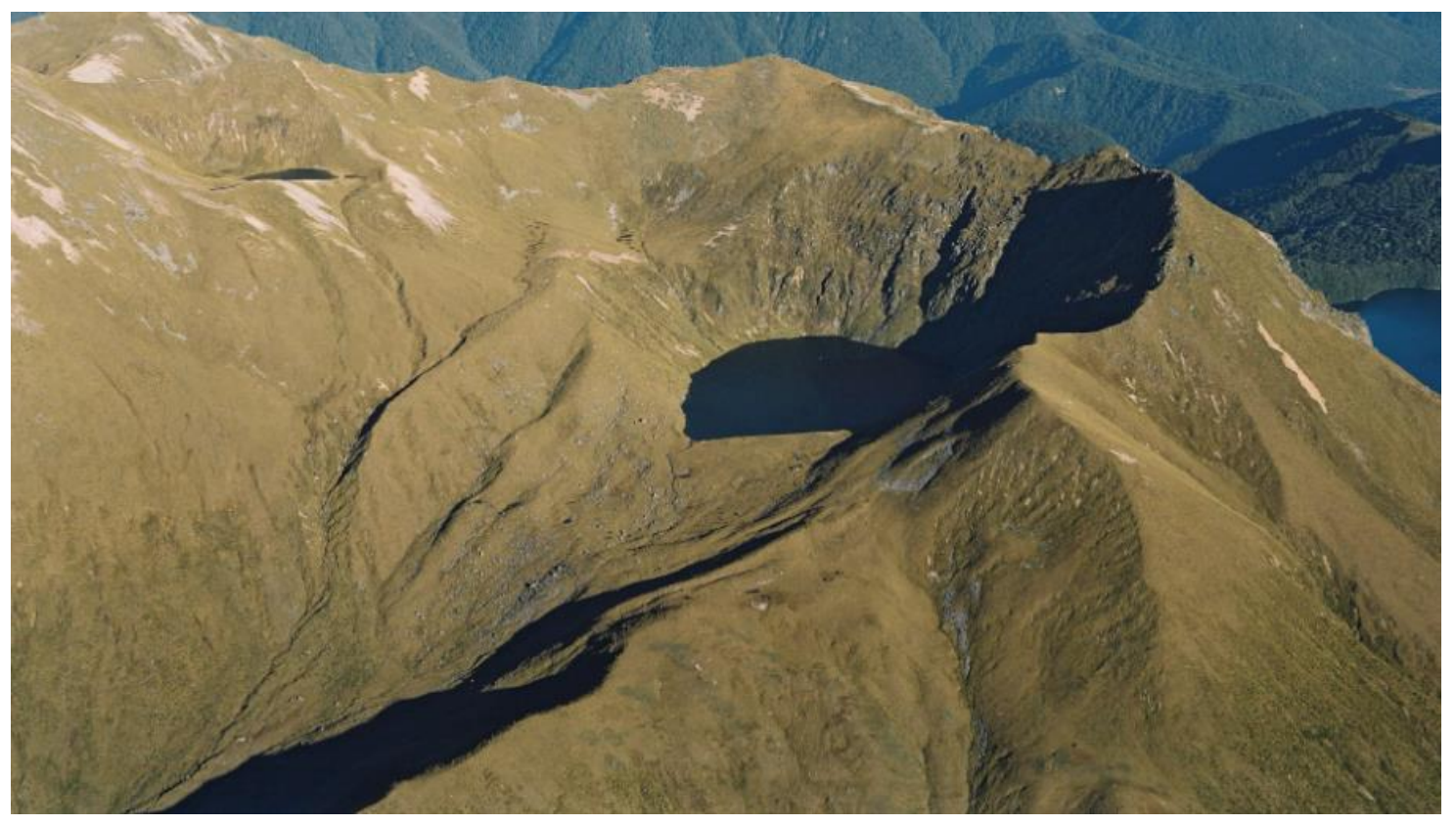

Figure 2.13: Oblique photograph of the Rocky Top cirque. Photograph taken looking approximately due west. Photograph taken by Lloyd Homer in 01/08/1976, retrieved from GNS Science VML, ID: 5489. 


\section{CHAPTER 3: METHODS}

\subsection{Geomorphological mapping of landforms at Rocky Top cirque}

\subsubsection{General approach and classification of landform type}

Geomorphological mapping is an established tool for the depiction of landforms, thus aiding analysis and understanding of the landscape. There are two main approaches to geomorphological mapping (Chandler et al., 2018): (1) Classical; the mapping of all geomorphological features and landforms which can be used to define the formation of the landscape in a particular area. (2) Thematic; constituting a theme, such as detailed mapping of a glacial environment with emphasis on glacial landforms and processes (e.g. Barrell et al., 2011a).

The mapping approach applied at Rocky Top was primarily based on the thematic mapping approach of Barrell et al. (2011b). The Rocky Top cirque geomorphic map focuses on landforms formed by glacial processes, such as moraines and outwash surfaces. Other landforms, such as those created by fluvial and mass-movement processes, may modify glacial landforms over time and influence their preservation, so these were also mapped (Tielidze et al., 2021). The detailed mapping of glacial landforms provides a basis for examining former glacier extent changes at Rocky Top cirque as the spatial distribution may inform patterns, rates, and magnitude of past glacier length change, thus directly contributing to my first thesis objective. Thematic mapping also informs understanding of past glacier behaviour and processes, therefore contributing to my second thesis aim "to make a quantitative reconstruction of paleoclimate at Rocky Top cirque”.

The mapping approach also drew inspiration from approaches by Schaefer et al. (2009) and Kaplan et al. (2010). Similarly to these studies, the mapping approach applied at Rocky Top utilised a combination of field observations, remotely sensed data and computer-based mapping, and attempted to maintain consistency with classification of mapped landform types. Consistency allowed for comparison with existing geomorphic maps and attempted to reduce variation in landform interpretation between map-creators. Mapped landform types were classified 
according to their morphology and formation processes (Barrell et al., 2011a).

Table 3.1 contains a summarised description of each mapped landform type that was used to create the final geomorphic map (see Figure 4.4).

Table 3.1: Summary descriptions of landform types, as used to create the geomorphic map. Table adapted from Barrell et al. (2011a).

\begin{tabular}{|c|c|}
\hline Landform type & Description of landform type \\
\hline Moraine & $\begin{array}{l}\text { Discrete hill-like ridge morphology formed by the build-up of } \\
\text { ice-deposited debris. Includes lateral and terminal moraines. } \\
\text { Often has vegetation cover and large boulders embedded. }\end{array}$ \\
\hline Moraine ridge & $\begin{array}{l}\text { Crest of moraine. Typically represents the ice margin but may } \\
\text { be modified post-deposition by fluvial or erosional processes. } \\
\text { Prominent ridge morphology, continuous or semi- } \\
\text { continuous. }\end{array}$ \\
\hline $\begin{array}{l}\text { Crest of ice- } \\
\text { contact slope }\end{array}$ & $\begin{array}{l}\text { Located on the innermost side of the moraine ridge to the } \\
\text { glacier. Delineates the former ice margins when glacier } \\
\text { extent was situated at the moraine. The degree of moraine } \\
\text { preservation may affect where these are expressed in the } \\
\text { landscape. }\end{array}$ \\
\hline Outwash & $\begin{array}{l}\text { Material reworked by fluvial processes. May appear as } \\
\text { hummocky or broadly planar flood plains in areas } \\
\text { surrounding moraines. Water source may include meltwater } \\
\text { channels and streams. }\end{array}$ \\
\hline Colluvial deposit & $\begin{array}{l}\text { Hummocky fan-like surface, created by gravitational mass- } \\
\text { wasting. Often located at the base of steeply sloping bedrock } \\
\text { walls. Typically lacks evidence of a tributary steam (to } \\
\text { distinguish from an alluvial fan). }\end{array}$ \\
\hline Bedrock & $\begin{array}{l}\text { Land surface consists of parent bedrock. Surface texture may } \\
\text { be irregular, may display evidence of fluvial gullying and } \\
\text { gravitational erosion processes. Slopes may be moderately- } \\
\text { steeply sloping, smooth and broadly planar. Surface tends to } \\
\text { be covered in regolith and/or alpine vegetation. May be ice- } \\
\text { scuplted. }\end{array}$ \\
\hline Stream & $\begin{array}{l}\text { Permanent or seasonal stream, transporting water } \\
\text { downvalley. May sit within a fluvially-eroded depression. }\end{array}$ \\
\hline $\begin{array}{l}\text { Meltwater } \\
\text { channel }\end{array}$ & $\begin{array}{l}\text { Channel cut by glacial meltwater beneath, alongside or } \\
\text { downstream of the ice mass. May form a depression in the } \\
\text { landscape. }\end{array}$ \\
\hline Pond & $\begin{array}{l}\text { Relatively small-sized permanent or seasonal water body. } \\
\text { Typically located near streams in landscape depressions. } \\
\text { Relatively shallow depth. }\end{array}$ \\
\hline Lake & Relatively large permanent water body. \\
\hline
\end{tabular}




\subsubsection{Landform identification}

Identification of landform types is often subjective, especially for complex landscapes such as the Rocky Top cirque. To minimise uncertainty associated with landform identification a variety of mapping resources were used, including field observations and computer-based datasets (Barrell et al., 2011a).

Prior to mapping in the field, remotely-sensed datasets such as Google Earth were used to obtain an overview of geomorphic features in the study area. Field observations were used for the confirmation ("ground-truthing") of remotely detected features and the addition of further detail that could not be obtained from remote sensing (Barrell et al., 2011a). During traverse of the study area by foot, observations such as the degree of landform preservation were recorded and numerous photographs of landforms were taken to aid later analysis.

Following fieldwork, computer-based mapping resources were used to precisely identify and locate landforms. Base map data such as aerial photography (Southland 0.75m rural aerial photos 2005-2011 (sourced from LINZ) and a topographic map (NZ Topo50 series 2020; sourced from LINZ) was imported into ArcGIS version 10.8 .

Three-dimensional landform visualisation was helpful for moraine identification, as moraines are mainly distinguished based on their ridge-like morphology (Kaplan et al., 2010). Smaller moraines may have subtler profiles that are unclear on topographic maps and from aerial photos. A three-dimensional model of the lower cirque area was produced using drone photographs and Structure from Motion technology (Figure 3.1). A series of aerial photographs were taken by a Mavic Pro 2 drone flown in a manual survey between 30-80 $\mathrm{m}$ above the surface. The photographs were directly georeferenced using the UAV GPS with an accuracy of $<2 \mathrm{~m}$. Photographs were imported into Agisoft PhotoScan Standard Edition for utilisation of Structure from Motion technology. Processing involved image alignment, where the software implemented algorithms to track common features throughout the overlapping photographs. The relative location of camera positions for each image were estimated by the software, allowing the generation of a 3D point-cloud of the tracked features. The resulting DEM and orthophoto were imported into ArcScene version 10.8 and a 3D model was produced with $25 \mathrm{~cm}$ 
resolution (Figure 3.1) (Chandler et al., 2018; Ryan et al., 2015). In addition Google Earth was also used as a quick 3D visual reference for landform identification, especially for the wider area not included in drone footage.

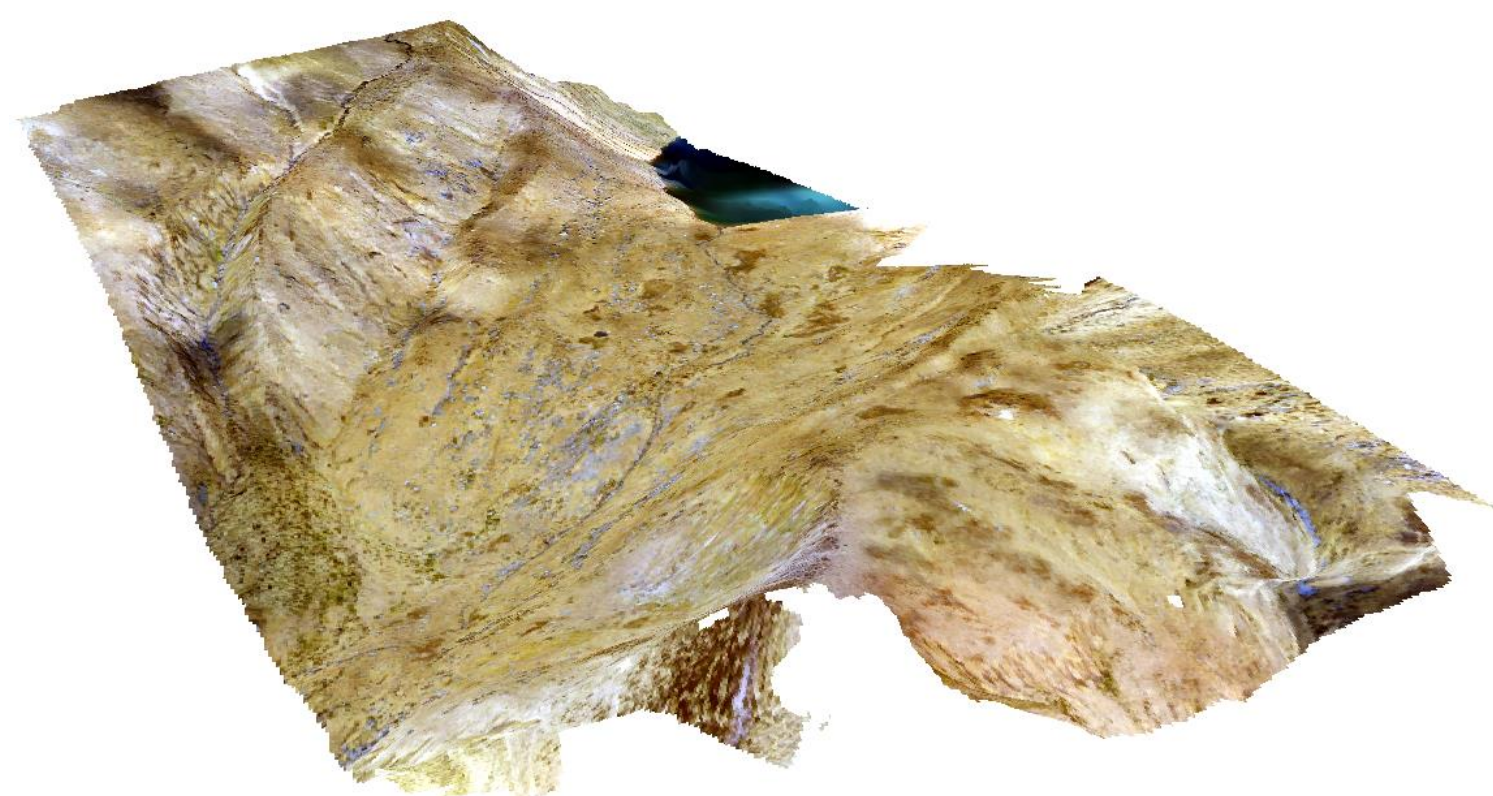

Figure 3.1: 3D model produced by compilation of drone photographs using Structure from Motion technology. Perspective looking northwest, up valley towards the cirque lake. Model has $25 \mathrm{~cm}$ resolution.

Following identification, landforms were mapped using ArcGIS. Landform types were digitised as lines or polygons, each distinguished by a unique colour and/or symbol. Colours were chosen in accordance with mapping convention (e.g. water bodies = blue) and to ensure there was sufficient contrast between landform types. The bedrock landform type symbol was left hollow, so the background hillshade created by the $15 \mathrm{~m}$ Te Anau DEM (sourced from LINZ) could show the general bedrock texture and aspect. Topographic contours were overlain at $25 \mathrm{~m}$ intervals, with emphasis of a thicker contour line at $100 \mathrm{~m}$ intervals. The boundary of the mapped study area was represented by a solid black line.

All layers on the map use the New Zealand Geodetic Datum (NZGD 2000) projection. Inset maps were included to show the location of the study site within New Zealand and in relation to notable locations nearby such as Green Lake and Lake Monowai. Other standard mapping conventions (e.g. north arrow) were added to the map. The final geomorphic map is displayed in Figure 4.4 (Section 4.1). 


\subsection{Cosmogenic ${ }^{10} \mathrm{Be}$ surface exposure dating}

Surface exposure dating of landforms using in situ cosmogenic ${ }^{10} \mathrm{Be}$ was used to constrain the timing of moraine formation at Rocky Top, as per my first research objective. The process required fieldwork to collect suitable samples, followed by sample preparation involving quartz separation and beryllium extraction, and finally ${ }^{10} \mathrm{Be}$ measurement and exposure age calculation (Dunai, 2010).

\subsubsection{Sample collection}

Sample collection was undertaken at Rocky Top cirque in December 2018. Moraine boulders at Rocky Top cirque consist of granitic-schist lithology, providing sufficient quartz as required for ${ }^{10} \mathrm{Be}$ surface exposure dating. Sample selection involves several assumptions that may be overcome by judicious sampling (Putnam et al., 2013b): (i) the targeted landform was formed by glacial processes; (ii) the sample surface did not undergo significant post-depositional erosion, burial or movement; (iii) the cosmogenic nuclide content in a sample represents the age of exposure since glacial deposition - i.e. does not contain inheritance. Applying recent best practice, sample boulders were chosen carefully to best satisfy these assumptions (Ivy-Ochs, 2008; Putnam et al., 2010b; Dunai and Lifton, 2014). The relative location and potential influences of surrounding topography such as debris fans and riverbanks were taken into account to ensure that the boulder was located on a moraine ridge with history of glacial transport. The degree of moraine preservation was considered (Ivy-Ochs, 2008). Large boulders embedded on the crests of well-preserved moraine ridges were preferred to reduce the likelihood of post-depositional movement or toppling. Boulders with evidence of significant weathering were avoided, to avoid underestimation of exposure age due to surface removal. Rocks that displayed granular disintegration weathering were preferred over those with splitting (as per Kaplan et al., 2004). Samples were taken from the apparent oldest surface of the boulder. Assuming no post-depositional boulder movement, the oldest surface was judged to be on top of the boulder in an area without sharp edges or other evidence of recent surface modification. Lichen was an indicator that the surface was recently unmodified (Ivy-Ochs, 2008). Where 
enough suitable boulders were present, 3-5 boulders were sampled on each moraine to account for outliers and improve precision of exposure age calculations per moraine (Dunai and Lifton, 2014; Ivy-Ochs, 2008).

At each selected sample boulder, observations were recorded regarding factors that could potentially affect the rate of cosmogenic nuclide production (Dunai and Lifton, 2014). GPS data was collected on a Trimble ProXH with $<30 \mathrm{~cm}$ accuracy and key data noted included time, altitude, longitude and latitude (Kaplan et al., 2010). Surface weathering was assessed by quartz vein height above the rock surface, where applicable. Topographic shielding was measured at the horizon using a clinometer and compass. Potential shielding by vegetation and snow cover was assessed. Snow cover must be $75-150 \mathrm{~cm}$ thick in order to reduce annual cosmogenic nuclide production by 5\% (Dunai, 2010), so modern snow cover was unlikely to impact results at Rocky Top (based on minimal end-of-winter snow extent in Google Earth observations). At the end of the LGM temperatures were colder so snow cover would have been thicker, but shielding by snow was assumed to be negligible as the prominent boulder tops were likely windswept and kept largely snow-free. Vegetation at Rocky Top was limited to small alpine shrubs so would also have negligible shielding. Where the sample surface was sloped, dip and orientation were measured using a clinometer and compass to minimise selfshielding (Gosse and Phillips, 2001). Samples were extracted using a hammer and chisel, and a portable angle grinder with a $115 \mathrm{~mm}$-diameter diamond-tipped blade when necessary. To collect a sufficient amount of quartz for exposure dating, quartz veins were targeted and boulders without suitable veins required collection of a larger volume of material. The average thickness of each piece of sample was recorded, as cosmogenic nuclide production decreases exponentially with depth (Dunai, 2010). A total of forty samples were collected across the moraine sequences. Samples were labelled in the format RT_XXYY; where RT = Rocky Top, $X X=$ date in December (13:16), YY = sample number (01:40). Of the forty samples, the twenty with the most potential to inform glacier length changes were processed for cosmogenic ${ }^{10} \mathrm{Be}$ nuclide surface exposure dating (Figure 3.2). 


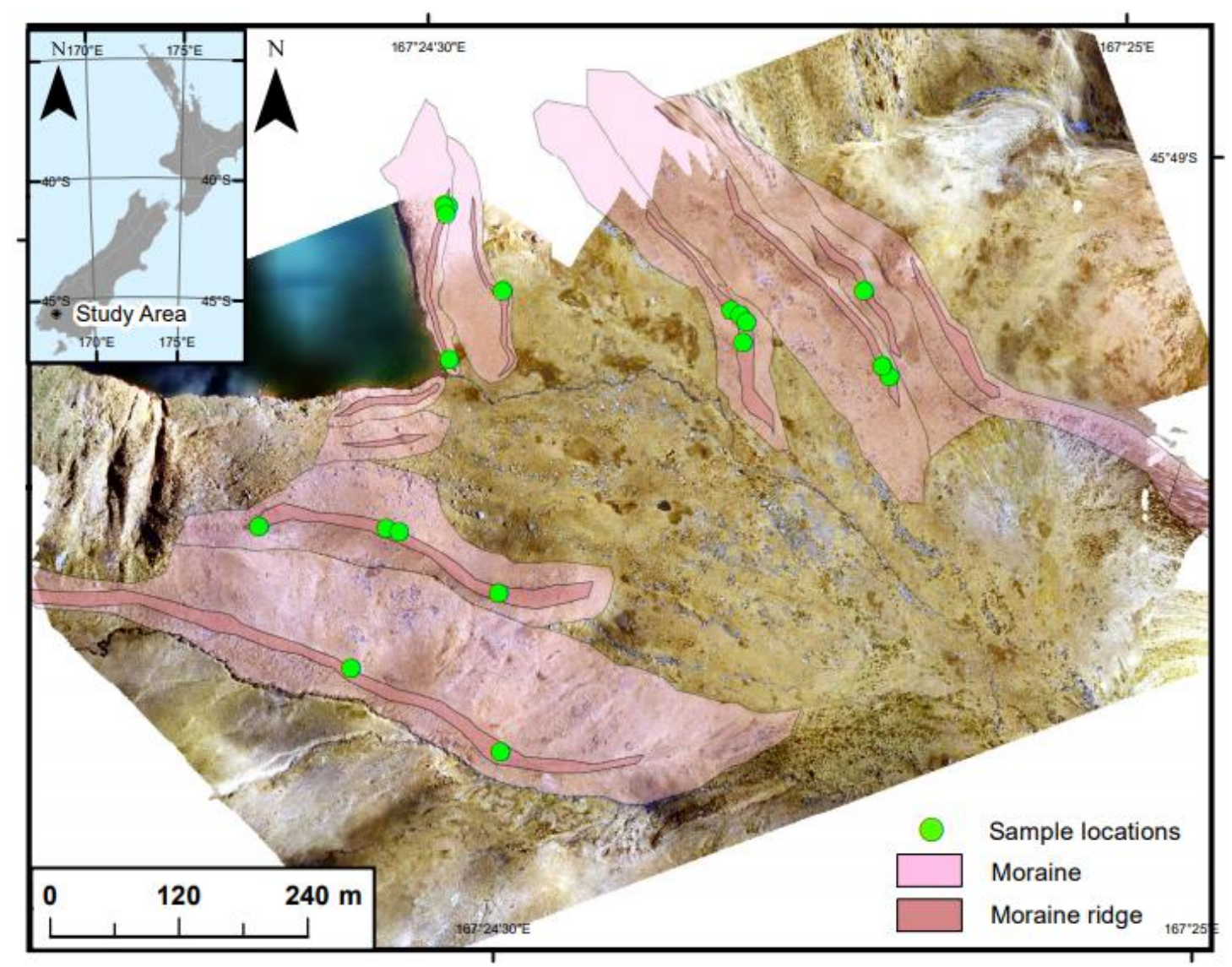

Figure 3.2: Locations of the twenty processed boulder samples that were collected for cosmogenic ${ }^{10}$ Be surface exposure dating at Rocky Top cirque. Identified moraines (see Section 4.1) are included to show the distribution of collected samples. The orthophoto was produced by the drone footage and has $25 \mathrm{~cm}$ resolution.

\subsubsection{Cosmogenic ${ }^{10}$ Be preparation}

Samples were processed by physical and chemical methods at Victoria University of Wellington. Standard laboratory procedures for quartz separation and beryllium extraction were followed for in situ cosmogenic ${ }^{10} \mathrm{Be}$ nuclide surface exposure dating (Von Blankenburg et al., 1996; Von Blankenburg et al., 2004; Norton et al., 2008). The procedure is summarised in Figure 3.3. Samples were processed in two batches of ten samples each. Each batch had an associated process blank to measure the level of background ${ }^{10} \mathrm{Be}$ (Norton et al., 2008). 


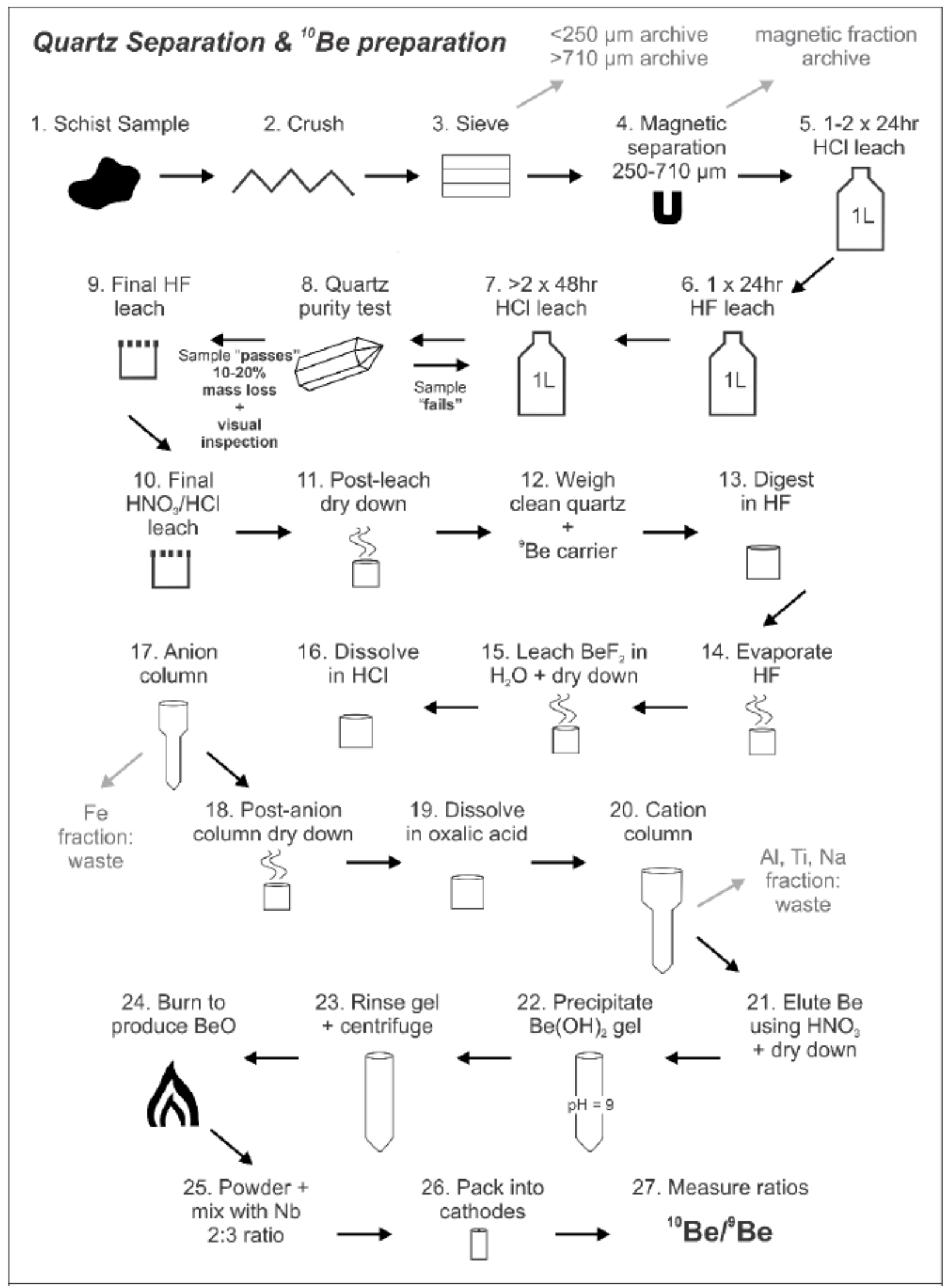

Figure 3.3: Flow chart showing steps used for quartz separation and cosmogenic ${ }^{10}$ Be preparation. Note that Step 15 was not applicable for the Rocky Top samples. Figure from Dowling (2019; adapted from Corbett et al. 2016). 


\section{Quartz separation}

The quartz separation stage aimed to extract at least $\sim 15 \mathrm{~g}$ of 250-500 $\mu \mathrm{m}$ clean quartz for each sample. Samples were crushed in a Boyd jaw-crusher and sieved to obtain $<1 \mathrm{~mm}$ particles. Using a sieve shaker samples were further sieved into four size fractions: $<250 \mu \mathrm{m}, 250-500 \mu \mathrm{m}, 500-710 \mu \mathrm{m}$, and $>710 \mu \mathrm{m}$. The first batch of samples exclusively used the 250-500 $\mu \mathrm{m}$ fraction for the remaining lab-work process, but the second batch used a combination of the $250-500 \mu \mathrm{m}$ and $<250 \mu \mathrm{m}$ fraction due to low sample masses. After sieving, samples were rinsed with water to remove fine dust coating the grains and oven-dried at $40^{\circ} \mathrm{C}$. Samples were put through an Induced Magnetic Roll (IMR) magnetic separator at amplitude 0.5 to separate the non-magnetic from the magnetic fraction. The non-magnetic fraction underwent a froth floatation procedure to isolate quartz from feldspar: following a $1 \mathrm{hr}$ leach of $600 \mathrm{ml}$ 1\% hydrofluoric (HF) acid to etch the feldspars, samples were agitated in a carbonated mixture of $1 \mathrm{~g}$ lauryl amine, $1 \mathrm{ml}$ glacial ascetic acid, a few drops of eucalyptus oil and $11 \mathrm{~L}$ water. Feldspars became suspended and were poured off.

To obtain clean quartz, samples were next purified by a series of acid leaches. The leaches removed remaining impurities such as organic material, weathering products and non-quartz mineral content, which contain interfering elements that can compromise Be isolation and/or measurement (Norton et al., 2008; Dunai, 2010). Firstly, samples were exposed to two successive $24 \mathrm{hr} 10 \% \mathrm{HCl}$ leaches. Approximately $\sim 50 \mathrm{~g}$ of each sample was put in $1 \mathrm{~L}$ Nalgene bottles and $800 \mathrm{ml}$ of $10 \% \mathrm{HCl}$ was added. Samples were agitated to ensure all grains were coated then left for $24 \mathrm{hrs}$ in a heated water bath at $50^{\circ} \mathrm{C}$. The $\mathrm{HCl}$ solution was inspected by eye to observe colour change, then decanted and the leaching process repeated.

Following the second $\mathrm{HCl}$ leach, samples were rinsed 3-4 times with $18.2 \mathrm{M} \Omega$ milliQ $\mathrm{H}_{2}$ O. MilliQ $\mathrm{H}_{2} \mathrm{O}$ was used throughout the remaining labwork process due to its high purification levels from filtering and de-ionization. The leaching process described for $\mathrm{HCl}$ was repeated for a series of HF leaches. Samples underwent two $24 \mathrm{hr}$ leaches in $800 \mathrm{ml}$ of $2.5 \% \mathrm{HF}$, then two $48 \mathrm{hr}$ leaches in $500 \mathrm{ml}$ of $1 \% \mathrm{HF}$. Samples were visually inspected between HF leaches to assess a rough estimate of mass loss and the degree of remaining visible impurity. After the final leach the majority of visible impurities had been removed and total mass loss was estimated to be roughly $15-20 \%$. 


\section{Cosmogenic ${ }^{10} \mathrm{Be}$ preparation}

Samples were transferred to Savillex beakers. Prior to transferring the sample, beakers (jar only) were weighed precisely to four decimal points and the measurement recorded. An anti-static gun was used during measurement to increase precision. For the first batch of samples, approximately $15 \mathrm{~g}$ of sample was added to the beakers, while for the second batch an average of $\sim 35 \mathrm{~g}$ of each sample was added. A final HF leach was carried out to remove any remaining impurities and meteoric ${ }^{10} \mathrm{Be}$. Between $\sim 20-50 \mathrm{ml}$ of $7 \mathrm{M}$ (molar) HF was added to each beaker to cover the quartz grains completely then beakers were heated for 1 hr at $120^{\circ} \mathrm{C}$. Beakers were removed from the hotplate and left to cool for 5 mins before being decanted and rinsed four times with milliQ $\mathrm{H}_{2} \mathrm{O}$. Beakers were heated overnight at $60^{\circ} \mathrm{C}$ until samples were completely dry.

Next, approximately $\sim 25 \mathrm{ml}$ of aqua regia (a 1:3 molar mixture of $\mathrm{HNO}_{3}: \mathrm{HCl}$ ) was added to each sample. Beakers were left uncapped for 15 minutes to de-gas, then capped and heated at $120^{\circ} \mathrm{C}$ for $2 \mathrm{hrs}$. The aqua regia was decanted and samples were rinsed 4-5 times then set on a hotplate uncapped at $60^{\circ} \mathrm{C}$ until samples had dried completely. The final beaker weight with sample (jar only) was precisely measured to determine the final sample masses.

Approximately $260 \mu \mathrm{g}$ of a ${ }^{9} \mathrm{Be}$ carrier solution (1008.3 ppm solution from Australia's Nuclear Science and Technology Organisation) was added to all samples. The amount of carrier added was measured precisely and recorded. As concentrations of in situ ${ }^{10} \mathrm{Be}$ in the samples were very low, addition of the ${ }^{9} \mathrm{Be}$ carrier created a fixed ${ }^{9} \mathrm{Be} /{ }^{10} \mathrm{Be}$ ratio, reducing the need for complete recovery of ${ }^{10} \mathrm{Be}$ during the remaining laboratory procedure (Dunai, 2010). Carrier was also added to a process blank, which was then treated the same as the other samples throughout the remaining procedures. There was one blank per batch of processed samples.

The samples and blank underwent closed beaker dissolution. To the first batch of samples, which were all around $15 \mathrm{~g}, 85 \mathrm{ml}$ concentrated $\mathrm{HF}$ and $17 \mathrm{ml} \mathrm{HNO}_{3}$ was added. To the second batch of samples, $170 \mathrm{ml} \mathrm{HF}$ and $34 \mathrm{ml} \mathrm{HNO}_{3}$ was added. Beakers were capped and heated at $60^{\circ} \mathrm{C}$ until the sample was completely dissolved, then beakers were uncapped and heated at $100^{\circ} \mathrm{C}$ to allow the solution to evaporate. Small white smears remained of the samples, which were dissolved 
by adding $10 \mathrm{ml}$ of $6 \mathrm{M} \mathrm{HCl}$. Samples were then transferred to $15 \mathrm{ml}$ centrifuge tubes (labelled Fe1) and centrifuged for 5 minutes at $3500 \mathrm{rpm}$.

A cation exchange procedure was used to remove iron from the samples, using 15 ml Eichron columns with $2 \mathrm{ml}$ of Biorad AG1-X8 100-200 mesh (anion) resin. Firstly the resin was cleaned by adding $5 \mathrm{ml}+5 \mathrm{ml}$ of $0.3 \mathrm{M} \mathrm{HCl}$, then conditioned by adding $2 \mathrm{ml}+2 \mathrm{ml}+2 \mathrm{ml}$ of $6 \mathrm{M} \mathrm{HCl}$. Samples, dissolved in $10 \mathrm{ml}$ of $6 \mathrm{M} \mathrm{HCl}$, were added to columns and collected in the original beakers which had been wiped clean with a Kimwipe. To elute the Be, $2 \mathrm{ml}+2 \mathrm{ml}+2 \mathrm{ml}$ of $6 \mathrm{M} \mathrm{HCl}$ was added and collected in beakers. To clean the resin $5 \mathrm{ml}+5 \mathrm{ml}$ of $0.3 \mathrm{M} \mathrm{HCl}$ was added and drained to waste. Beakers were heated at $120^{\circ} \mathrm{C}$ until the solution evaporated. Once evaporated, samples were dissolved in $8 \mathrm{ml}$ of $0.4 \mathrm{M}$ oxalic acid. Samples were moved to clean $15 \mathrm{ml}$ centrifuge tubes (labelled Be1) and centrifuged for 5 minutes at $3500 \mathrm{rpm}$.

A further cation exchange procedure extracted beryllium from the samples, using $15 \mathrm{ml}$ Eichron columns with $5 \mathrm{ml}$ of Biorad AG50-X8 200-400 mesh (cation) resin. To clean the resin, $5 \mathrm{ml}+5 \mathrm{ml}$ of $5 \mathrm{M} \mathrm{HNO}_{3}$ was added, followed by $5 \mathrm{ml}+5 \mathrm{ml}$ of milliQ $\mathrm{H}_{2} 0$. To condition the columns $5 \mathrm{ml}+5 \mathrm{ml}$ of $0.4 \mathrm{M}$ oxalic acid was added and drained to waste. Samples already dissolved in $8 \mathrm{ml}$ of $0.4 \mathrm{M}$ oxalic acid were added and collected in cleaned original beakers. Next, $2 \mathrm{ml}+2 \mathrm{ml}+20 \mathrm{ml}$ of $0.4 \mathrm{M}$ oxalic acid was added to elute $\mathrm{Fe}, \mathrm{Al}$ and $\mathrm{Ti}$ waste, then $3 \mathrm{ml}+3 \mathrm{ml}$ milliQ $\mathrm{H}_{2} \mathrm{O}$. For elution of $\mathrm{Na}, 4 \mathrm{ml}+4 \mathrm{ml}+8 \mathrm{ml}$ of $0.5 \mathrm{M} \mathrm{HNO}_{3}$ was added and drained to clean $15 \mathrm{ml}$ centrifuge tubes (labelled Be2). Be was eluted by addition of $4 \mathrm{ml}+4 \mathrm{ml}+8 \mathrm{ml}$ of $1 \mathrm{M} \mathrm{HNO}_{3}$, and collected in clean $50 \mathrm{ml}$ centrifuge tubes (labelled $\mathrm{Be} 3$ ). To elute the remaining elements and clean the resin $5 \mathrm{ml}+5 \mathrm{ml}$ of $5 \mathrm{M} \mathrm{HNO}_{3}$ was added and drained to $\mathrm{Be} 1$ tubes. Finally $5 \mathrm{ml}+5 \mathrm{ml}$ of milliQ $\mathrm{H}_{2} \mathrm{O}$ was added and drained to waste.

To $\mathrm{Be} 3$ centrifuge tubes, $1.8 \mathrm{ml}$ ammonia $\left(\mathrm{NH}_{4} \mathrm{OH}\right)$ was added. Samples were vortexed for 30 seconds at high speed, then left to sit for 15 minutes. During this stage Be was precipitated from the Be fraction as $\mathrm{Be}(\mathrm{OH})_{2}$ (Dunai 2010). Next, samples were centrifuged for $5 \mathrm{mins}$ at $3500 \mathrm{rpm}$, then poured out so only $\mathrm{Be}(\mathrm{OH})_{2}$ gel remained. Samples were rinsed twice to remove remaining soluble $\mathrm{Be}(\mathrm{OH})_{3}$ by adding $5 \mathrm{ml}$ of milliQ water, centrifuging for $5 \mathrm{mins}$ at $3500 \mathrm{rpm}$ and decanting (Dunai 2010). 
Finally, $0.25 \mathrm{ml}$ of $5 \mathrm{M} \mathrm{HNO}_{3}$ was added to samples then samples were transferred to quartz crucibles. Crucibles were heated uncapped at $120^{\circ} \mathrm{C}$ until the solution evaporated. Next the uncapped crucible was held near the edge of a Bunsen burner flame until brown gas formed and dissipated, then the crucible was held in the centre of the flame for 1 minute to allow $\mathrm{Be}(\mathrm{OH})_{2}$ to calcine (thermally decompose) to $\mathrm{BeO}$ (Dunai, 2010). The powdered $\mathrm{BeO}$ was then mixed with $3 \mu \mathrm{g}$ of $\mathrm{Nb}$ and packed into steel cathodes. Cathodes were mailed to Lawrence Livermore National Laboratory (USA) for the ${ }^{9} \mathrm{Be} /{ }^{10} \mathrm{Be}$ ratio to be measured on their Accelerator Mass Spectrometer (AMS).

\subsubsection{Cosmogenic ${ }^{10}$ Be measurement and exposure age calculation}

The ${ }^{10} \mathrm{Be} /{ }^{9} \mathrm{Be}$ ratio for each sample was measured by the Accelerator Mass Spectrometer (AMS) at Lawrence Livermore National Laboratory (USA) and the resulting ratios were normalised using the 07KNSTD standard (Nishiizumi et al., 2007). The AMS utilises a detection system to measure the extremely small number of rare cosmogenic nuclides $\left({ }^{10} \mathrm{Be}\right)$ relative to a stable reference nuclide $\left({ }^{9} \mathrm{Be}\right)$ present in known amounts (Von Blankenburg and Willenbring, 2014). AMS results provided the ${ }^{10} \mathrm{Be} /{ }^{9} \mathrm{Be}$ ratio and uncertainty for all samples as well as the process blanks. ${ }^{10} \mathrm{Be} /{ }^{9} \mathrm{Be}$ ratio results for all samples were corrected for background 10Be detected in the full-chemistry process blank, and the analytical, blank, and carrier uncertainties were calculated according to Balco (2006). Incorporating the uncertainties, the final ${ }^{10} \mathrm{Be}$ concentration (atoms/g) and associated uncertainty was calculated.

Surface exposure ages were calculated using version 3 of "The online exposure age calculator formerly known as the CRONUS-Earth online exposure age calculator" (Balco et al., 2008; https://hess.ess.washington.edu/). Though there are a variety of exposure age calculators in existence (e.g. Marrero et al., 2016), the Balco et al. (2008) calculator was chosen as it is suitable for ${ }^{10}$ Be surface sample nuclide production, incorporates recent scaling model methods (e.g. LSDn method; Lifton et al. (2014)) and maintains acceptable precision (Balco et al., 2008).

Calibration data from the Macaulay site, NZ, was used as input for the online calculator (Putnam et al., 2010b). The dataset acts as an independent age control 
and is derived from radiocarbon dating of a debris flow (Putnam et al., 2010b). The Macaulay dataset is commonly used for surface exposure dating applications in New Zealand, as the regional applicability of the production rate has been tested and found to be suitable for sites in the Southern Alps dating back to LGMHolocene (Putnam et al., 2010b). Calibration data was sourced from: http://calibration.ice-d.org/site/MACAULAY.

Table 3.2 lists inputs into the online calculator. Firstly, all inputs were submitted for the calibration site and then all inputs were submitted for the processed Rocky Top samples.

Table 3.2: Description of inputs and values used for the online exposure-age calculator (Balco et al., 2008; https://hess.ess.washington.edu/).

\begin{tabular}{|c|c|}
\hline $\begin{array}{l}\text { Input category for online } \\
\text { calculator }\end{array}$ & Input value used/source \\
\hline Sample ID & As listed, e.g. "RT_1404”. \\
\hline Latitude, longitude, elevation & As recorded by the Trimble ProXH GPS. \\
\hline Elevation flag & $\begin{array}{l}\text { Standard "STD” used, applicable for sites } \\
\text { outside Antarctica. }\end{array}$ \\
\hline Average sample thickness & As recorded in field. \\
\hline Sample density & $\begin{array}{l}\text { Value of } 2.7 \text { used for granitic-schist (Hatherton } \\
\text { and Leopard, 1964). }\end{array}$ \\
\hline Topographic shielding & As calculated from field shielding values. \\
\hline Erosion & $\begin{array}{l}\text { Value of } 0 \text { used - samples with virtually nil } \\
\text { erosion were targeted. }\end{array}$ \\
\hline Year of sample collection & 2018 \\
\hline Target nuclide & ${ }^{10} \mathrm{Be}$ \\
\hline Mineral & Quartz \\
\hline${ }^{10}$ Be concentration & As calculated based on AMS results \\
\hline${ }^{10} \mathrm{Be}$ concentration uncertainty & As calculated based on AMS results \\
\hline${ }^{10} \mathrm{Be}$ standard & 07KNSTD (Nishiizumi et al., 2007). \\
\hline
\end{tabular}

The exposure-age calculator returned results of exposure age, internal and external uncertainty for certain scaling methods. The internal uncertainties refer to measurement uncertainties for the nuclide concentration only, while the external uncertainties include both measurement uncertainty and production rate uncertainty. Scaling methods used by the online calculator were St (Stone, 2000), Lm (Balco et al., 2008), and LSDn (Lifton et al., 2014). 


\subsection{Paleoclimate reconstruction}

\subsubsection{Equilibrium-line altitude reconstruction}

The equilibrium-line altitude (ELA) represents the elevation of a glacier where accumulation is balanced by ablation (net mass balance equals zero) (Nesje and Dahl, 2000). During a relatively cool climate ELAs lower in elevation and glaciers increase in volume, which may cause glacier advance if the climatic conditions persist for long enough. Conversely, during a relatively warmer climate ELAs increase in elevation and glacier volume decreases, potentially causing glacier retreat over time (Mackintosh et al., 2017b). Thus, the reconstruction of paleoELAs for former glacier extents can provide important information on past climate fluctuations. The ELA-derived information is most useful when combined with chronological data to investigate palaeoclimate at a certain former glacier extent(s).

Former glacier reconstruction works on the assumption that the moraine geometries accurately represent the former glacier margins. The crests of lateral and terminal moraines form a basis to outline the extent of the former glacier, by extrapolating the former ice surface up-valley from the crests to the head of the catchment. The former ice margins in the accumulation area are difficult to constrain because there is often a lack of geomorphic evidence (e.g. no moraines). The 'larger-volume ice model' approach of Kaplan et al. (2010) reconstructs paleoglacier accumulation areas as extending to the ridgeline of the upper catchment. The Kaplan et al. (2010) approach was used here, as it is an objective method of constraining former upper ice margins where there is often little robust geomorphic evidence, as in the case of Rocky Top cirque. While the approach assumes that all the upper catchment area contributed mass to the former glacier (e.g. if not by direct snowfall, then by avalanching), the steep slopes at the site support this theory (Eaves et al., 2017).

Reconstruction of former glacier geometry enables estimation of the paleo-ELA. A variety of methods exist for paleo-ELA reconstruction, such as (1) the glacier terminus-to headwall altitude ratio (THAR), (2) the maximum elevation of lateral moraines (MELM), (3) the accumulation-area ratio (AAR) (Nesje, 2014). 
The AAR method was chosen for this study, as it allows for valley morphology variations which have the potential to affect the area-altitude distribution of the glacier and therefore glacier hypsometry (Porter, 2000; Nesje and Dahl, 2000). The method requires well-preserved moraines to constrain the glacier margins and reconstruct the former ice surface (Porter 2000, Eaves et al., 2017). The AAR method was used for moraines IN, L3, R3 and L4/L5 (see Figure 4.1 for moraine reference), but was not suitable for moraine R4, which lacked geomorphic evidence to sufficiently constrain the former glacier extent. For similar reasons the methods THAR and MELM were also unsuitable, so no paleo-ELA was reconstructed for moraine $\mathrm{R} 4$.

The AAR method assumes the ELA of a steady-state glacier is located at an icesurface elevation defined by a fixed accumulation/ablation area ratio (Figure 3.4). The ratio divides the total area of past glacier extent into accumulation and ablation areas, where the reconstructed ice-surface elevation at the dividing line between the two areas is an estimate of the paleo-ELA (Figure 3.4). The AAR value used depends on factors such as glacier geometry and debris cover, typically ranging between 0.5-0.8 (Porter, 2000; Nesje, 2014). A ratio of 0.67 was used, as Chinn et al. (2012) suggested this value to be appropriate for New Zealand glaciers and it has been commonly adopted in previous studies (Kaplan et al., 2010; Putnam et al., 2013a; Eaves et al., 2017).

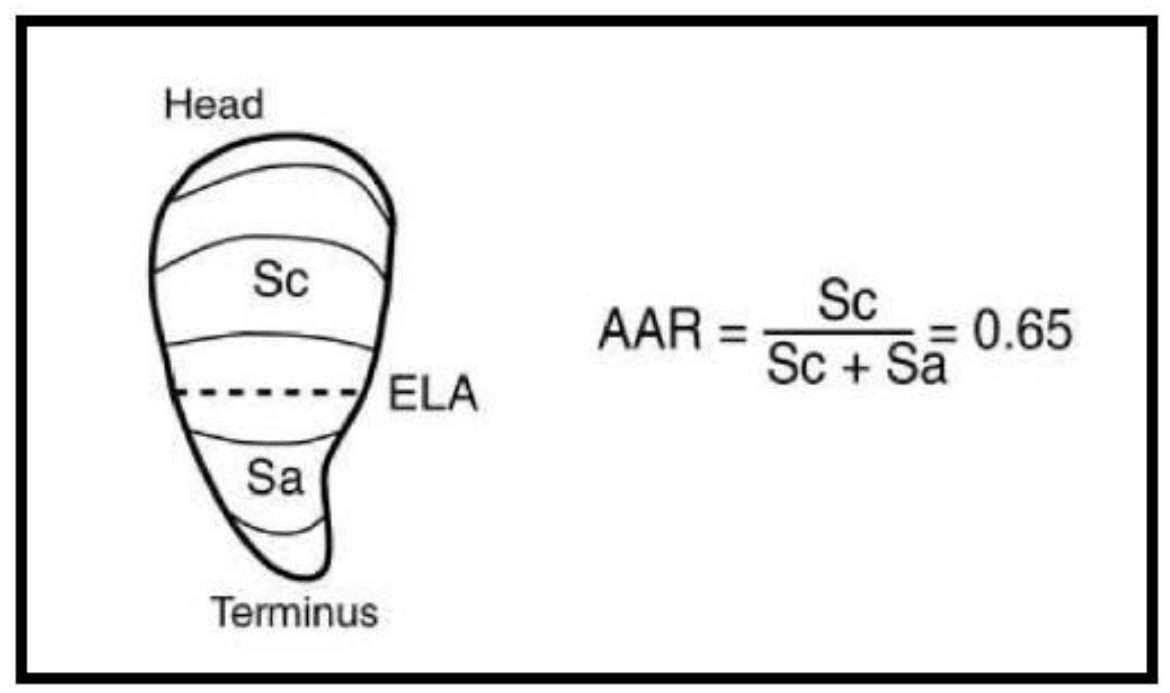

Figure 3.4: ELA calculation using the accumulation-area ratio (AAR) method. An AAR of 0.67 was used for the Rocky Top Cirque, as suggested by Chinn et al. (2012). Abbreviations: Sc, accumulation area; Sa, ablation area (Figure from Porter, 2000). 
A GIS-based method was utilised to reconstruct the former glacier extent(s) and locate the paleo-ELA(s). Firstly, former ice limits were identified by geomorphic mapping of lateral and terminal moraines (see Section 4.1). Where appropriate, moraines were grouped based on chronological and geomorphic data (see Section 4.2). For each discrete moraine landform that represented a former glacier extent, a paleo-ELA was reconstructed. On ArcGIS version 10.8, polygons were created to outline each of the former glacier extents that could be delimited from the moraines, following the 'larger-volume ice model' approach (Kaplan et al., 2010).

Overlaid on each polygon of former glacier extent, contours representing former glacier hypsometry were calculated using slope. On a modern topographic map elevation increments of $50 \mathrm{~m}$ were identified where the present-day contours intercepted the reconstructed glacier outline, then contours were projected across the glacier following principles of steady-state glacier flow. Contours were perpendicular to ice flow direction, being concave in the accumulation zone (above ELA) and convex in the ablation zone (below ELA), with the degree of concavity or convexity increasing with distance from the ELA (Porter, 2000; Bate, 2008).

The surface area between each contour was calculated by creating polygons on ArcGIS between each contour increment. A cumulative curve graph was created displaying the glacier's area/altitude distribution (Figure 3.5). The AAR value of 0.67 (Chinn et al., 2012) was applied to the cumulative curve, determining the ELA. The ELA was drawn on the glacier reconstructions as a straight line.

The largest source of inaccuracy related to the AAR method is the reconstruction of the surface contours, or glacier hypsometry. The imprecise and subjective nature of contour position can lead to varying results between users. Variable curvature of contours creates a tendency for glaciers advancing into flat areas to underestimate the ELA depression, while glaciers advancing into steeply sloping areas tend to overestimate the ELA depression (Eaves et al., 2016). 


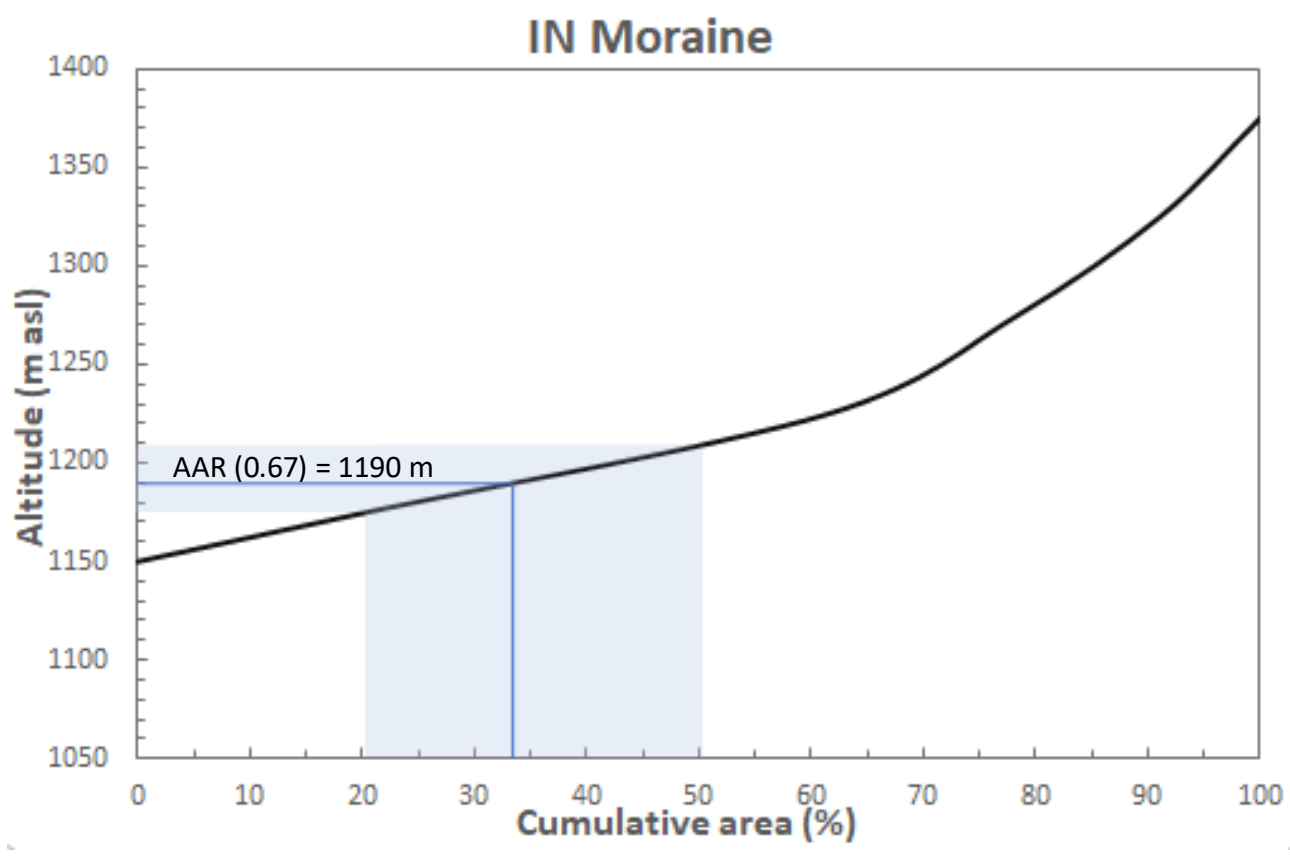

Figure 3.5: Example of a cumulative curve graph, showing the area/altitude distribution of the reconstructed former glacier of IN moraine at Rocky Top cirque. The shaded area indicates uncertainty in the AAR value and resulting uncertainty in altitude. The AAR value (0.67) is applied to determine the paleo-ELA (see Section 4.3) (Figure based on approach by Eaves et al., 2016).

\subsubsection{Paleotemperature reconstruction}

The paleo-ELA can be used to derive a quantitative estimate of paleotemperature (relative to present) for the reconstructed glacier. The difference between the paleo-ELA and modern ELA represents the climatic shift associated with the change in glacier geometry. The magnitude of ELA change is related to temperature change using temperature lapse rates (Eaves et al., 2017).

The temperature lapse rate describes how temperature decreases with elevation and can vary temporally and spatially (Eaves et al., 2017). In New Zealand a summer lapse rate of $5.3^{\circ} \mathrm{C} \mathrm{km}^{-1}$ tends to perform well in alpine regions (Norton, 1985). The temperature lapse rate may be applied by the equation:

$$
\Delta T=\Delta z E L A d T-d z
$$

Where $\Delta \mathrm{T}$ is temperature change from present day, $\Delta \mathrm{zELA}$ is the difference between past and present-day ELA $(\mathrm{km})$, and $\mathrm{dT}-\mathrm{dz}$ is the temperature lapse rate $\left(5.3^{\circ} \mathrm{C} \mathrm{km}-1\right)$ (Norton, 1985). Assumptions involved in the AAR method and 
variables used may introduce considerable uncertainty in the results. To account for uncertainty the approach of Eaves et al. (2016) was followed, which generates a probability distribution of paleotemperature estimates using Monte Carlo techniques to resample the uncertain input parameters.

The mean and standard deviation of variables (i) AAR, (ii) temperature lapse rate and (iii) present-day ELA, were specified and input to the Monte Carlo algorithm. A normal distribution of values was simulated for each variable, where the values suggested by literature were more heavily weighted. For the AAR, a mean of 0.67 was used, based on the recommendation of Chinn et al. (2012), with a nominal 1 standard deviation uncertainty of 0.05 . The temperature lapse rate used a mean of $0.0053^{\circ} \mathrm{C} \mathrm{m}^{-1}\left(5.3^{\circ} \mathrm{C} \mathrm{km}^{-1}\right)$ and standard deviation of $0.001^{\circ} \mathrm{C} \mathrm{m}^{-1}$, based on the suggestion by Norton (1985).

The present-day ELA is required in order to estimate paleotemperature from an ELA reconstruction. In the case of a presently non-glaciated site such as Rocky Top cirque, present-day ELA is commonly obtained from observations of end of summer snowline of a nearby modern glacier(s).

In the absence of nearby glaciers, the mean summer (DJF) air temperature was used as a proxy for the modern ELA (Brook, 2009). The proxy works by using the temperature at a certain elevation and the temperature lapse rate to estimate the elevation summer isotherm. Data was obtained from The National Climate Database (https://cliflo.niwa.co.nz/) pertaining to the weather station Manapouri West Arm 2, located approximately $34 \mathrm{~km}$ to the northwest of Rocky Top. The mean air temperature of DJF months from 1970-2010 was averaged to calculate an overall mean and standard deviation $\left(13.53^{\circ} \mathrm{C}\right.$ and $0.59^{\circ} \mathrm{C}$ respectively), which were input to the Monte Carlo algorithm. Station elevation (232 $\mathrm{m}$ asl (above sea level)) was also input to the algorithm. Using this approach gives a present-day ELA for Rocky Top produced as 2900 m (see Section 4.3), which was clearly incorrect as the value was unrealistically similar to the present-day ELA in the North Island (between 2400-3200 m asl; Eaves and Brook, 2021). Based on the $\sim 1000 \mathrm{~km}$ latitudinal difference between Rocky Top and the central North Island, the present-day ELA at Rocky Top would be expected to be relatively much lower due to the latitudinal temperature gradient. 
The nearest substantial ( $>30 \mathrm{~km}^{2}$ ) glaciers to Rocky Top include Bryant Glacier, Park Pass Glacier and Barrier Peak (Willsman et al., 2010). These glaciers are highlighted in Figure 3.6, showing their location roughly 100 km north of Rocky Top cirque. The elevation ranges of the Bryant, Park Pass and Barrier Peak glaciers are 1660-2180 m, 1500-2200 m and 1420-1900 m respectively (Willsman et al., 2010). Over $100 \mathrm{~km}$ a latitudinal temperature gradient would still influence the snowline elevation between the three glaciers and Rocky Top cirque, with Rocky Top likely exhibiting a snowline at a relatively lower elevation. As such, the elevation ranges of Bryant, Park Pass and Barrier Peak glaciers indicate an upper limit ( 2000-2100 m) for the present-day ELA at the latitude of Rocky Top. 


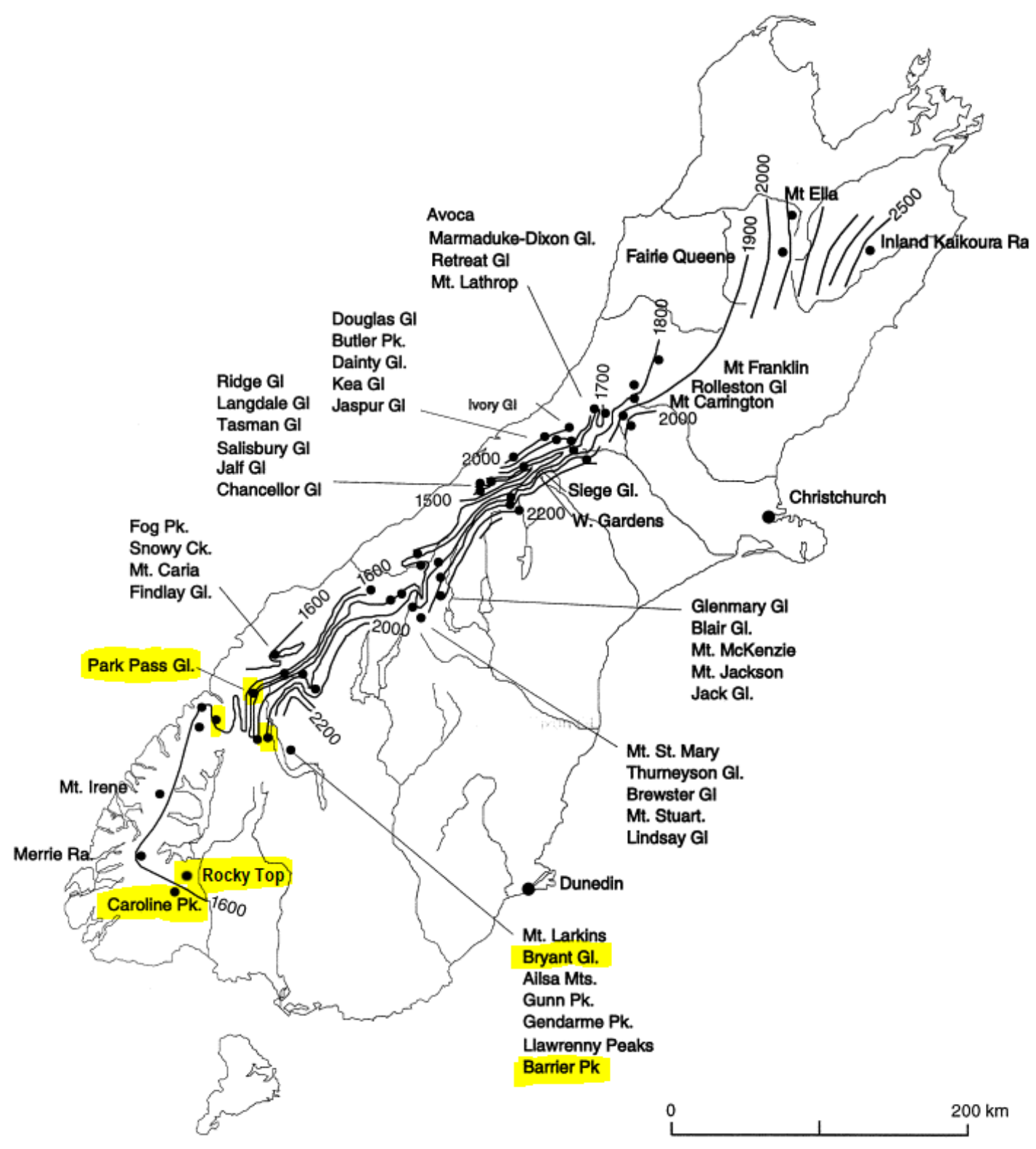

Figure 3.6: Distribution of index glaciers in the Southern Alps, with isolines inferring mean elevations of end-of-summer-snowlines. The location of Rocky Top cirque is highlighted as well as Caroline Peak and locations of the three substantial glaciers discussed. Figure modified from Lamont et al., (1999).

Figure 3.6 shows the distribution of a number of Southern Alps glaciers with isolines interpolating the mean elevations of end of summer snowlines (Lamont et al., 1999). The nearest glacier to Rocky Top is Caroline Peak (Figure 3.6), which has an average ELA of 1365 m (Willsman et al., 2010). However if the Caroline Peak snowline was representative of the present-day ELA at Rocky Top, then Rocky Top peak (1450 m asl) and Cleughearn Peak (1578 m asl) should have glaciers. As they do not presently have glaciers, a lower limit of present-day ELA at Rocky Top may 
be inferred to be $1600 \mathrm{~m}$ asl. The isolines on Figure 3.6 draw the same conclusion, with a $1600 \mathrm{~m}$ snowline isoline close to Rocky Top cirque. Note that the ELA surface depicted by the contours in Figure 3.6 exhibits a steep west-east inclination, due to the orographic precipitation effect (Lamont et al., 1999). The west-east gradient is relatively unconstrained in the region of Rocky Top, making it difficult to understand the degree to which Caroline Peak represents the regional ELA. The nature of the Caroline Peak snowline and reasons for variability between glacier snowlines will be discussed in Section 5.2.

As such, the best estimate for the present-day ELA at Rocky Top is $\sim 1800 \mathrm{~m}$ asl, a mean of the lower and upper limits ( 1600-2000 m) (discussed further in Section 5.3). To the Monte Carlo algorithm, the mean ELA of $1800 \mathrm{~m}$ was input with a nominal standard deviation of $100 \mathrm{~m}$. Including all other aforementioned inputs, the ELA and temperature reconstruction algorithm was run for each reconstruction of glacier extent. For each run, the elevation increments and incremental area of the particular glacier extent were input and the aforementioned variable inputs were randomly sampled 100,000 times, a number which produced results that were not impacted by outliers and would not be significantly improved with more iterations. Outputs included the average presentday ELA, average ELA anomaly (paleo-ELA) and average temperature anomaly. The uncertainty was presented as a cumulative probability graph (see Section 4.3). 


\section{CHAPTER 4: RESULTS}

\subsection{Glacial geomorphology of the Rocky Top cirque}

The geomorphic map for the Rocky Top cirque is displayed in Figure 4.4. The landform types represented in the map legend are described in Table 3.1 (Section 3.1.1). Descriptions of mapped landforms are organised into two sections: The lower cirque and the upper cirque. The lower cirque area focuses on the moraines and surrounding landforms directly downstream of the cirque lake. The upper cirque area represents the remaining landforms of the mapped area, to the southwest of the cirque lake. The lower cirque was mapped with greater detail and precision, as field observations and high-resolution drone footage was limited to this area.

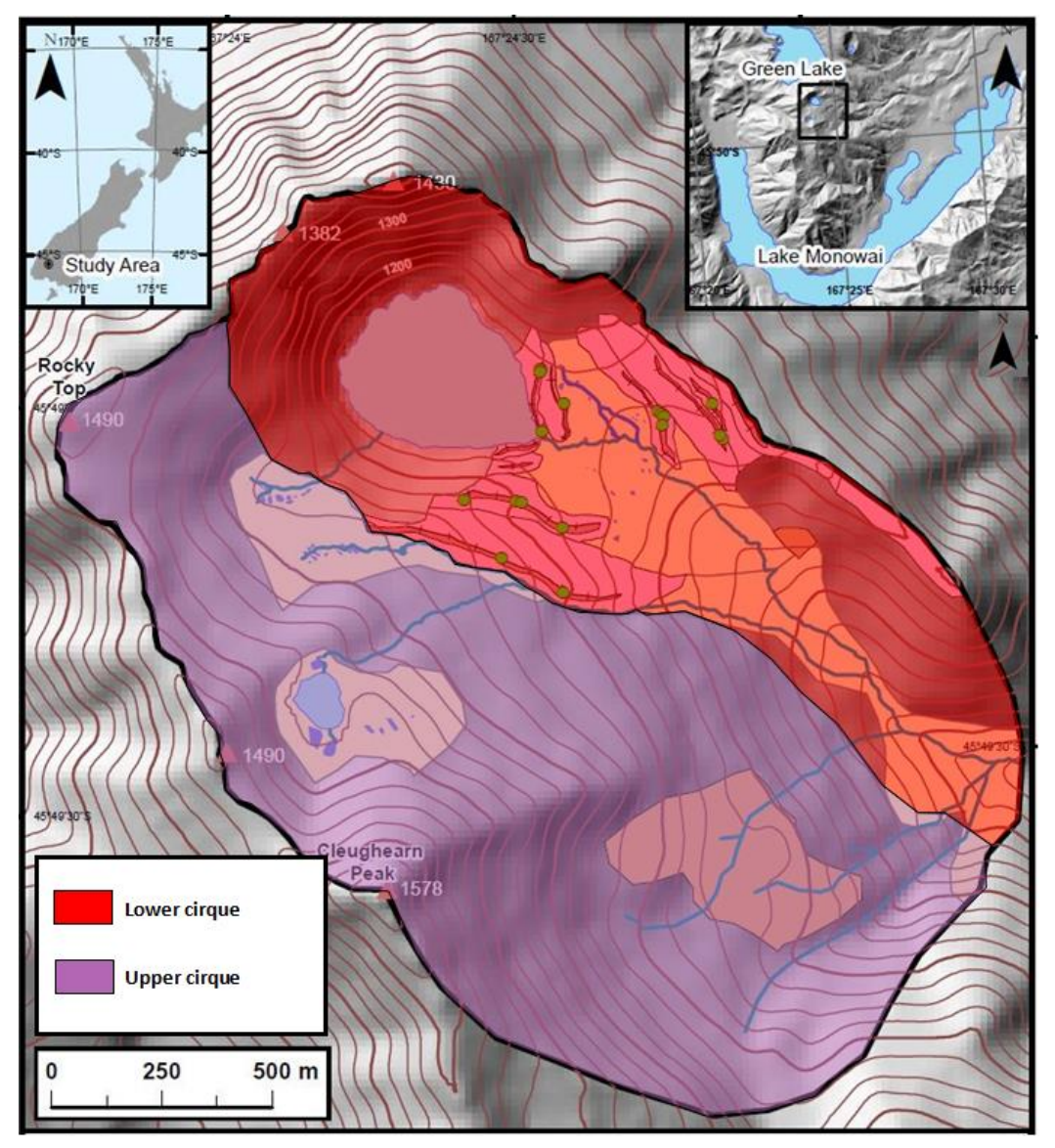

Figure 4.1: Map showing the "lower cirque" and "upper cirque" areas, as referred to in this study. For reference, areas are presented as an overlay on the final geomorphic map. See the final geomorphic map (Figure 4.4) for geomorphic symbols. 


\subsubsection{Lower cirque geomorphology}

The cirque is a classic bowl-shape, with steep concave headwalls of glaciallyeroded bedrock to the northwest. The bedrock has an irregular, hummocky surface texture (Figure 4.3C). The ridge of the headwall is of uneven elevation, bare and narrow, and it is unclear how much the ridge may have eroded since glacial occupation. Fan-like patches of unconsolidated debris and rockfall are evidence of active mass-wasting processes. There is a roughly-circular permanent lake (tarn) of $\sim 0.12 \mathrm{~km}^{2}$ at the centre of the cirque (Figure 4.3A). The lake outlet drains to the southeast, away from the headwalls.

To the southeast of the cirque is a series of lateral and terminal moraines. Figure 4.2 provides labels for reference of the moraines identified.

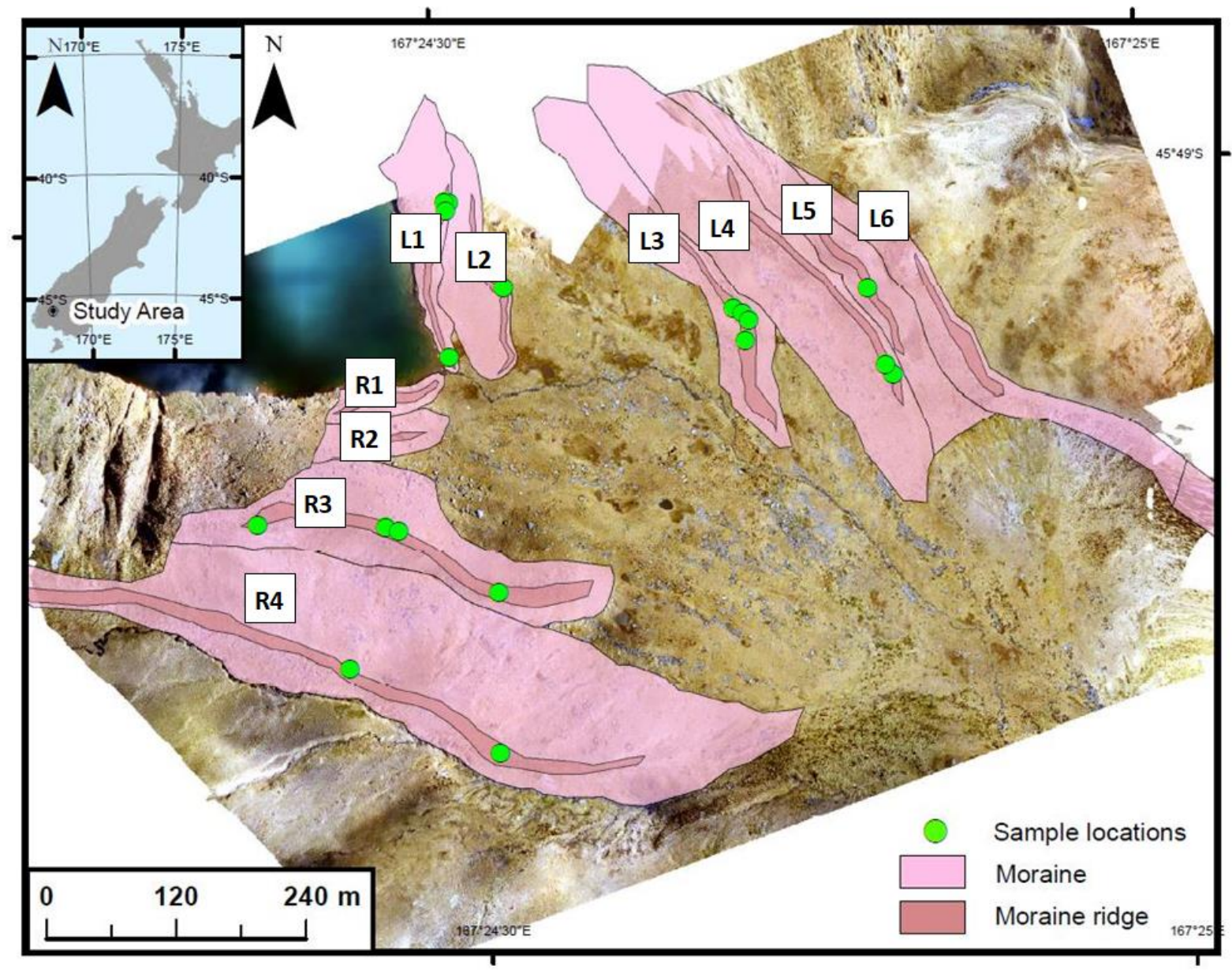

Figure 4.2: Moraines identified and labelled for reference. Moraines were labelled based on location on the true left $(L)$ or right $(R)$ side of the valley, and numbered according to proximity to the cirque lake (1:6). 
There are two sets of paired moraines (L1 and R1, L2 and R2), innermost to the cirque lake, representing the most recent episodes of moraine deposition. These terminal moraines have been eroded in the centre by an active stream exiting the lake and potentially in the past by meltwater drainage. The moraine sets have low relief, exhibiting ridges that protrude only $\sim 1-2 \mathrm{~m}$ above the surrounding landscape. The ridge of the innermost set of moraines closely borders the lake. The innermost moraines and the true left moraine (R1, L1, L2) had suitable boulders for sampling, while the true right moraine (R2) did not.

Downstream of the innermost moraines are a series of lateral moraines. On the true right side two distinct lateral moraines were identified (R3, R4), while there were four identified on the true left side that were relatively narrower (L3, L4, L5, L6).

The outermost true right moraine (R4) is very sharp-crested and prominent in the landscape, reaching 1380 m elevation (Figure 4.3D and Figure 4.5). The inner (true left) side of the moraine is much wider and more gently sloping than the outer (true right) side, which slopes moderately-steeply into a stream that bounds the outer side of the moraine. The moraine had several suitable boulders for sampling. The second outer true right moraine (R3) also had a distinct crest, reaching 1320 m elevation, and had multiple suitable boulders.

Moraines L3 and L4 were expressed similarly, with distinct ridges that were roughly parallel. Both ridges were situated on the outer edge of their respective moraine. L3 had multiple suitable boulders along its length, while L4 had suitable boulders only in its lower portion. Moraine L5 was relatively small and indistinct, situated $\sim 5 \mathrm{~m}$ above the ridge of $\mathrm{L} 4$. There were three suitable boulders along the ridge of L5.

The outermost true left moraine (L6) exhibited a relatively low relief (1-2 m) moraine ridge along its upper portion (>1125 m a.s.l.), but the upper portion did not have suitable boulders for sampling. The lower portion of L6 was very sharpcrested and had several suitable boulders for sampling. A concave section of the ridge below L6 had a hummocky mound at the base, which is interpreted as a colluvial deposit. The proximity of the moraine to the upper boundary of the colluvial deposit and location on a hill ridge result indicate that the lower portion of the L6 landform might not be formed by glacial processes, resulting in an 
unclear maximum downstream former-glacier extent. Interpretation of aerial photographs combined with field observations suggest that L6 moraine extent reaches to at least $1125 \mathrm{~m}$ a.s.l., though potentially extends down to $1100 \mathrm{~m}$ a.s.l.

Downstream of the outermost moraines (below 1100-1000 m a.s.l.) there are no more apparent moraines and the valley floor becomes more steeply sloping and narrowly bounded by bedrock. As such, any moraines that were potentially deposited in this area would be unlikely to be preserved.

There is a large outwash surface alongside the stream that drains the lake, between the lateral moraines (Figure 4.3B). The surface is gently undulating and has multiple small ponds. Most ponds are situated close to streams and where the outwash surface is relatively flat. The outwash surface is covered in alpine vegetation and tends to have a swampy water-logged texture. Somewhat linear ridges of 1-2 m relief could arguably be described as moraines but have been classified as outwash because they are not clear and discrete, having potentially been reworked by flooding of the stream or outpouring of glacial meltwater. Boulders on the outwash surface have high chances of having been moved or altered post-deposition.

A linear swampy depression between moraines L2 and L3 has been interpreted as a meltwater channel. There are many small ponds in this depression and an intermittent stream. The depression is not directly connected to the cirque lake.

\subsubsection{Upper cirque geomorphology}

Below Rocky Top peak, to the west of the cirque, the landscape consists of mainly moderately-steeply sloping bedrock (Figure 4.4). The planar bedrock is partially covered in alpine vegetation and has patches of exposed debris which may be evidence of recent rockfall. Just above the western cirque headwalls there is a relatively flat area consisting of alluvium. There are numerous small ponds in the flat area that drain via two main streams, one over the cirque headwall into the main lake and the other southwards along the outer edge of the true right moraine R4. 
The northern slopes of Cleughearn Peak are bedrock, steeply sloping in a partial bowl shape. About $175 \mathrm{~m}$ below Cleughearn Peak at the centre of the partial bowl is a flat area with a $0.01 \mathrm{~km}^{2}$ pond. The pond is surrounded by outwash and several smaller ponds, all of which drain via a stream to the lower cirque area in the northeast. The partial bowl shape could be interpreted as evidence of glacial occupation, but no moraines were observed.

To the southeast of Cleughearn Peak the hillslope is concave, comprised of steeply sloping irregularly-textured bedrock, incised by multiple channels. About $300 \mathrm{~m}$ to the west below Cleughearn Peak a gently-sloping area of hummocky texture is interpreted as a colluvial deposit. Several streams dissect the deposit, draining to the northeast. The deposit has a prominent mound at $1144 \mathrm{~m}$ elevation, possibly indicating that streams on either side of the mound have eroded much of the colluvial material away. 


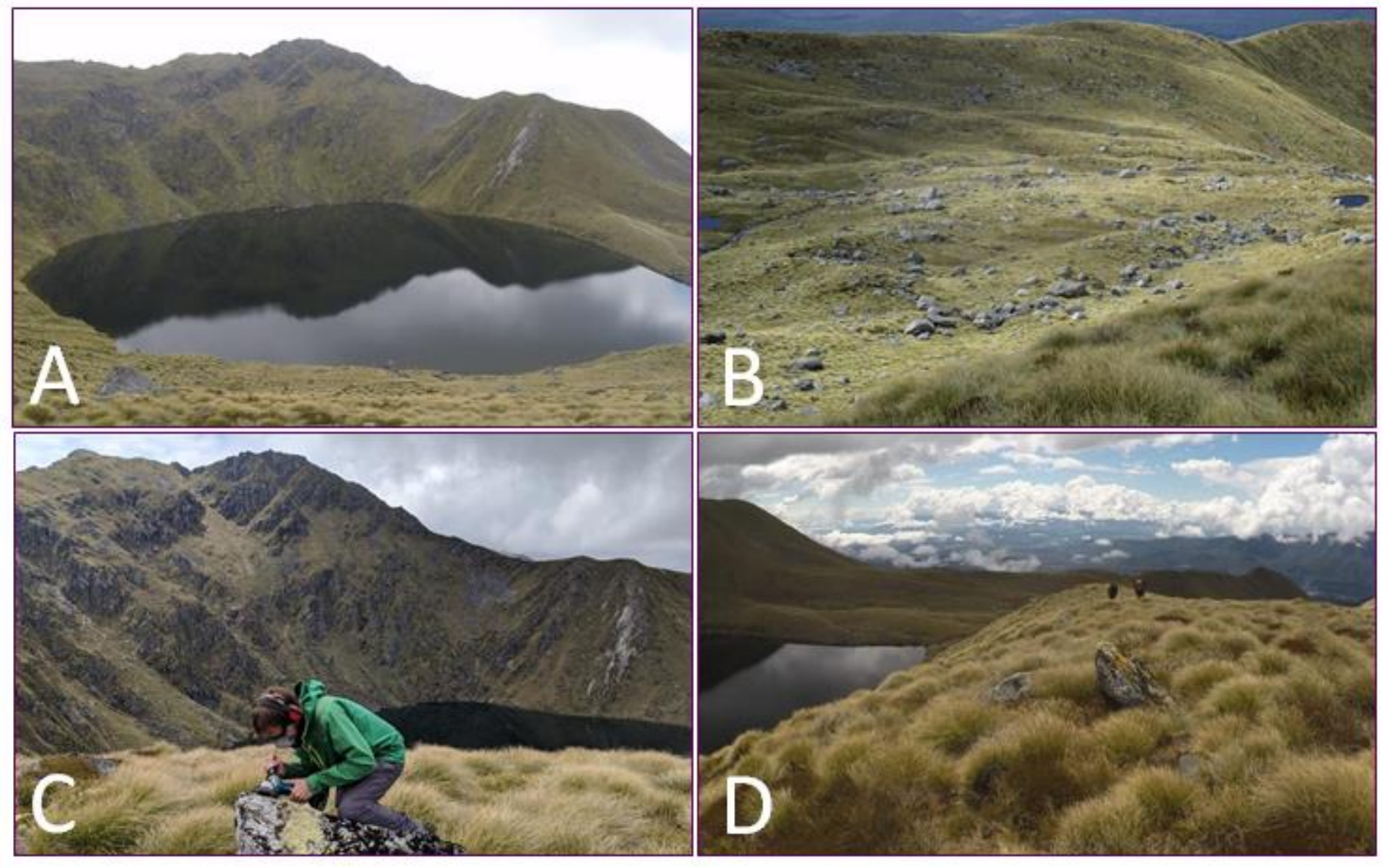

Figure 4.3: Photographs of geomorphic features at the study site. (A) View of lake, looking northeast from the crest of Moraine R4. (B) Outwash surface, undulating with large boulders. Image taken from crest of Moraine R4 looking down valley (C) Steep bedrock headwalls of cirque, looking north from the crest of moraine R4. (D) Moraine R4 continuing down valley; boulder can be seen embedded in crest. 


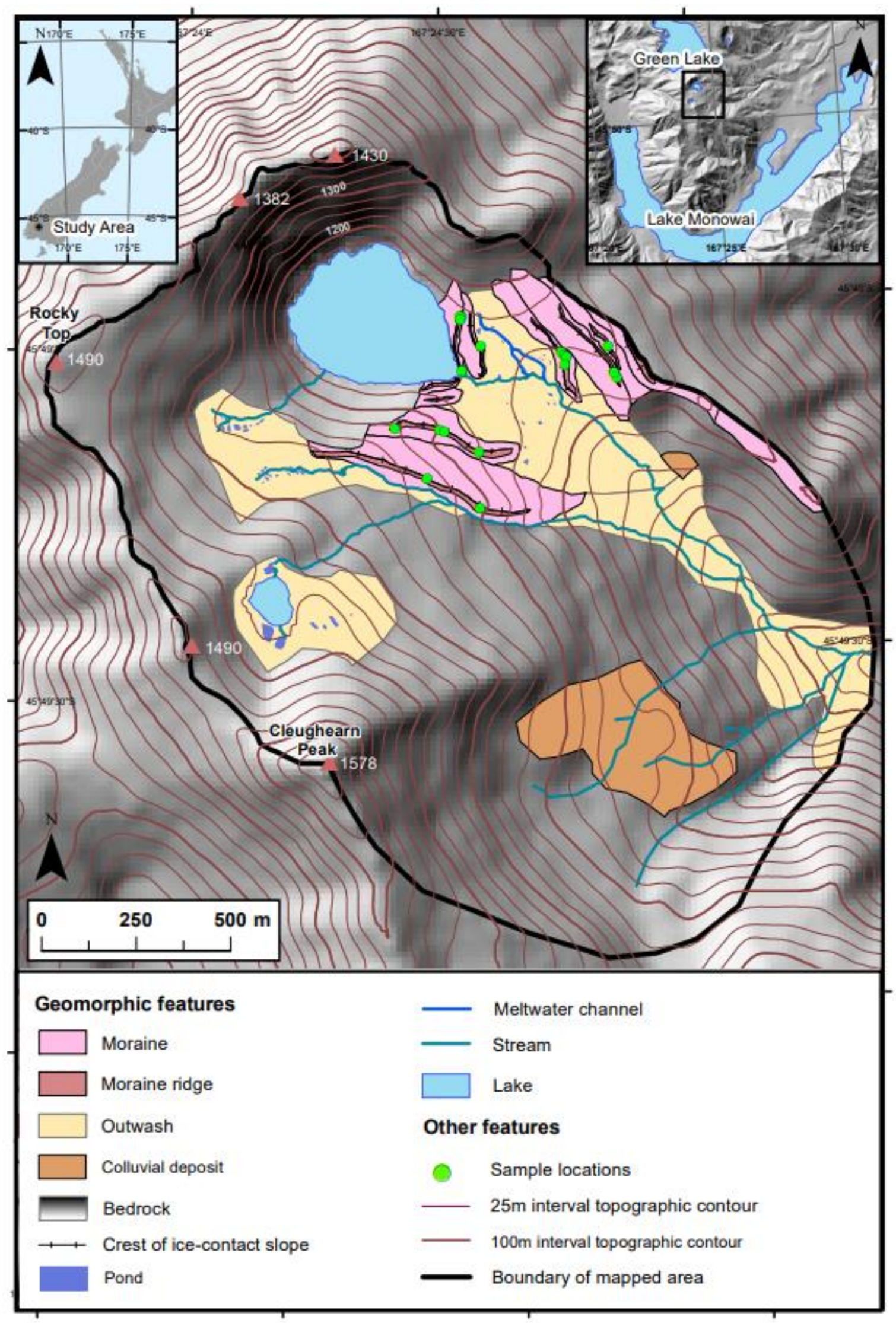

Figure 4.4: Geomorphological map of the Rocky Top cirque (1:12,500). 

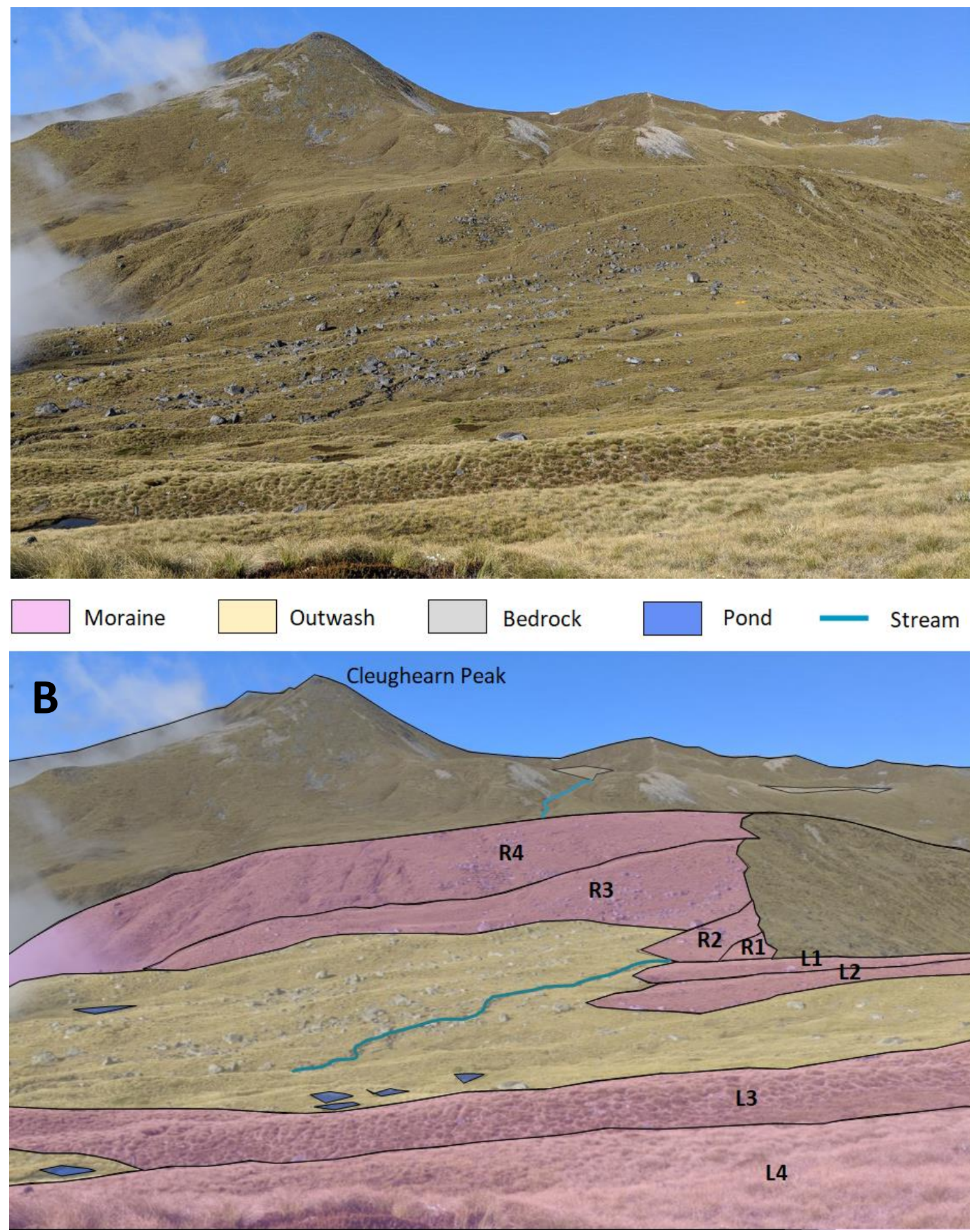

Figure 4.5: Glacial geomorphology mapping comparison. (A) Photograph taken in field, standing on crest of Moraine L4 and looking southwest across the valley. (B) Annotated photo with features mapped in accordance with the geomorphic map (see Figure 4.4). Moraines labelled (see Figure 4.2). 


\subsection{Cosmogenic ${ }^{10} \mathrm{Be}$ surface exposure ages}

The results from cosmogenic ${ }^{10} \mathrm{Be}$ surface exposure dating and the associated process blank data are presented in Tables 4.2 and 4.3, respectively. The exposure ages of samples are presented with their associated moraines, displayed with their internal (analytical-only) uncertainties which are $\sim 2-3 \%$ of the overall age (Table 4.2 , Figures 4.5, and 4.7). Some moraines were grouped as a single landform due to their close proximity, very similar ages (within $1 \sigma$ internal uncertainty) and similar expression of moraines. Henceforth grouped moraines L1, L2, R1 and R2, will be referred to as "IN (Innermost) moraine", and grouped moraines L4 and L5 will be referred to as "L4/L5 moraine".

The process blanks indicate that the amount of background ${ }^{10} \mathrm{Be}$ introduced during sample preparation for each batch of samples was $4.155 \times 10^{4}$ and $4.256 \times 10^{4}{ }^{10} \mathrm{Be}$ atoms, with analytical uncertainties of $10 \%$ and $19 \%$ respectively (Table 4.3 ). For the first batch, ${ }^{10} \mathrm{Be}$ introduced during lab work represented an average of $2.17 \%$ of the total ${ }^{10} \mathrm{Be}$ content in each sample. As the second batch of samples had higher quartz masses, the percentage of total ${ }^{10} \mathrm{Be}$ introduced during lab work is slightly lower, at an average of $2.00 \%$ per sample. The specific process blank number used for blank correction is reported for each sample in Table 4.1.

For each interpreted moraine landform, the version 3 exposure age calculator (Balco, 2017) produced output of summary statistics and normal kernel density plots or "camel diagrams" that show aggregated results (Figures 4.6 and 4.8). Summary statistics included the arithmetic mean and standard deviation, pruned arithmetic mean and chi-squared and p-value (Table 4.4). The innermost moraine, IN moraine, has five exposure ages that range from $16836 \pm 368$ yrs to $18149 \pm$ 404 yrs (Table 4.2). The ages are clustered around an arithmetic mean exposure age of $17370 \pm 528$ yrs. Moraine L3 has four exposure ages, ranging from $14788 \pm$ 331 yrs to $17921 \pm 399$ yrs and an arithmetic mean of $16620 \pm 1319$ yrs. The youngest and oldest ages of Moraine L3 were not within the $1 \sigma$ internal uncertainty value, so the exposure ages of the moraine underwent outlier detection. Four exposure ages from the R3 moraine range from $16953 \pm 373$ yrs to $18919 \pm 415$ yrs, with an arithmetic mean of $18273 \pm 897$. The L4/L5 moraine had 
three exposure ages ranging from $14875 \pm 323$ yrs to $19998 \pm 444$, with an arithmetic mean of $18053 \pm 2775$. The sample dataset was treated with outlier detection. The outermost true right moraine, R4, had two exposure ages of 28642 \pm 633 yrs and $40574 \pm 884$ and an arithmetic mean of $34608 \pm 8437$ yrs.

For each sample, comparison of exposure ages shows that regardless of the scaling scheme used, ages agree with their $1 \sigma$ uncertainties (Table 4.2). Therefore, the choice of scaling scheme does not influence the precision of the calculated surface exposure ages. The Lm scaling model was chosen and hereafter exposure ages are stated using the 'Lm' scheme and 'Macaulay' production rate calibration (Putnam et al., 2010b). The Lm scaling model was selected for reasons such as: (i) consistency with other ${ }^{10} \mathrm{Be}$ exposure dating studies in the Southern Alps, allowing for ease of comparison (e.g. Putnam et al. 2010b; Putnam et al., 2013a; Putnam et al., 2013b), and (ii) suitability to Rocky Top cirque, a mid-latitude, high-altitude site, that requires a scaling scheme that can account for both spatial and temporal variation in ${ }^{10} \mathrm{Be}$ cosmogenic nuclide production (Dunai, 2010; Balco, 2008).

The version 3 exposure age calculator (Balco, 2017) was used to perform a chisquared outlier detection routine to assess the spread in ${ }^{10} \mathrm{Be}$ exposure ages of samples from a single moraine landform (Table 4.4). If a dataset has a p-value greater than $0.05(\mathrm{p}>0.05)$, the hypothesis cannot be excluded that the data belong to a single population at 95\% confidence. In this case no outliers are removed and the error-weighted mean and standard error are reported as the best estimate of moraine age. If a dataset has a p-value between 0.01 and $0.05(0.01<p$ $<0.05$ ) the hypothesis that the ages in the dataset belong to a single landform can be excluded. Outliers were identified by computing the p-value of the chi-squared statistic. The sample measurement that is farthest from the mean in relation to its measurement uncertainty is classed as an outlier and "pruned" (removed), then the $\mathrm{p}$-value of the pruned dataset is recomputed. The outlier identification process is repeated as necessary until (i) an acceptable p-value is obtained, (ii) there are less than three sample data remaining, or (iii) half the data is discarded. If the final $\mathrm{p}$-value is less than $0.05(\mathrm{p}<0.05)$ the arithmetic mean and standard deviation are reported as the best estimate of moraine age (Table 4.4). Moraines R3, L3, and L4/L5 each had one outlier pruned, while Moraines R4 and IN had none pruned. 
The error-weighted mean ages (pruned and otherwise) are similar to the arithmetic mean ages at Rocky Top cirque, but have a much narrower range of uncertainty (Table 4.4). Hereafter to describe the exposure age of each moraine the error-weighted mean ages and their uncertainty will be used (with the exception of Moraine R4 for which this was not applicable, the arithmetic mean will be used). 
Table 4.1: Inputs to the exposure age calculator for Rocky Top moraines. Other inputs to the exposure age calculator listed in Table 3.2.

\begin{tabular}{|c|c|c|c|c|c|c|c|c|c|c|c|c|}
\hline $\begin{array}{l}\text { Sample } \\
\text { ID }\end{array}$ & $\begin{array}{l}\text { Latitude } \\
\text { (DD) }\end{array}$ & Longitude (DD) & $\begin{array}{c}\text { Elevation } \\
\text { (m a.s.l.) }\end{array}$ & $\begin{array}{c}\text { Sample } \\
\text { thickness } \\
\text { (cm) }\end{array}$ & $\begin{array}{c}\text { Topographic } \\
\text { shielding } \\
\text { correction } \\
\end{array}$ & $\begin{array}{c}\text { Quartz } \\
\text { mass (g) }\end{array}$ & $\begin{array}{c}{ }^{9} \mathrm{Be} \\
\text { mass } \\
(\mathrm{mg})\end{array}$ & $\begin{array}{c}{ }^{10} \mathrm{Be} /{ }^{9} \mathrm{Be} \\
\left(10^{-13}\right)\end{array}$ & $\begin{array}{c}10 \mathrm{Be} /{ }^{9} \mathrm{Be} \\
(1 \sigma)\left(10^{-}\right. \\
15)\end{array}$ & $\begin{array}{l}\text { 10Be conc. } \\
\left(10^{3} \text { at }^{-1}\right)\end{array}$ & $\begin{array}{c}10 \text { Be conc. } \\
(1 \sigma)\left(10^{3}\right. \\
\left.\text { at } g^{-1}\right)\end{array}$ & Blank \\
\hline \multicolumn{13}{|c|}{ IN Moraine } \\
\hline RT_1414 & -45.81662 & 167.40862 & 1178.3 & 2.5 & 0.966 & 15.60 & 0.2666 & 1.600 & 2.975 & 182.122 & 4.043 & 1 \\
\hline RT_1415 & -45.81661 & 167.40858 & 1178.5 & 1.5 & 0.965 & 15.70 & 0.269 & 1.621 & 3.017 & 185.630 & 4.121 & 1 \\
\hline RT_1416 & -45.81668 & 167.40858 & 1177.81 & 1.25 & 0.966 & 43.28 & 0.2641 & 4.449 & 8.257 & 181.971 & 3.962 & 2 \\
\hline RT_1534 & -45.81736 & 167.40921 & 1170.2 & 1.5 & 0.99 & 15.33 & 0.2678 & 1.650 & 3.068 & 199.689 & 4.428 & 1 \\
\hline RT_1640 & -45.81790 & 167.40851 & 1166.96 & 1.5 & 0.97 & 22.63 & 0.2659 & 2.418 & 4.501 & 189.591 & 4.158 & 2 \\
\hline \multicolumn{13}{|c|}{ L3 Moraine } \\
\hline RT_1527 & -45.8176 & 167.41191 & 1150.76 & 1.75 & 0.992 & 10.15 & 0.2651 & 1.069 & 1.990 & 184.080 & 4.105 & 2 \\
\hline RT_1528 & -45.81770 & 167.41202 & 1149.10 & 2 & 0.992 & 43.65 & 0.265 & 4.437 & 8.224 & 180.526 & 3.927 & 2 \\
\hline RT_1529 & -45.81776 & 167.41208 & 1147.9 & 1.75 & 0.992 & 16.00 & 0.2677 & 1.655 & 3.076 & 193.644 & 4.291 & 1 \\
\hline RT_1530 & -45.81793 & 167.41202 & 1146.5 & 1 & 0.992 & 14.69 & 0.2674 & 1.443 & 2.683 & 159.894 & 3.560 & 1 \\
\hline \multicolumn{13}{|c|}{ R3 Moraine } \\
\hline RT_1408 & -45.81917 & 167.4061 & 1233.3 & 2.5 & 0.989 & 34.01 & 0.2649 & 3.718 & 6.937 & 193.884 & 4.243 & 2 \\
\hline RT_1410 & -45.81926 & 167.40761 & 1211.09 & 2 & 0.991 & 29.16 & 0.2644 & 3.493 & 6.507 & 211.939 & 4.635 & 2 \\
\hline RT_1411 & -45.81930 & 167.40785 & 1208.14 & 1 & 0.981 & 27.81 & 0.2648 & 3.270 & 6.0876 & 208.220 & 4.554 & 2 \\
\hline RT_1412 & -45.81987 & 167.4089 & 1184.77 & 4 & 0.991 & 31.67 & 0.2647 & 3.684 & 6.844 & 206.113 & 4.497 & 2 \\
\hline \multicolumn{13}{|c|}{ R4 Moraine } \\
\hline RT_1404 & -45.82042 & 167.40707 & 1246.2 & 3 & 0.996 & 15.54 & 0.2659 & 2.585 & 4.805 & 336.756 & 7.392 & 1 \\
\hline RT_1407 & -45.82120 & 167.40879 & 1215.41 & 1.6 & 0.985 & 33.32 & 0.265 & 8.712 & 1.602 & 465.596 & 10.04 & 2 \\
\hline \multicolumn{13}{|c|}{ L4/L5 Moraine } \\
\hline RT_1518 & -45.81830 & 167.41375 & 1149.8 & 1.5 & 0.995 & 16.86 & 0.2677 & 1.853 & 3.441 & 210.160 & 4.641 & 1 \\
\hline RT_1519 & -45.81821 & 167.41366 & 1152.9 & 2.5 & 0.996 & 13.81 & 0.2683 & 1.519 & 2.715 & 160.343 & 3.465 & 1 \\
\hline RT_1526 & -45.81757 & 167.41351 & 1157.5 & 1.75 & 0.99 & 15.20 & 0.2662 & 1.703 & 3.152 & 217.967 & 4.814 & 1 \\
\hline
\end{tabular}


Table 4.2: Cosmogenic ${ }^{10}$ Be exposure ages for the Rocky Top cirque moraines, as calculated using the exposure age calculator by Balco (2017) (inputs listed in Tables 3.2 and 4.1). Reported exposure ages (years before AD2018) were calculated using three scaling schemes: St (Stone, 2000), Lm (Balco, 2008), and LSDn (Lifton et al.,

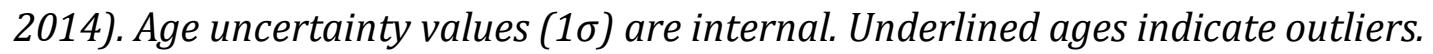

\begin{tabular}{|c|c|c|c|}
\hline Sample ID & St Age (yrs) & Lm Age (yrs) & LSDn Age (yrs) \\
\hline \multicolumn{4}{|l|}{ IN Moraine } \\
\hline RT_1414 & $17524 \pm 391$ & $17017 \pm 379$ & $16472 \pm 367$ \\
\hline RT_1415 & $17731 \pm 395$ & $17210 \pm 384$ & $16661 \pm 371$ \\
\hline RT_1416 & $17335 \pm 379$ & $16836 \pm 368$ & $16303 \pm 357$ \\
\hline RT_1534 & $18724 \pm 417$ & $18149 \pm 404$ & $17570 \pm 391$ \\
\hline RT_1640 & $18184 \pm 401$ & $17638 \pm 389$ & $17087 \pm 376$ \\
\hline \multicolumn{2}{|c|}{ Arith. Mean $(n=5)$} & $17370 \pm 528$ & \\
\hline \multicolumn{2}{|c|}{ Pruned Arith. Mean $(n=5)$} & $17342 \pm 172$ & \\
\hline \multicolumn{4}{|c|}{ L3 Moraine } \\
\hline RT_1527 & $17525 \pm 393$ & $17019 \pm 381$ & $16493 \pm 369$ \\
\hline RT_1528 & $17244 \pm 377$ & $16750 \pm 366$ & $16243 \pm 355$ \\
\hline RT_1529 & $18482 \pm 411$ & $17921 \pm 399$ & $17370 \pm 387$ \\
\hline RT_1530 & $15170 \pm 339$ & $\underline{14788 \pm 331}$ & $14358 \pm 321$ \\
\hline \multicolumn{2}{|c|}{ Arith. Mean $(n=4)$} & $16620 \pm 1319$ & \\
\hline \multicolumn{2}{|c|}{ Pruned Arith. Mean ( $n=3)$} & $17196 \pm 220$ & \\
\hline \multicolumn{4}{|c|}{ R3 Moraine } \\
\hline RT_1408 & $17459 \pm 384$ & $\underline{16953 \pm 373}$ & $16374 \pm 360$ \\
\hline RT_1410 & $19345 \pm 425$ & $18731 \pm 412$ & $18102 \pm 398$ \\
\hline RT_1411 & $19084 \pm 419$ & $18487 \pm 406$ & $17869 \pm 393$ \\
\hline RT_1412 & $19543 \pm 429$ & $18919 \pm 415$ & $18304 \pm 401$ \\
\hline \multicolumn{2}{|c|}{ Arith. Mean $(n=4)$} & $18273 \pm 897$ & \\
\hline \multicolumn{2}{|c|}{ Pruned Arith. Mean $(n=3)$} & $18709 \pm 237$ & \\
\hline \multicolumn{4}{|c|}{ R4 Moraine } \\
\hline RT_1404 & $30012 \pm 664$ & $28642 \pm 633$ & $27513 \pm 608$ \\
\hline RT_1407 & $42619 \pm 929$ & $40574 \pm 884$ & $39040 \pm 850$ \\
\hline \multicolumn{2}{|c|}{ Arith. Mean (n= 2) } & $34608 \pm 8437$ & \\
\hline \multicolumn{2}{|c|}{ Pruned Arith. Mean $(n=2)$} & $34608 \pm 8437$ & \\
\hline \multicolumn{4}{|c|}{ L4/L5 Moraine } \\
\hline RT_1518 & $19934 \pm 442$ & $19287 \pm 428$ & $18683 \pm 415$ \\
\hline RT_1519 & $15265 \pm 331$ & $\underline{14875 \pm 323}$ & $14440 \pm 313$ \\
\hline RT_1526 & $20698 \pm 460$ & $19998 \pm 444$ & $19362 \pm 430$ \\
\hline \multicolumn{2}{|c|}{ Arith. Mean $(\mathrm{n}=3)$} & $18053 \pm 2775$ & \\
\hline \multicolumn{2}{|c|}{ Pruned Arith. Mean $(n=2)$} & $19629 \pm 308$ & \\
\hline
\end{tabular}


Table 4.3: Process blank ${ }^{10} \mathrm{Be} /{ }^{9} \mathrm{Be}$ ratios and number of ${ }^{10} \mathrm{Be}$ atoms

\begin{tabular}{|c|c|c|c|c|c|}
\hline Blank ID & $\begin{array}{l}{ }^{9} \mathrm{Be} \text { mass } \\
(\mu \mathrm{g})\end{array}$ & $\begin{array}{l}{ }^{10} \mathrm{Be} /{ }^{9} \mathrm{Be} \\
\left(10^{-15}\right)\end{array}$ & $\begin{array}{l}{ }^{10} \mathrm{Be} /{ }^{9} \mathrm{Be} \\
(1 \sigma)\left(10^{-16}\right)\end{array}$ & $\begin{array}{l}{ }^{10} \mathrm{Be} \\
\left(10^{5} \text { at) }\right.\end{array}$ & $\begin{array}{l}{ }^{10} \mathrm{Be}(1 \sigma) \\
\left(10^{5} \text { at }\right)\end{array}$ \\
\hline Blank 1 & 268.6 & 2.352 & 4.512 & 4.256 & 0.818 \\
\hline Blank 2 & 263.856 & 2.357 & 2.482 & 4.155 & 0.440 \\
\hline
\end{tabular}




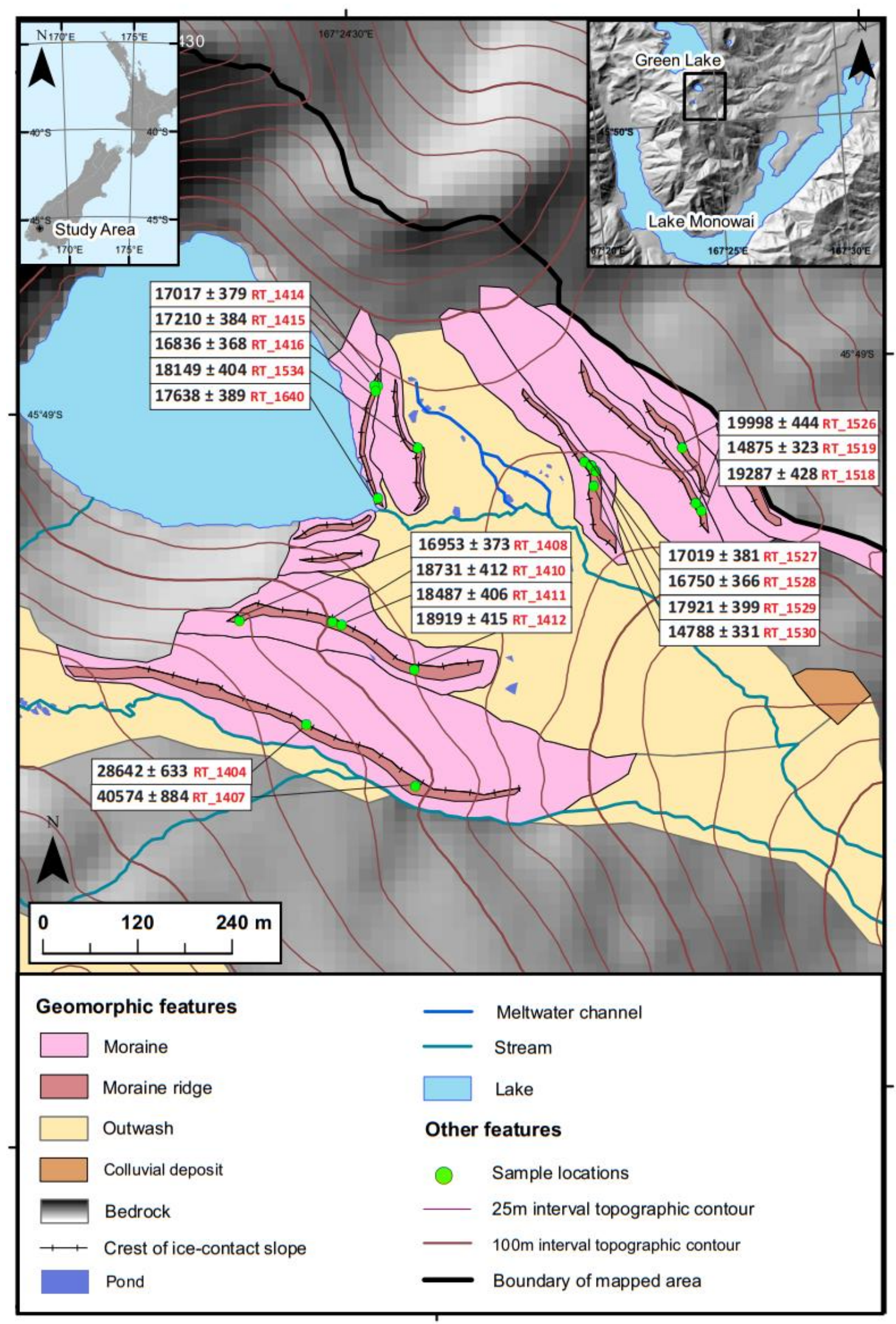

Figure 4.6: Sample exposure ages overlaid on the geomorphic map. The geomorphic map is zoomed in to focus on the moraines. 

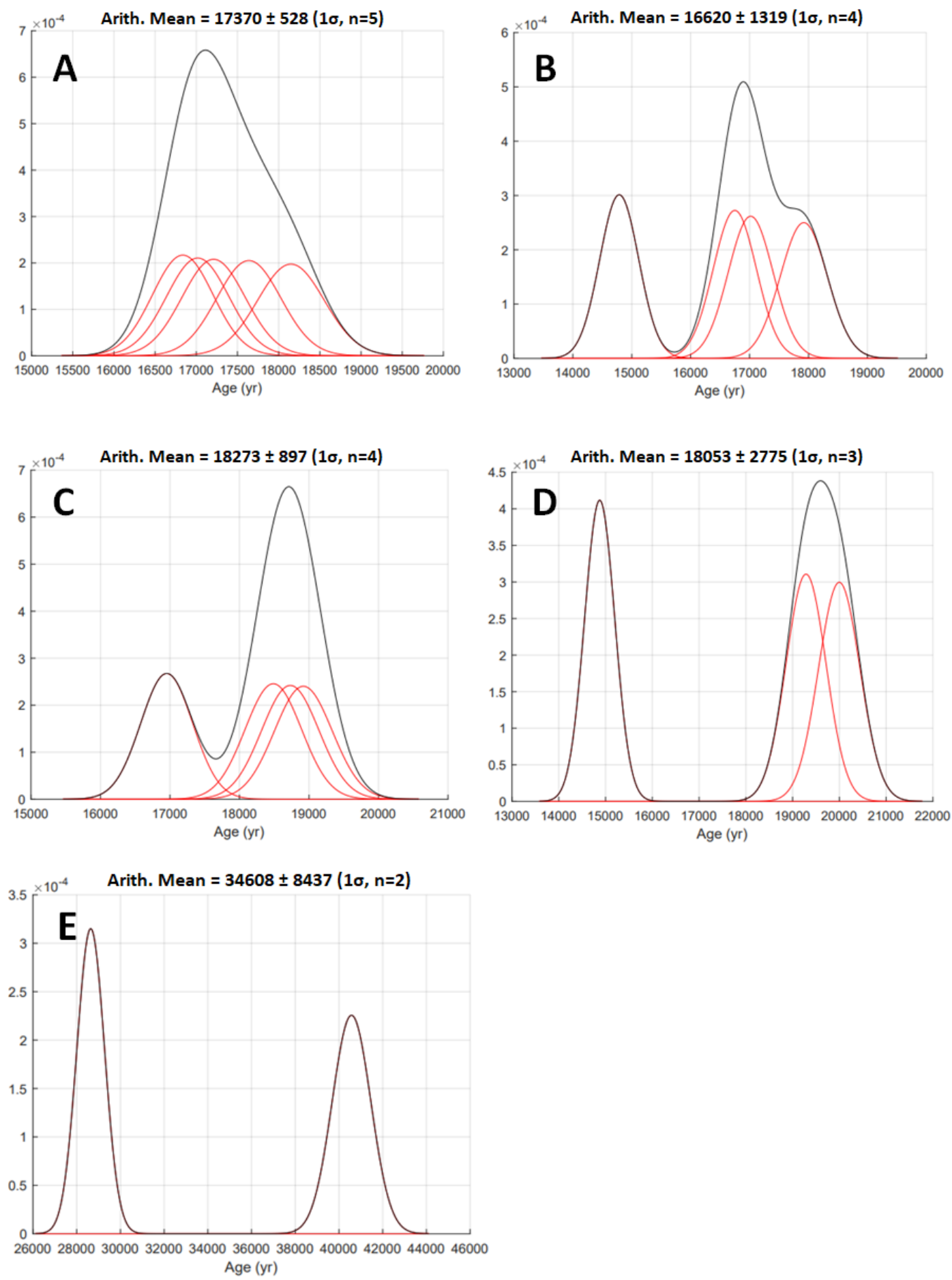

Figure 4.7: Camel diagrams of arithmetic mean ages $( \pm 1 \sigma)$ for individual moraines: (A) IN moraine, (B) L3 moraine, (C) R3 moraine, (D) L4/L5 moraine, and (E) R4 moraine. Outliers (underlined in Table 4.2) are included, expressed on some plots as bimodal peaks. The red lines represent the individual age probabilities for each boulder sample and the black lines represent the cumulative age probabilities for each moraine. 


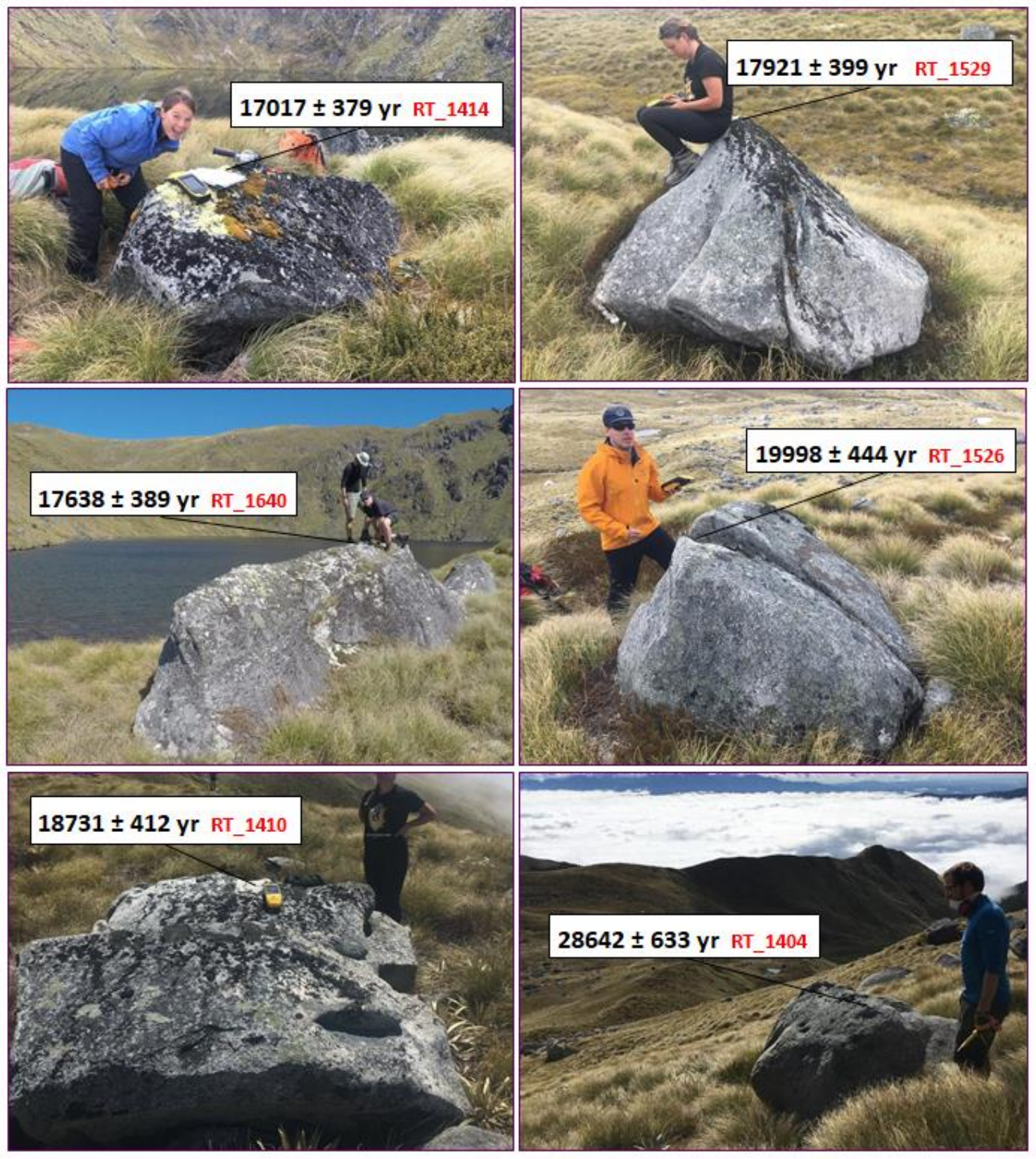

Figure 4.8: Photographs of some sampled boulders and their associated exposure ages. Boulder sample IDs are in red. Exposure ages were produced using the Lm scaling scheme (Putnam et al., 2010b), as reported in Table 4.2. 
Table 4.4: Summary statistics for each moraine landform at Rocky Top cirque. Statistics were produced by a chi-squared outlier detection routine in the online exposure age calculator (Balco, 2017). Outliers (as underlined in Table 4.2) were removed from the arithmetic mean to achieve the pruned arithmetic mean.

\begin{tabular}{|c|c|c|c|c|c|c|c|}
\hline Landform & $\begin{array}{c}\text { No. of } \\
\text { samples in } \\
\text { unpruned } \\
\text { datset }\end{array}$ & $\begin{array}{l}\text { Arithmetic } \\
\text { mean }( \pm 1 \sigma)\end{array}$ & $\begin{array}{c}\text { No. of } \\
\text { samples } \\
\text { pruned }\end{array}$ & $\begin{array}{c}\text { No. of } \\
\text { samples in } \\
\text { pruned } \\
\text { dataset } \\
\end{array}$ & $\begin{array}{c}\text { p-value for } \\
\text { pruned } \\
\text { dataset }\end{array}$ & $\begin{array}{c}\text { Method for reported } \\
\text { pruned age }\end{array}$ & $\begin{array}{c}\text { Pruned ages } \\
\qquad \pm \\
\text { uncertainty) }\end{array}$ \\
\hline L3 Moraine & 4 & $16620 \pm 1319$ & 1 & 3 & $\mathrm{p}>0.05$ & Error-weighted mean & $17196 \pm 220$ \\
\hline R3 Moraine & 4 & $18273 \pm 897$ & 1 & 3 & $\mathrm{p}>0.05$ & Error-weighted mean & $18709 \pm 237$ \\
\hline L4/5 Moraine & 3 & $18053 \pm 2775$ & 1 & 2 & $p>0.05$ & Error-weighted mean & $19629 \pm 308$ \\
\hline
\end{tabular}


Err. Weighted Mean $=17342 \pm 172(1 \sigma, n=5)$

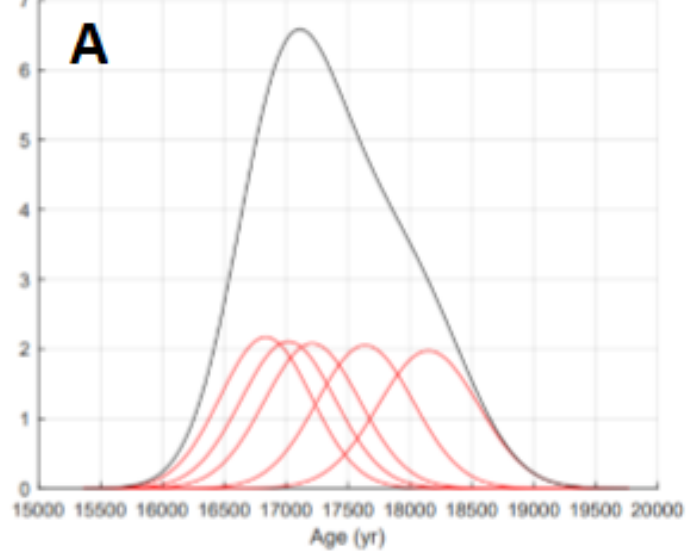

Err. Weighted Mean $=18709 \pm 237(1 \sigma, n=3)$

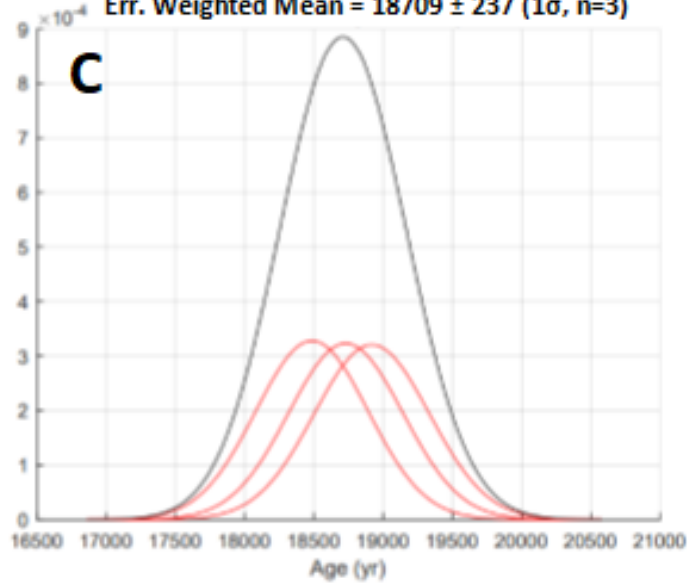

Arith. Mean $=34608 \pm 8437(1 \sigma, n=2)$

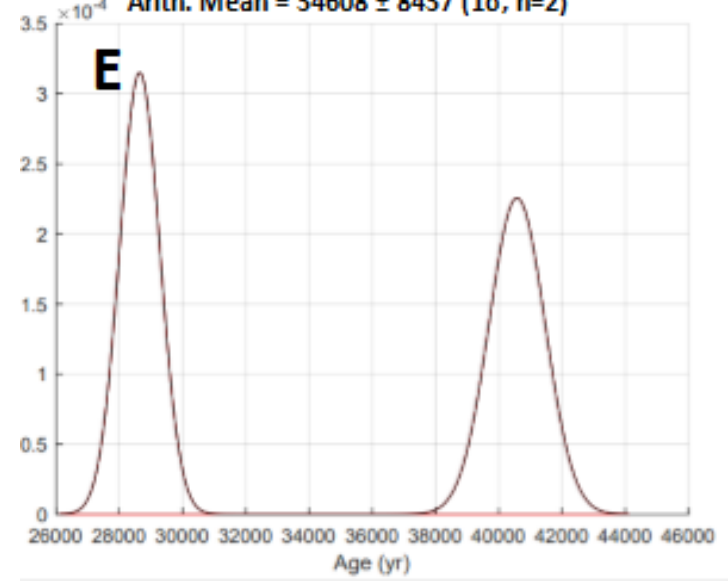

Err. Weighted Mean $=17196 \pm 220(1 \sigma, n=3)$

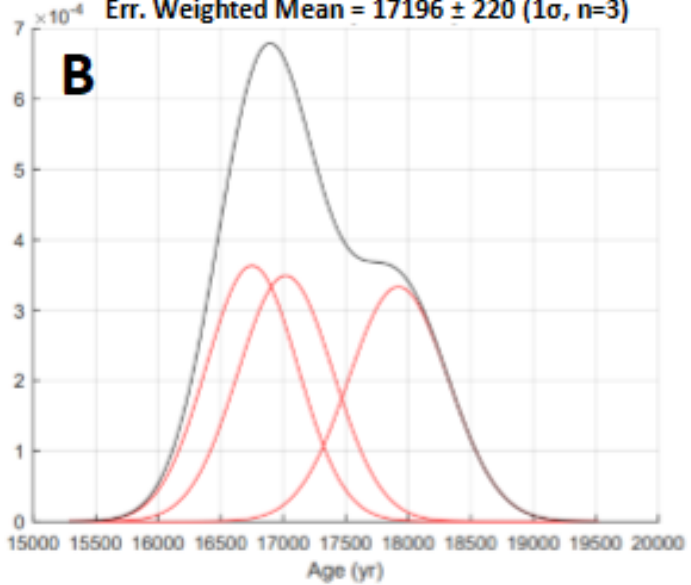

Err. Weighted Mean $=19629 \pm 308(1 \sigma, n=2)$

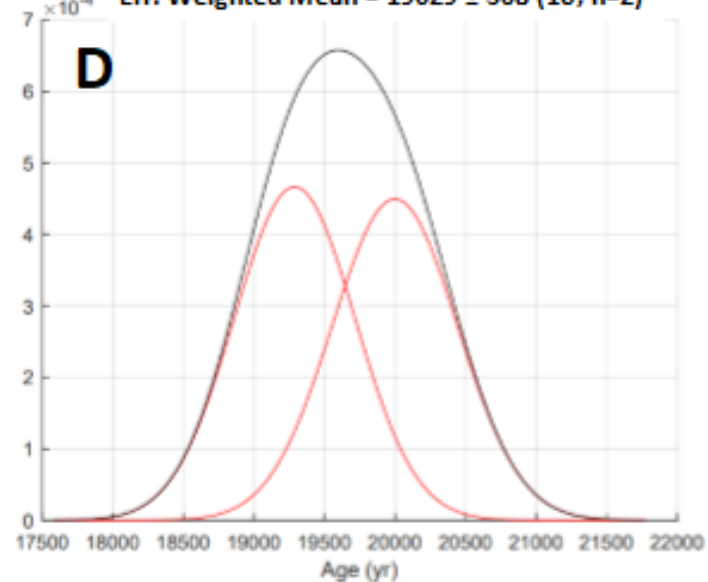

Figure 4.9: Camel diagrams of mean ages ( $\pm 1 \sigma$ ) for individual moraines: $(A)$ IN moraine, (B) L3 moraine, (C) R3 moraine, (D) L4/L5 moraine, and (E) R4 moraine. Outliers (underlined in Table 4.2) are excluded where applicable. A-D are all errorweighted means, while $E$ is an arithmetic mean (Table 4.4). The red lines represent the individual age probabilities for each boulder sample and the black lines represent the cumulative age probabilities for each moraine. 


\subsection{Paleoclimate reconstruction}

\subsubsection{Equilibrium-line altitude reconstruction}

This section details the results of equilibrium-line altitude (ELA) reconstruction using the accumulation-area ratio (AAR) method. The method was used for moraines IN, L3, L3 and L4/L5, but not Moraine R4 due to the lack of geomorphic evidence to constrain the former glacier outline. The ELA for each specified former glacier extent was derived by both manual glacier surface reconstruction and a Monte Carlo algorithm.

Manual glacier surface reconstruction was based on the assumption that the present-day moraine geometry represents the former glacier margins. The moraine geometry constrained the lower limit of former glacier extent and the upper limit was constrained by the 'larger-volume ice model approach' of Kaplan et al. (2010) (Figure 4.10). Glacier hypsometry was overlaid in $50 \mathrm{~m}$ contour increments and the altitude-area distribution of each former glacier extent was calculated (Table 4.5).

A cumulative curve graph was created for each former glacier extent to display the area/altitude distribution, then the AAR value of 0.67 (Chinn et al., 2012) was applied to the graph to determine the ELA (Figure 4.10). 

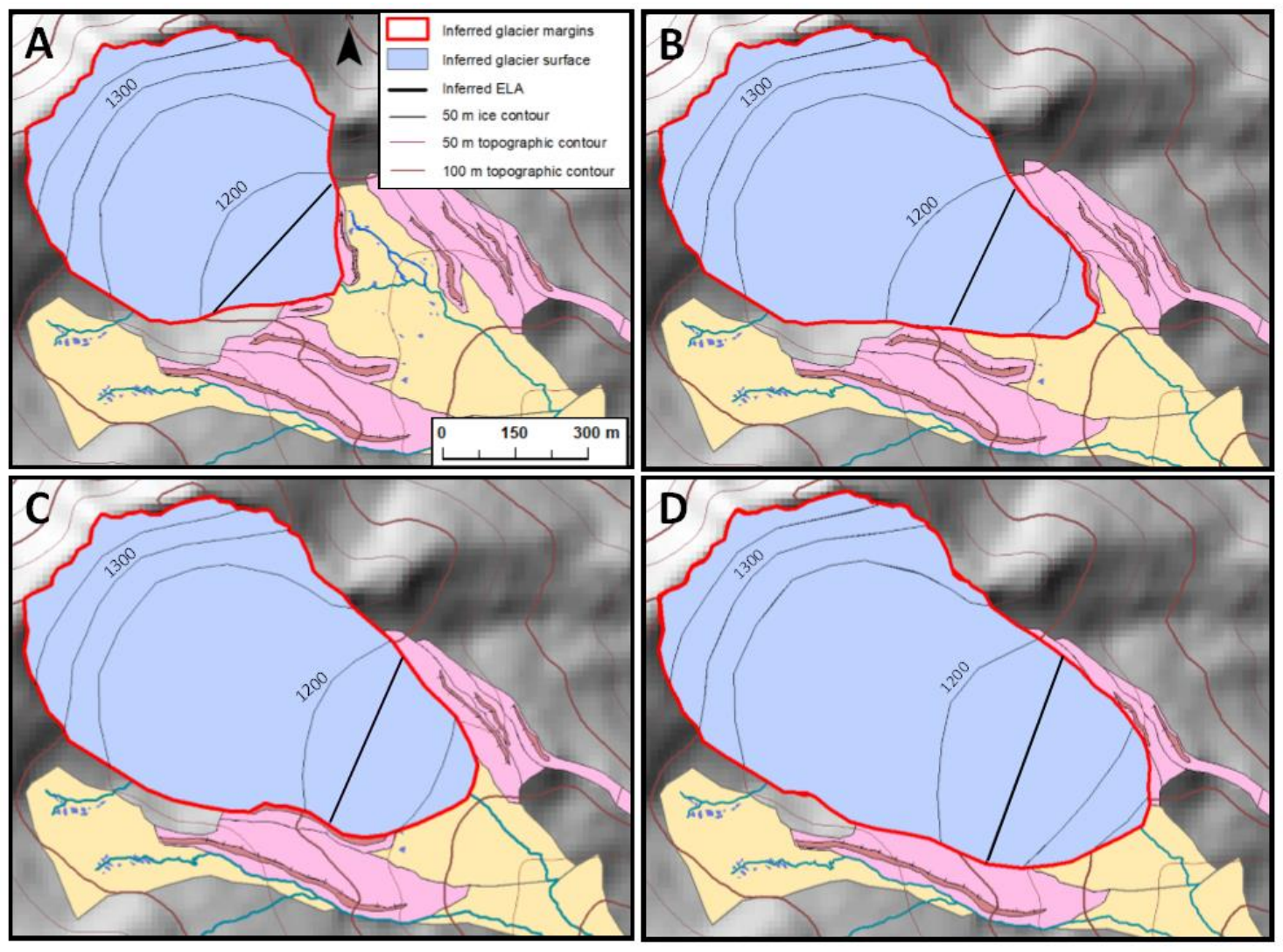

Figure 4.10: Manual glacier surface and equilibrium-line altitude reconstruction ( $A A R=0.67)$ of the former glacier terminating at moraines: (A) IN, (B) L3, (C) R3, and (D) L4/L5. The larger-volume ice model approach of Kaplan et al. (2010) was used. See Figure 4.4 for geomorphic symbols legend. 
Table 4.5: Altitude-area distribution of each moraine landform at Rocky Top cirque, as displayed on the cumulative curve graphs (Figure 4.10).

\begin{tabular}{cccccc}
\hline $\begin{array}{c}\text { Elevation } \\
\text { range (m asl) }\end{array}$ & $\begin{array}{c}\text { Elevation } \\
\text { midpoint (m asl) }\end{array}$ & $\begin{array}{c}\text { IN } \\
\text { moraine }\end{array}$ & $\begin{array}{c}\text { L3 } \\
\text { moraine }\end{array}$ & $\begin{array}{c}\text { R3 } \\
\text { moraine }\end{array}$ & $\begin{array}{c}\text { L4/L5 } \\
\text { moraine }\end{array}$ \\
\hline $1050-1100$ & 1075 & 0 & 0 & 0 & 3250 \\
$1100-1150$ & 1125 & 0 & 14370 & 20240 & 31400 \\
$1150-1200$ & 1175 & 79750 & 109530 & 112390 & 157760 \\
$1200-1250$ & 1225 & 161260 & 217350 & 262870 & 273390 \\
$1250-1300$ & 1275 & 66050 & 66050 & 66050 & 66050 \\
$1300-1350$ & 1325 & 49780 & 49780 & 49780 & 49780 \\
$1350-1400$ & 1375 & 34900 & 34900 & 34900 & 34900 \\
\hline & Total: & 391740 & 491980 & 546230 & 616530 \\
\hline
\end{tabular}



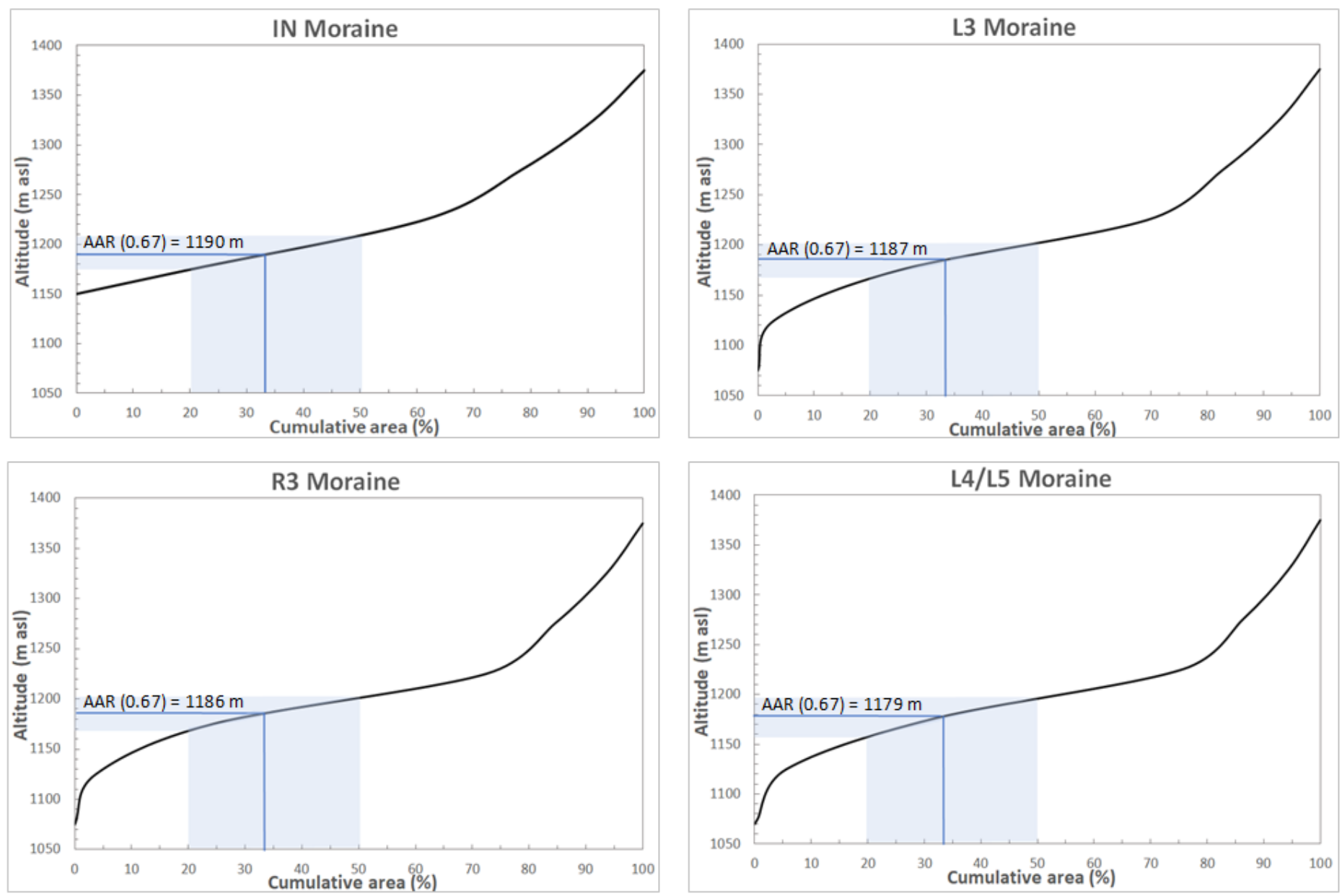

Figure 4.11: Cumulative curve graphs, showing the altitude-area distribution of reconstructed glacier extent at moraines. The ELA is identified as determined by the AAR (0.67). Shaded areas represent the uncertainty, using an AAR range of 0.5-0.8 (after Eaves et al., 2017). 
Table 4.6: Paleo-ELAs derived using AAR (0.67) for each moraine-constrained glacier extent. Paleo-ELAs produced using both the manual glacier surface reconstruction method and different present-day ELA inputs to Monte Carlo algorithm. Moraine ages use Lm scaling scheme (Section 4.2).

\begin{tabular}{|c|c|c|c|c|}
\hline Moraine & Age (yr) & $\begin{array}{l}\text { Paleo-ELA } \\
\text { (manual glacier } \\
\text { reconstruction) }\end{array}$ & $\begin{array}{l}\text { Paleo-ELA } \\
\text { (present-day } \\
\text { ELA } 2907 \mathrm{~m} \text { asl) }\end{array}$ & $\begin{array}{l}\text { Paleo-ELA } \\
\text { (present-day } \\
\text { ELA } 1800 \pm 100 \\
\text { m asl) }\end{array}$ \\
\hline IN & $\begin{array}{l}17342 \pm \\
172\end{array}$ & $1190 \pm \sim 15$ & $1207 \pm 599$ & $1191 \pm 101$ \\
\hline L3 & $\begin{array}{l}17196 \pm \\
220\end{array}$ & $1187 \pm \sim 16$ & $1184 \pm 609$ & $1183 \pm 101$ \\
\hline R3 & $\begin{array}{l}18709 \pm \\
237\end{array}$ & $1186 \pm \sim 16$ & $1183 \pm 584$ & $1184 \pm 101$ \\
\hline L4/L5 & $\begin{array}{l}19629 \pm \\
308\end{array}$ & $1179 \pm \sim 18$ & $1176 \pm 602$ & $1176 \pm 98$ \\
\hline
\end{tabular}

Paleo-ELAs derived by manual glacier surface reconstruction (Figures 4.10 and 4.11) are presented in Table 4.6. Ages for each glacial extent delimited by moraines are included, based on cosmogenic ${ }^{10} \mathrm{Be}$ surface exposure dating results (Section 4.2). Results show that the ELA consistently increases in elevation with each younger moraine, as would logically be expected for a pattern of glacier retreat. During documented glacial retreat from $19629 \pm 308$ to $17342 \pm 172$ yrs ago (Moraines L4/L5 and IN respectively), the ELA increased in elevation from $1185 \mathrm{~m}$ to $1190 \mathrm{~m}$.

The Monte Carlo algorithm produced output that included the average ELA anomaly from present-day ELA. As discussed in Section 3.3, two values for presentday ELA were input to the algorithm. Based on the mean air temperature (DJF, 1970-2010) proxy, the average present-day ELA was $2907.7 \pm 602.4 \mathrm{~m}$ asl. The "best estimate" present-day ELA of $1800 \pm 100$ m (see Section 3.3) was also input. The average ELA anomalies (paleo-ELA) produced by the algorithm were very similar to those produced by the manual glacier surface reconstruction method (Table 4.6). The strong similarity of results is due to the inputs to the algorithm (area-altitude distribution, $\mathrm{AAR}=0.67$ ) being the same as those used to calculate the paleo-ELA in the manual method. The slight variation between results is due to the normal distribution function of the algorithm when selecting the AAR value $(\mathrm{AAR}=0.67 \pm 0.05)$. 


\subsubsection{Paleotemperature reconstruction}

The difference between the paleo-ELA and present-day ELA represents the climatic shift associated with the change in glacier geometry (Eaves et al., 2017). As such, the paleo-ELA was used to derive a quantitative estimate of paleotemperature (relative to present) for each reconstructed glacier extent using temperature lapse rates. The Monte Carlo algorithm used a temperature lapse rate of $0.0053 \pm 0.001\left(5.3^{\circ} \mathrm{C} / \mathrm{km}\right)$, based on the suggestion by Norton (1985).

The present-day ELA value used had a significant impact on the temperature anomaly produced. Both present-day ELA values of 2907.7 $\pm 602.4 \mathrm{~m}$ asl (mean air temperature proxy) and $1800 \pm 100 \mathrm{~m}$ asl ("best estimate"; see Section 3.3) were input to the algorithm. The derived paleotemperature and associated uncertainty for each former glacier extent are presented as cumulative probability graphs. Results for the mean air temperature proxy and "best estimate" are presented in Figures 4.12 and 4.13 respectively.

Table 4.7 presents the calculated paleotemperatures for each present-day ELA input to the algorithm. For a present-day ELA of $2907.7 \pm 602.4 \mathrm{~m}$ asl (mean air temperature proxy), temperature anomalies of $-8.4 \pm 1.1^{\circ} \mathrm{C}$ to $-8.6 \pm 1.1^{\circ} \mathrm{C}$ relative to present were derived. The "best estimate" present-day ELA of $1800 \pm 100 \mathrm{~m}$ asl produced temperature anomalies of $-3.2 \pm 0.8^{\circ} \mathrm{C}$ to $-3.3 \pm 0.8^{\circ} \mathrm{C}$ relative to present. The present-day ELA value used significantly impacted the paleotemperature results, with a $\sim 5^{\circ} \mathrm{C}$ difference in results between the two inputs to the algorithm. The $\sim 5 \mathrm{~m}$ paleo-ELA change from $19629 \pm 308$ to $17342 \pm 172$ yrs ago translates into a warming of around $\sim 0.2 \pm 1.1^{\circ} \mathrm{C}$ or $\sim 0.1 \pm 0.8^{\circ} \mathrm{C}$ (for present-day ELAs of $\sim 2907 \mathrm{~m}$ and $\sim 1800 \mathrm{~m}$ respectively). Note that precipitation variation is neglected. The paleotemperature results will be discussed in Section 5.3. 

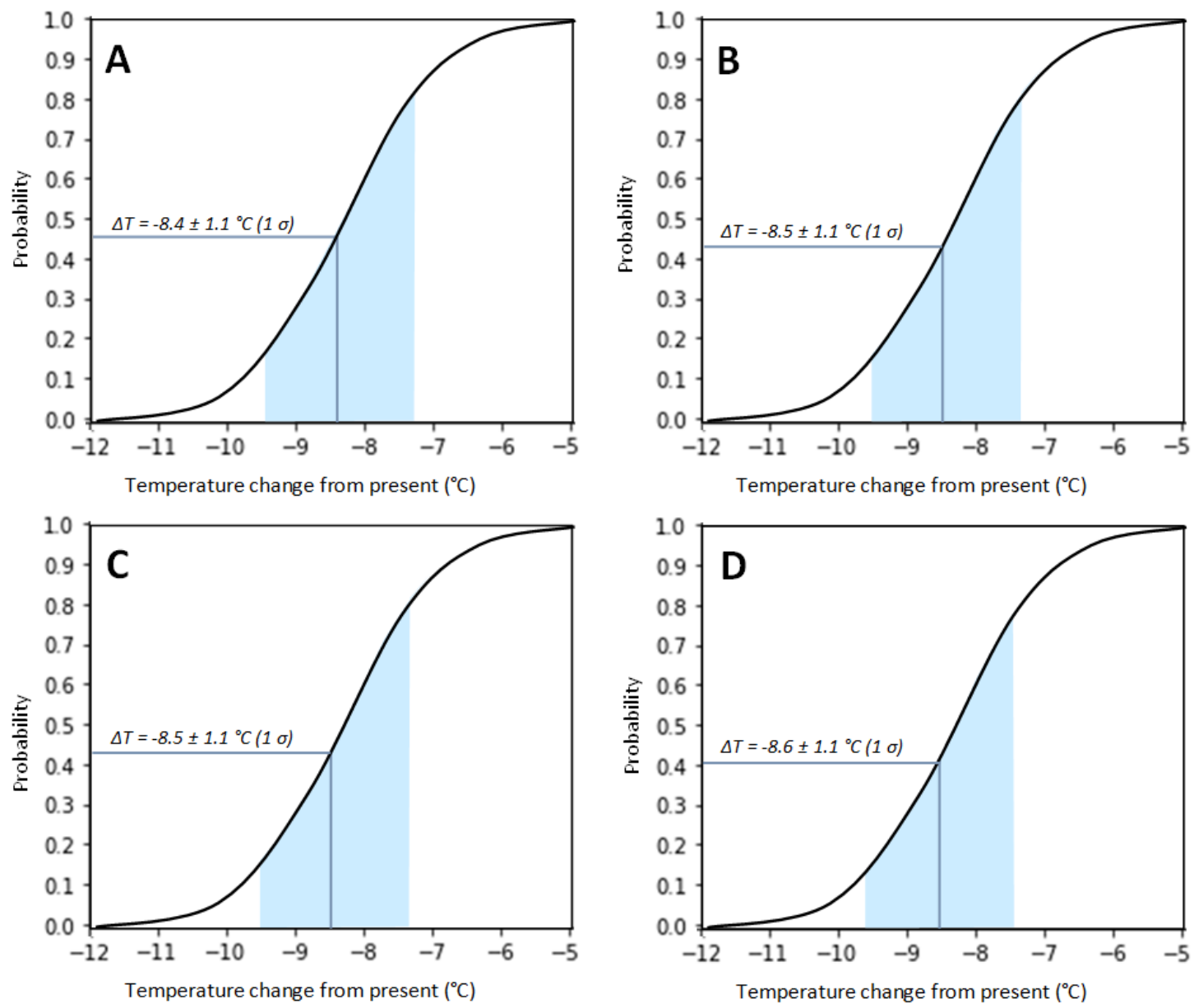

Figure 4.12: Cumulative probability graphs displaying the average temperature anomaly relative to present-day, produced using a present-day ELA of $2907.7 \pm 602.4$ $m$ (mean air temperature proxy). Calculated for the former glacier terminating at moraines: (A) IN, (B) L3, (C) R3, and (D) L4/L5. 

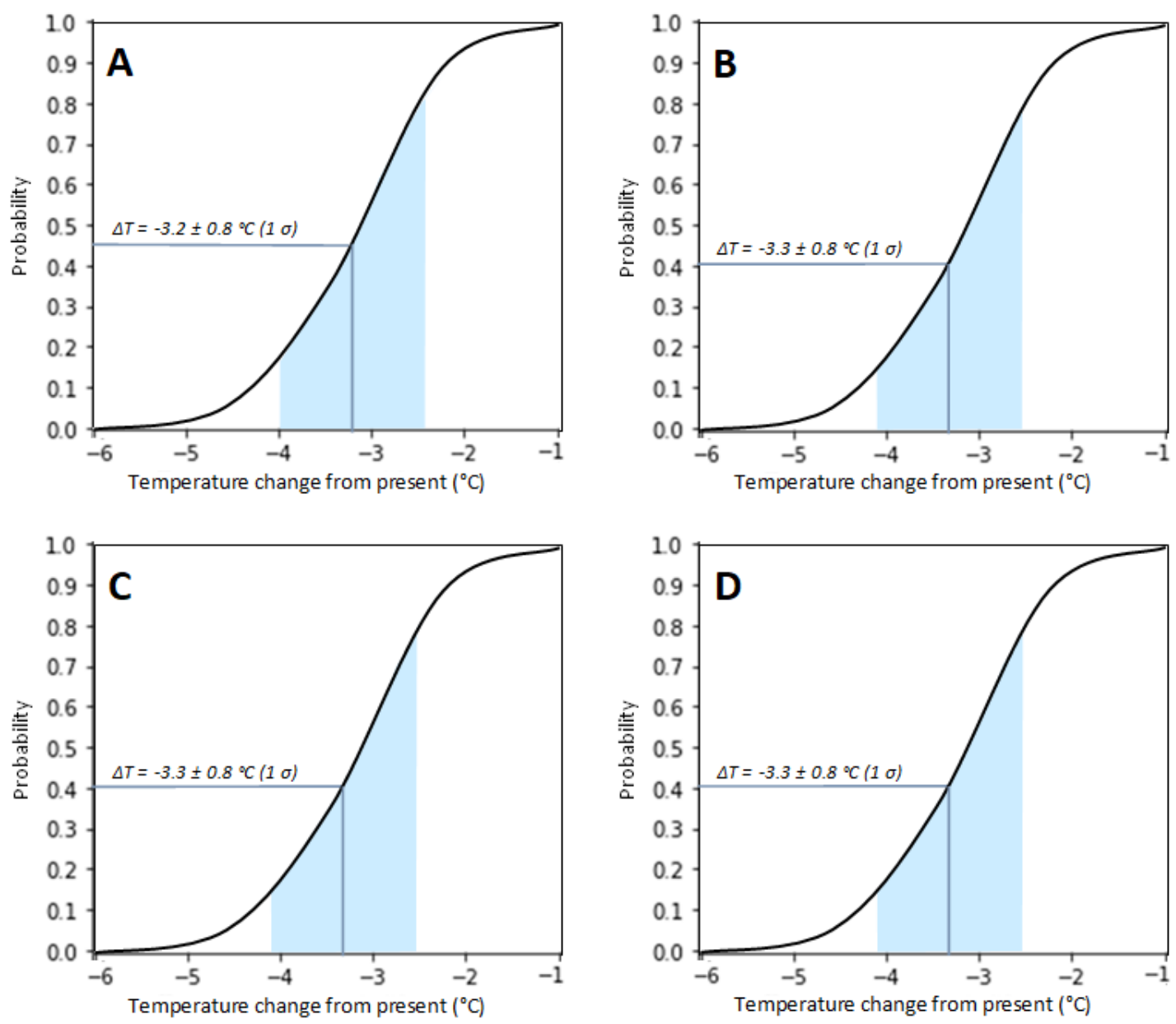

Figure 4.13: Cumulative probability graphs displaying the average temperature anomaly (from present-day), produced using a present-day ELA of $1800 \pm 100 \mathrm{~m}$ ("best estimate"; see Section 3.3). Calculated for the former glacier terminating at moraines: (A) IN, (B) L3, (C) R3, and (D) L4/L5. 
Table 4.7: Temperature anomalies (relative to present-day) produced by the algorithm for the former glacier terminating at each moraine extent. Paleotemperature significantly differs based on the present-day ELA inputs of 2907.7 $\pm 602.4 \mathrm{~m}$ asl (mean summer air temperature proxy) and $1800 \pm 100$ m ("best estimate"; see Section 3.3).

\begin{tabular}{|c|c|c|c|c|c|}
\hline Moraine & Age (yr) & $\begin{array}{l}\text { Paleo-ELA } \\
\text { (present-day ELA } \\
2907 \text { m asl) }\end{array}$ & $\begin{array}{l}\text { Paleo-ELA } \\
\text { (present-day ELA } \\
1800 \mathrm{~m} \text { asl) }\end{array}$ & $\begin{array}{l}\text { Temp. anomaly }{ }^{\circ} \mathrm{C} \\
\text { (present-day ELA } \\
2907 \text { m asl) (1 SD) }\end{array}$ & $\begin{array}{l}\text { Temp. anomaly }{ }^{\circ} \mathrm{C} \\
\text { (present-day ELA } \\
1800 \mathrm{~m} \text { asl) (1 SD) }\end{array}$ \\
\hline IN & $17342 \pm 172$ & $1207 \pm 599$ & $1191 \pm 101$ & $-8.4 \pm 1.1$ & $-3.2 \pm 0.8$ \\
\hline L3 & $17196 \pm 220$ & $1184 \pm 609$ & $1183 \pm 101$ & $-8.5 \pm 1.1$ & $-3.3 \pm 0.8$ \\
\hline R3 & $18709 \pm 237$ & $1183 \pm 584$ & $1184 \pm 101$ & $-8.5 \pm 1.1$ & $-3.3 \pm 0.8$ \\
\hline L4/L5 & $19629 \pm 308$ & $1176 \pm 602$ & $1176 \pm 98$ & $-8.6 \pm 1.1$ & $-3.3 \pm 0.8$ \\
\hline
\end{tabular}




\section{CHAPTER 5: DISCUSSION}

This discussion is structured around my objectives which are: (1) to constrain the timing and magnitude of glacier length changes at Rocky Top cirque; and (2) to make a quantitative reconstruction of paleoclimate.

Geomorphological mapping and ${ }^{10} \mathrm{Be}$ surface exposure dating results are combined in Section 5.1 to examine the timing and magnitude of past glacier extents at Rocky Top cirque. The ${ }^{10} \mathrm{Be}$-dated moraine sequence from Rocky Top is then compared to other moraine sequences in the Southern Alps to assess whether glacier length changes occurred simultaneously on a regional scale (Section 5.2). Section 5.3 explores climatic implications of the present-day and paleo-ELAs and investigates the robustness of the paleotemperature reconstruction produced in Section 4.3.

\subsection{The chronology of glacier length changes at Rocky Top cirque}

Geomorphological mapping of the glacial landforms at Rocky Top cirque, such as moraines and crests of ice-contact slopes, indicated former glacier extents and identified suitable locations for surface exposure dating of boulders. The detailed mapping identified ten discrete moraines, four of which were paired (L1 paired with R1; L2 paired with R2). The paired moraines outlined the former glacier terminus while all other moraines were lateral, thus only permitting partial constraint of the former ice margin. Moraines L1, L2, R1 and R2, and L4 and L5, were treated as single landforms based on their close proximity, indistinguishable ages within internal error, and similar landscape expression (hereafter referred to as 'IN moraine' and 'L4/L5 moraine' respectively, as established in Section 4.2). As such, treating the grouped moraines as individual landforms would have negligible impact on results. Statistical analysis of surface exposure dating results confirmed that moraines IN, L3, R3, L4/L5 and R4 were continuous landforms in agreement of exposure age. Table 5.1 summarises the results of cosmogenic ${ }^{10} \mathrm{Be}$ surface exposure dating of the moraines. 
Table 5.1: Summarised results of cosmogenic ${ }^{10}$ Be surface exposure dating using the Lm scaling scheme and internal uncertainties (Putnam et al. 2010b). Outliers are italicised, as identified by the chi-squared outlier detection routine (Section 4.2).

\begin{tabular}{|c|c|}
\hline Sample ID & Age (yrs) \\
\hline \multicolumn{2}{|l|}{ IN Moraine } \\
\hline RT_1414 & $17017 \pm 379$ \\
\hline RT_1415 & $17210 \pm 384$ \\
\hline RT_1416 & $16836 \pm 368$ \\
\hline RT_1534 & $18149 \pm 404$ \\
\hline RT_1640 & $17638 \pm 389$ \\
\hline Arith. Mean $(n=5)$ & $17370 \pm 528$ \\
\hline Pruned Arith. Mean $(n=5)$ & $17342 \pm 172$ \\
\hline \multicolumn{2}{|l|}{ L3 Moraine } \\
\hline RT_1527 & $17019 \pm 381$ \\
\hline RT_1528 & $16750 \pm 366$ \\
\hline RT_1529 & $17921 \pm 399$ \\
\hline$R T_{-} 1530$ & $14788 \pm 331$ \\
\hline Arith. Mean $(n=4)$ & $16620 \pm 1319$ \\
\hline Pruned Arith. Mean $(n=3)$ & $17196 \pm 220$ \\
\hline \multicolumn{2}{|l|}{ R3 Moraine } \\
\hline$R T \_1408$ & $16953 \pm 373$ \\
\hline RT_1410 & $18731 \pm 412$ \\
\hline RT_1411 & $18487 \pm 406$ \\
\hline RT_1412 & $18919 \pm 415$ \\
\hline Arith. Mean $(n=4)$ & $18273 \pm 897$ \\
\hline Pruned Arith. Mean $(n=3)$ & $18709 \pm 237$ \\
\hline \multicolumn{2}{|l|}{ L4/L5 Moraine } \\
\hline RT_1518 & $19287 \pm 428$ \\
\hline$R T_{-} 1519$ & $14875 \pm 323$ \\
\hline RT_1526 & $19998 \pm 444$ \\
\hline Arith. Mean ( $n=3)$ & $18053 \pm 2775$ \\
\hline Pruned Arith. Mean $(n=2)$ & $19629 \pm 308$ \\
\hline \multicolumn{2}{|l|}{ R4 Moraine } \\
\hline RT_1404 & $28642 \pm 633$ \\
\hline RT_1407 & $40574 \pm 884$ \\
\hline Arith. Mean $(n=2)$ & $34608 \pm 8437$ \\
\hline Pruned Arith. Mean $(n=2)$ & $34608 \pm 8437$ \\
\hline
\end{tabular}


The chi-squared outlier detection routine identified a total of three outliers, as italicised in Table 5.1. Moraine R3 had an outlier (sample RT_1408) which was $\sim 1700$ years younger than the pruned arithmetic mean. The boulder was fractured and split into multiple pieces with sharp edges, though the surfaces were covered in lichen and there was no evidence of recent weathering/splitting (Figure 5.1A). The fractured nature (particularly the sharp edges) and low height $(62 \mathrm{~cm})$ of the boulder may suggest that the underestimation of exposure age was due to fracturing followed by erosion of the surface layer. Another outlier was identified on moraine L3 (sample RT_1530) which was 2400 years younger than the pruned arithmetic mean. There was no obvious reason for the underestimation of age, as the boulder was well-embedded in the crest of the moraine and displayed minimal evidence of fracturing or weathering (Figure 5.1B). However, as the sample was located at the lowest-elevation end of the moraine (closest to the stream and outwash surface), it could have potentially been disturbed postdeposition by stream reworking. Moraine L4/L5 had an outlier (sample RT_1519) which was $\sim 5000$ years younger than the pruned arithmetic mean. The boulder surface was smooth with no major fracturing (Figure 5.1C). The boulder was situated about $5 \mathrm{~m}$ from the edge of the moraine crest, and its dimensions were much wider and longer than they were high $(168 \mathrm{~cm}, 207 \mathrm{~cm}$, and $62 \mathrm{~cm}$ respectively). The boulder was not well-embedded in the moraine surface, which suggests that at some point the boulder may have toppled from the ridge crest, resulting in nuclide accumulation in a previously unexposed surface. 

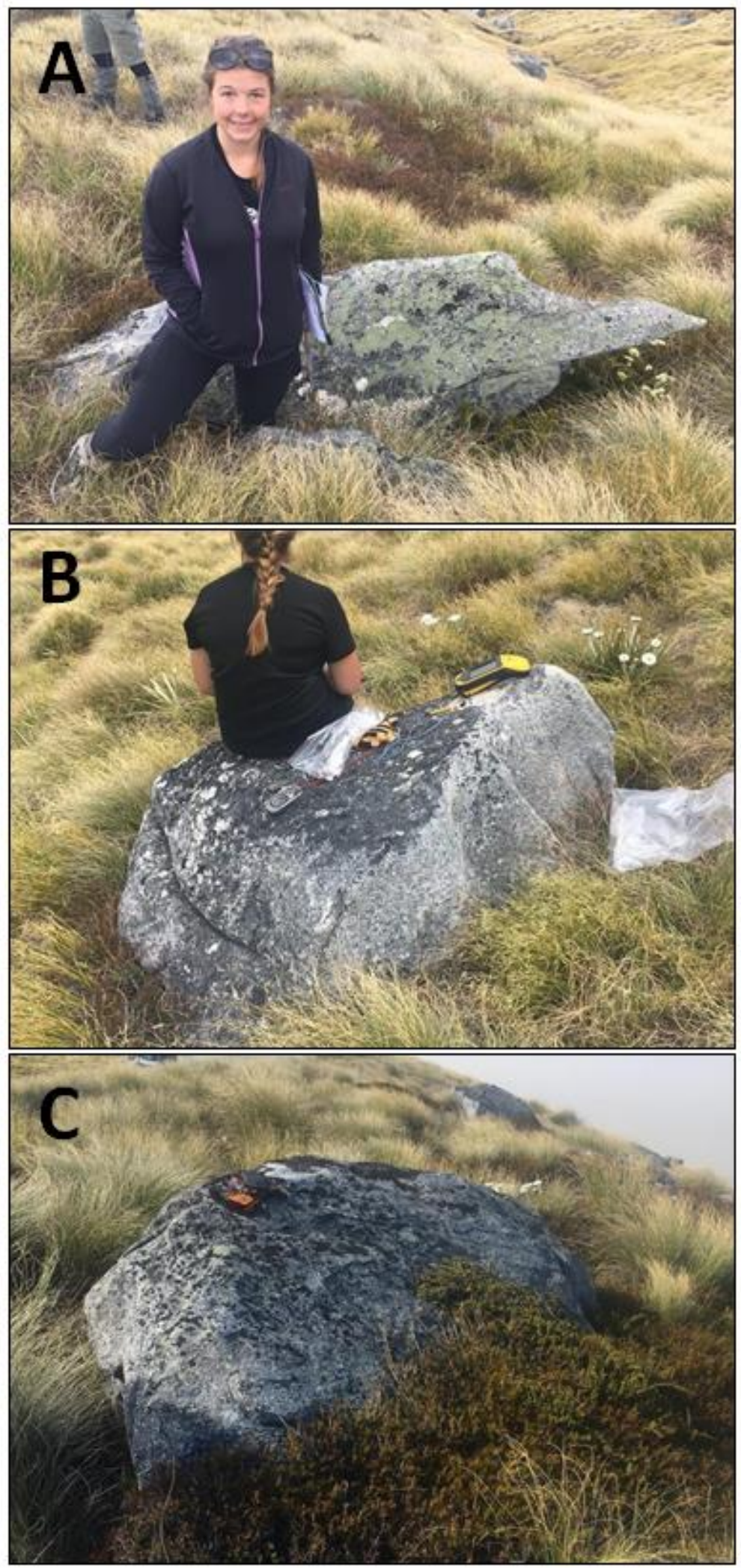

Figure 5.1: Photographs of boulders that were identified as outliers during the chisquared outlier detection routine (see Section 4.2). Sample IDs of outliers are: (A) $R T_{-} 1408$, (B) RT_1530, and (C) RT_1519. 
Moraine R4 has an arithmetic mean age of $34608 \pm 8437 \mathrm{ka}$ (Table 5.1). The age is

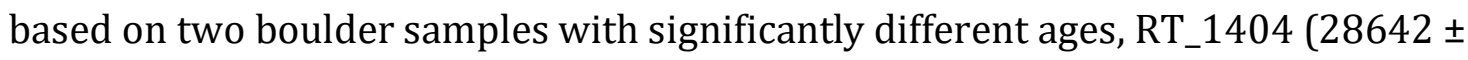
$633 \mathrm{ka}$ ) and RT_1407 (40574 $\pm 884 \mathrm{ka}$ ) (Figure 5.2A and B respectively). Due to the variation the resulting mean age has a wide margin of error (1 SD of $8437 \mathrm{ka}$, or roughly $30 \%$ of the mean age). Reasons for the variation between sample ages could include: (i) inheritance in the older sample, (ii) erosion/fracturing of the surface of the younger sample, and (iii) post-depositional movement or modification of the younger sample. I argue that the most likely explanation is significant erosion/fracturing of the surface of the younger sample (RT_1404). The RT_1404 boulder has a large cavity on the surface (cavity dimensions 140 x 60 x 30 $\mathrm{cm}$ ) (Figure 5.2A). The cavity may indicate significant erosion or weakness of the boulder, suggesting a considerable amount of the boulder surface has been removed since deposition. Given the old exposure age of Moraine R4 (likely between $28642 \pm 633 \mathrm{ka}$ and $40574 \pm 884 \mathrm{ka}$ ) significant erosion is probable. Sample RT_1407 also showed evidence of erosion (minimum $5 \mathrm{~mm}$ ), though remains intact with a relatively smooth surface. Both boulders are large (190 x 192 x 408 cm (RT_1407) and 150 x 120 x 222 cm (RT_1404)), reducing the likelihood of post-depositional movement or toppling. It remains uncertain whether boulder RT_1407 contained inherited cosmogenic ${ }^{10} \mathrm{Be}$ from previous exposure.

Inheritance is possible, given that the former glacier was small and the location of the boulder makes it unlikely that it could have travelled subglacially where it would have been more subject to erosion. However, compilations of data from regions of former temperate glaciation indicate that inheritance is a far less common cause of outliers compared to post-depositional modification (such as erosion) (Heyman et al., 2011). Given the observed evidence of significant erosion on at least one of the boulders (RT_1404), I argue that the variable erosion ages are probably due to erosion processes on the boulder surface(s) rather than inheritance (Heyman et al., 2011). To better constrain the timing of Moraine R4 glacier extent, more processed boulder samples from Moraine R4 would narrow the standard deviation and aid outlier detection. Standard sampling procedure recommends sampling of at least $\sim 4-5$ boulders on each moraine (Ivy-Ochs and Briner, 2014; Dunai and Lifton, 2014). The uncertainty of the age of Moraine R4 which is based on only two boulder samples reinforces the usefulness of the sampling procedure recommendation. 


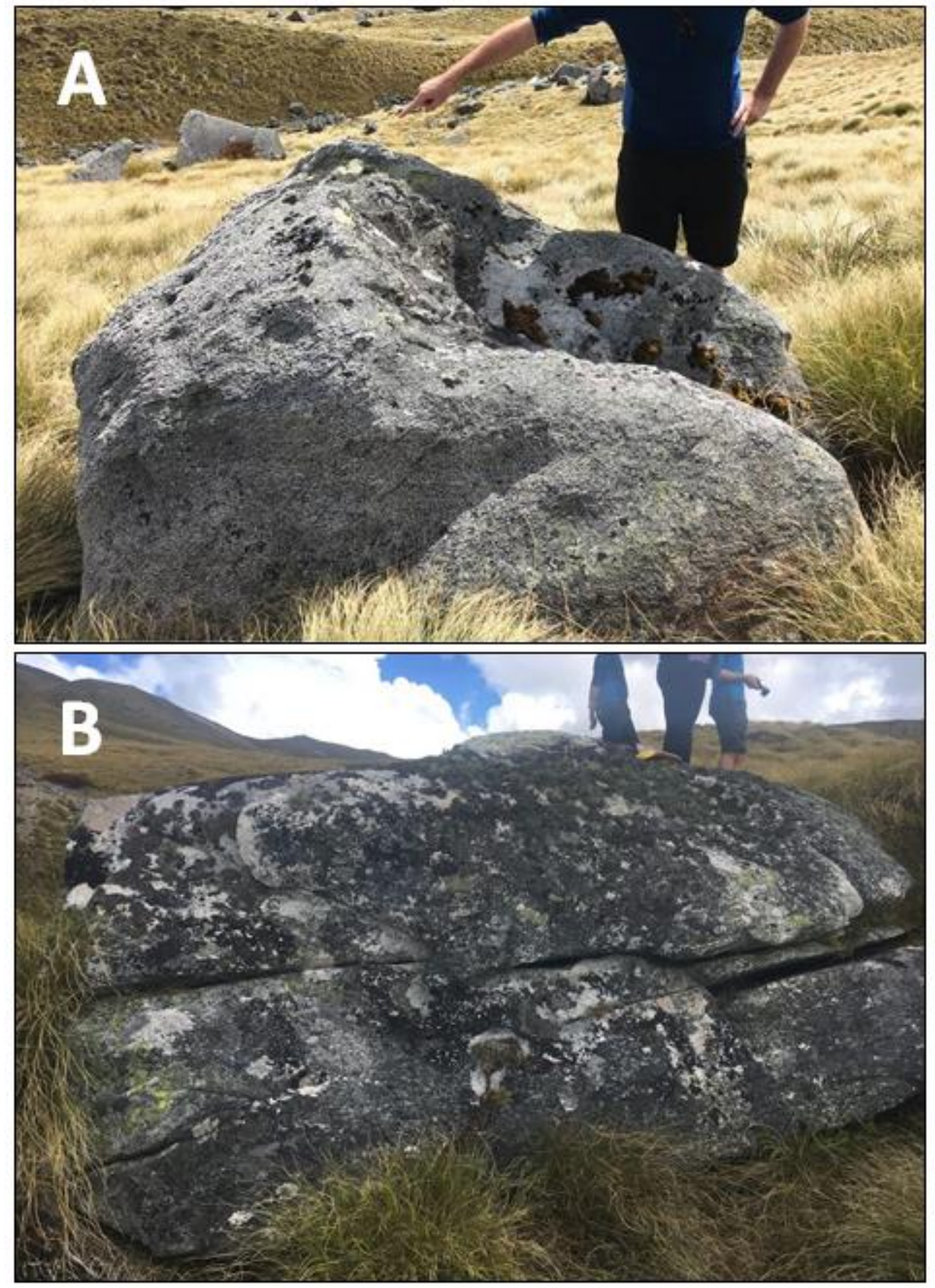

Figure 5.2: Photographs of sampled boulders on Moraine R4. The boulders have significantly different surface exposure ages, probably due to erosion. Sample IDs of pictured boulders are (A) RT_1404, and (B) RT_1407. 
Overall, combined results from geomorphological mapping and ${ }^{10} \mathrm{Be}$ surface exposure dating of moraines tightly constrain the timing and magnitude of glacier length changes at Rocky Top cirque. The oldest moraine, R4 (34608 \pm 8437 ), is more extensive than the younger moraines, suggesting an overall pattern of retreat. The exposure ages of moraines IN, L3, R3 and L4/L5 (17342 $\pm 172,17196$ $\pm 220,18709 \pm 237$ and $19629 \pm 308$ respectively) suggest the timing of events of glacier re-advance or standstills. It is possible that there were other minor readvances or standstills, but there may not be any evidence of these remaining due to processes including obliterative overlap or post-depositional modification (Gibbons et al., 1984). Also, down-valley of the moraine sequence where the cirque drops away to Lake Monowai, the steep topography is not conducive to moraine preservation. This means that any earlier, more extensive glacier advances were likely not preserved. The suggested periods of glacier retreat, re-advance and standstills may have occurred in response to regional climatic fluctuations. Comparison of the moraine record at Rocky Top with other moraine records of similar age in the Southern Alps can be used to assess whether glacier length changes across different sites followed a regional trend. 


\subsection{Glacier length changes in the Southern Alps}

The majority of the ${ }^{10} \mathrm{Be}$ moraine chronologies produced at Rocky Top cirque have exposure ages between 19-17 ka, overlapping with the beginning of the local LGIT at $18 \mathrm{ka}$ (as defined by Barrell et al., 2013b). The straddling of the temporal boundary between the end of the LGM and the start of the local LGIT may afford insight to the onset of deglaciation in the Southern Alps region. In order to determine whether the described glacier length changes at Rocky Top cirque were driven by regional fluctuations in climate, the ${ }^{10} \mathrm{Be}$ moraine ages may be compared with other similar ${ }^{10} \mathrm{Be}$ moraine chronologies in the Southern Alps. Studies by Barrows et al. (2013) in the Kumara/Moana region, at Lake Ohau by Putnam et al. (2013a) and in the Rakaia Valley by Putnam et al. (2013b) produced ${ }^{10}$ Be moraine records that are comparable to those at Rocky Top, though there is some variation between moraine chronologies. Note that the three studies mentioned all use the Lm scaling scheme, which makes direct comparison of ages with Rocky Top appropriate (Putnam et al., 2010b).

Moraines IN and L3 (17342 \pm 172 and $17196 \pm 220$ respectively) are within error of eachother (within $1 \sigma$ of the mean exposure age) and formed coevally to other moraines in the Southern Alps. Moraines of similar age include (i) the Moana Formation as reported by Barrows et al. (2013) at 17,300 $\pm 500 \mathrm{yr}$, (ii) the Ohau VI set of moraines from Putnam et al. (2013a) at $17280 \pm 140$, and (iii) the Lake Coleridge, Castle Hill and Double hill moraines at 17,020 \pm 70 yrs, 17,100 \pm 110 yrs, 16,960 \pm 370 yrs respectively (Putnam et al., 2013b). The mean ages of the moraines listed are indistinguishable within error of moraines IN and L3. Studies have suggested that New Zealand glaciers commenced rapid retreat around 18-17 ka (Barrows et al., 2013; Putnam et al., 2013a; Putnam et al., 2013b; Putnam et al., 2010a), which is in agreement with the findings of Moraines IN and L3. Though their ages are indistinguishable, Moraine IN is located 200-250 m upstream of Moraine L3, implying rapid glacier length change.

There are few ${ }^{10} \mathrm{Be}$ chronologies recorded in the Southern Alps that have ages similar to those of moraines R3 and L4/L5. Moraine R3 (18709 \pm 237 ) formed slightly before Ohau IV moraine $(18210 \pm 130)$ as reported by Putnam et al. (2013a). Moraine L4/L5 (19629 \pm 308$)$ is within error of the lower end of the age 
range for the Larrikins Formation $(20,800 \pm 500$ to 20,000 $\pm 400 \mathrm{yr}$ ) (Barrows et al., 2013). The lack of comparable ages could be due to different glacier response times and moraine preservation across sites, or it could indicate that post-LGM glacier retreat became generally ubiquitous at a later date. Putnam et al. (2013b) suggests that post-LGM glacier retreat in the Rakaia Valley began around $\sim 18 \mathrm{ka}$, which is in agreement with the "beginning of LGIT" as defined by Barrell et al. (2013b).

The arithmetic mean age $(34608 \pm 8437)$ for Moraine R4 is similar to that of the Ohau II moraine (Putnam et al., 2013a) at 32,540 \pm 440 . However the wide margin of internal error for the exposure age of Moraine R4 does not lend much confidence to the comparison between sites.

The slight variation between similar moraine ages at Rocky Top and the discussed sites is likely due to individual glacier response times and glacier length sensitivities, which influence moraine formation and preservation (Mackintosh et al., 2017b). As outlined in Section 2.2.1 glaciers with faster response times and/or higher length sensitivities tend to respond faster to climate fluctuations, thus creating slight discrepancies between the exact timing of moraine formation between differently responding glaciers. For example the former Rocky Top glacier was relatively small and simple, so thus may have adjusted to climatic fluctuations relatively quickly when compared to larger glaciers such as Ohau Glacier (Putnam et al. 2013a) and Taramakau Glacier (Barrows et al. 2013).

As described above, Rocky Top Moraines IN, L3, and R3 have similar ${ }^{10}$ Be exposure ages to Lake Ohau moraines VI, IV and II. However there are additional Lake Ohau moraines that do not have a corresponding match at Rocky Top, such as the Ohau V moraine $(17,700 \pm 190)$, which falls within the age range of observed moraines at Rocky Top (between $17196 \pm 220$ and $34608 \pm 8437$ ). The absence of a moraine of similar age at Rocky Top could be an artefact of sampling, if the moraine is assumed to exist but not have been identified or sampled in the field. Putnam et al. (2013a) describe the Ohau V moraines as subdued discontinuous ridges; a subdued ridge is more susceptible to be obscured or removed by post-depositional modification processes. Alternatively, different glacier response times and length 
sensitivity between the former Rocky Top and Ohau Glacier may suggest that a chronologic match to the Ohau V moraine was never deposited at Rocky Top.

Moraine R4 is the oldest observed moraine at Rocky Top at $34608 \pm 8437 \mathrm{yrs}$ (Table 5.1), though moraines have been recorded in the Southern Alps dating back to 130 ka (Putnam et al., 2013a). It is possible that moraines were deposited at Rocky Top prior to deposition of Moraine R4, though older moraines may have been removed by post-depositional processes. Post-depositional modification or removal is highly likely given the advanced age of moraines and setting in a tectonically active and fast-weathering environment.

Overall, the ${ }^{10} \mathrm{Be}$ moraine chronology at Rocky Top cirque exhibits a similar pattern of glacier length changes to other sites in the Southern Alps with existing ${ }^{10} \mathrm{Be}$ moraine chronologies. The discussed variations in the timing of moraine formation across different sites are most likely due to individual glacier response times and glacier length sensitivities. Despite the variation, comparison of the moraine record at Rocky Top cirque with other records from the Southern Alps can be used to assess whether glacier length changes across different sites were driven by regional fluctuations in climate. 


\subsection{Paleoclimatic implications of glacier length changes at Rocky Top cirque}

\subsubsection{Implications of the paleo-ELA}

For each moraine-constrained former glacier extent the equilibrium-line altitude (ELA) was reconstructed using the accumulation area ratio (AAR) method (Section 3.3). A cumulative curve was created to display the area/altitude distribution, then an AAR value of 0.67 (Chinn et al., 2012) was applied to determine the ELA. Results produced a clear trend of paleo-ELAs decreasing in altitude with older moraines of increasing glacier extent (Section 4.3), as summarised in Table 5.2.

Table 5.2: Paleo-ELAs derived using the AAR method (AAR =0.67) for each moraineconstrained glacier extent (excluding Moraine R4) at Rocky Top cirque. Ages (yr) for each moraine landform represent the pruned arithmetic mean, reported using the Lm scaling scheme and internal uncertainty (see Section 4.2).

\begin{tabular}{lll}
\hline Moraine & Age (yr) & ELA (AAR method) $(\mathbf{m}$ asl) \\
\hline IN & $17342 \pm 172$ & 1190 \\
L3 & $17196 \pm 220$ & 1185 \\
R3 & $18709 \pm 237$ & 1187 \\
L4/L5 & $19629 \pm 308$ & 1178 \\
\hline
\end{tabular}

The 'larger-volume ice model' approach of Kaplan et al. (2010) used the upper ridgeline to outline the upper limit of former ice volume extent. Change in elevation of the ridgeline since moraine formation can impact the paleo-ELA results produced using the AAR method. The ridgeline at Rocky Top cirque may have lowered since moraine formation, possibly associated with the Green Lake landslide (Hancox and Perrin, 2009). The Green Lake landslide occurred approximately $12-13,000$ yrs BP, shifting a great volume of debris $\left(\sim 27 \mathrm{~km}^{3}\right)$ that formed a dam and consequent lake. The landslide was likely triggered by a large earthquake ( $\geq$ M 7.5-8) associated with the Alpine Fault (Hancox and Perrin, 2009). The Green Lake landslide occurred in close proximity to Rocky Top cirque, as located in Figure 5.3. Figure 5.3 shows a steep headscarp along the northern edge of Rocky Top cirque, the ridgeline of which represents the upper limit of glacier extent for each AAR glacier reconstruction. The headscarp is likely prone to 
small failures, triggered by recurrent earthquakes and increasingly prone to weathering following the Green Lake landslide. Lowering of the ridgeline elevation since moraine formation would cause the paleo-ELA calculated by the AAR method to be artificially depressed. This may lead to anomalously cold temperature reconstructions at the depressed paleo-ELA.

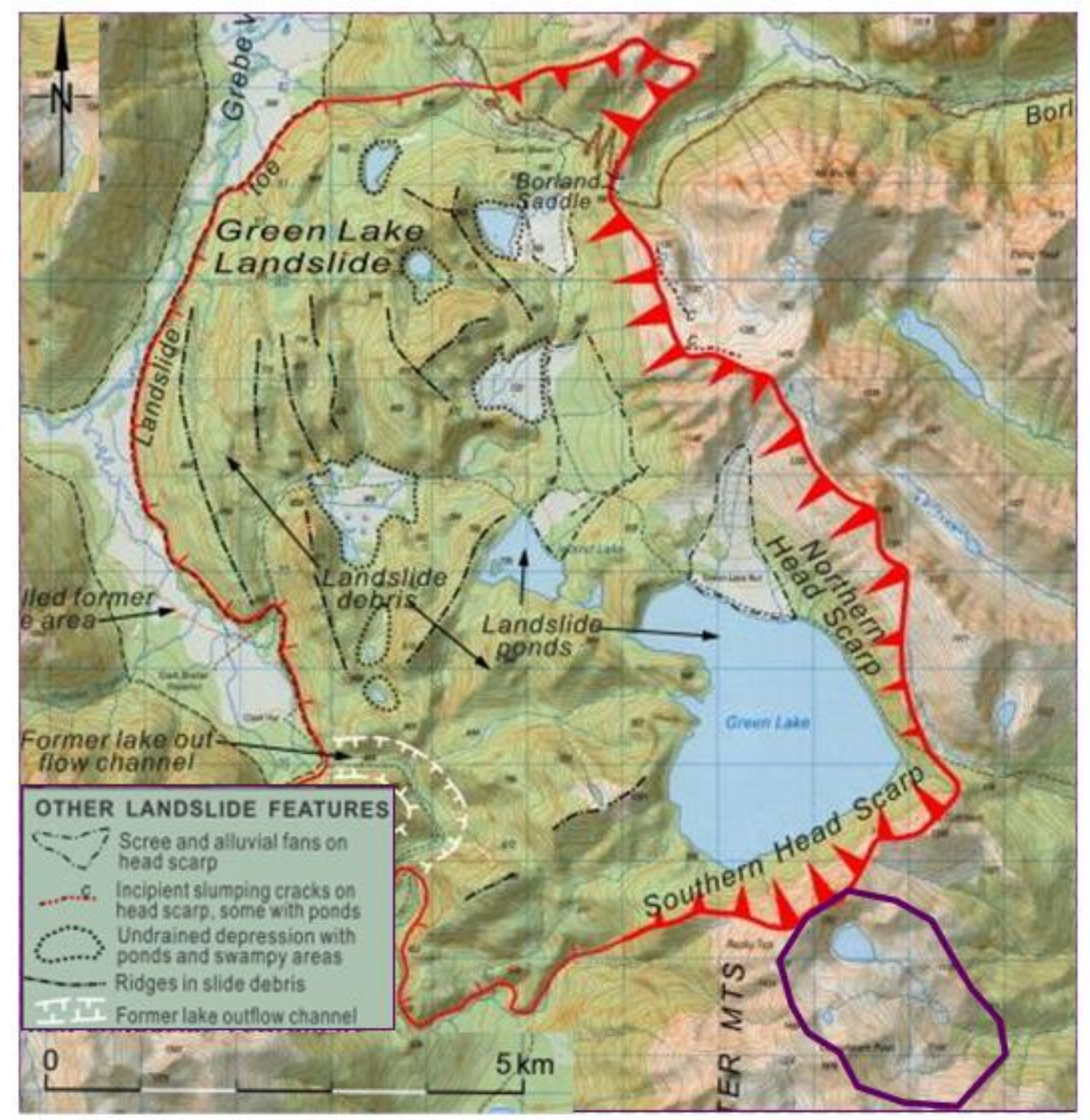

Figure 5.3: Map showing the location of the Green Lake landslide relative to Rocky Top cirque. The mapped area boundary of Rocky Top cirque is approximately outlined in purple. Note that the 'Southern Head Scarp' (as labelled on map) partially borders the ridgeline of Rocky Top cirque. Figure modified from Hancox and Perrin (2009). 


\subsubsection{Implications of the present-day ELA}

The mean summer air temperature method for calculating present-day ELA appeared to be a poor proxy. The method used data from the Manapouri West Arm 2 weather station (232 m asl) between 1970-2010 to calculate an overall mean austral summer air temperature and standard deviation $\left(13.53^{\circ} \mathrm{C}\right.$ and $0.59^{\circ} \mathrm{C}$ respectively). The Monte Carlo algorithm results (Eaves et al., 2016) (Section 4.3) placed the average present-day ELA at $2907.7 \pm 602.4 \mathrm{~m}$, which is inconsistent with present-day glacier ELA observations around New Zealand. As mentioned in Section 3.3.2, the estimate of $2907.7 \mathrm{~m}$ at Rocky Top was unrealistically similar to the present-day ELA in the North Island (between $\sim 2400-3200 \mathrm{~m}$ asl; Eaves and Brook, 2021), considering the $\sim 1000 \mathrm{~km}$ latitudinal difference and resulting temperature gradient between Rocky Top and the central North Island. This section discusses a more realistic value for the present-day ELA at Rocky Top. In 2010 the ELAs of fifty index glaciers ranged from $1365 \mathrm{~m}$ (Caroline Peak) to 2504 m (Kaikoura Range) (Figure 5.4) (Willsman et al., 2010). The range of ELA values is largely due to location within the Southern Alps, partly caused by the latitudinal gradient (Lamont et al., 1999). The ELAs descend southwards, from $2504 \mathrm{~m}$ in the north (Kaikoura Range) to $1365 \mathrm{~m}$ in the south (Caroline Peak). As such, present-day ELA for Rocky Top is expected to at the lower end of the ELA range due to the location at the far southern end of the Southern Alps. 


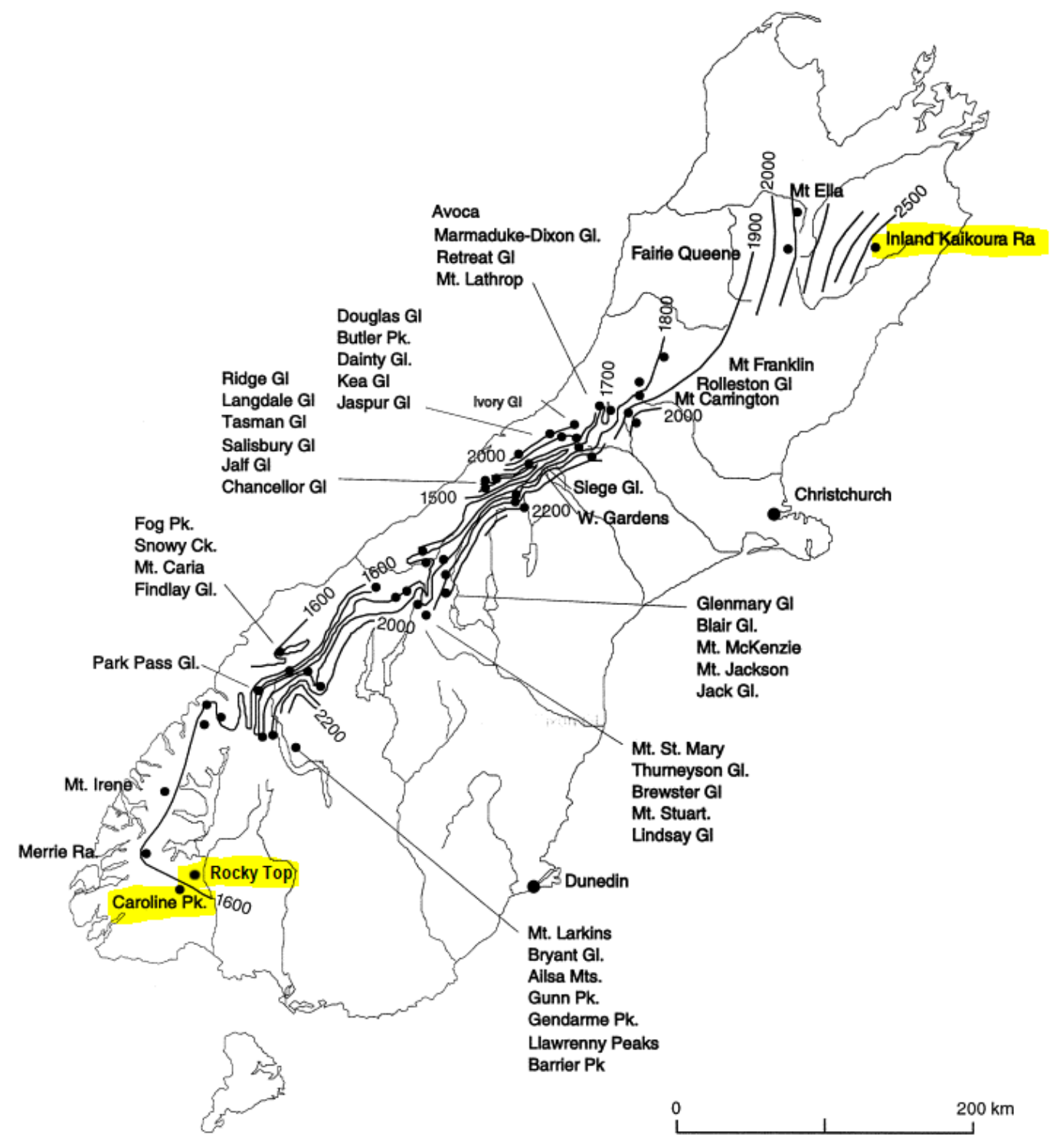

Figure 5.4: Distribution of index glaciers in the Southern Alps, with isolines inferring mean elevations of end-of-summer-snowlines. The location of Rocky Top cirque is highlighted as well as the locations of Kaikoura Range and Caroline Peak. Figure modified from Lamont et al., (1999).

Other causes of variation between ELA values in the Southern Alps include orographic climate differences and glacier aspect. On a longitudinal gradient ELAs rise steeply from 1600 m west of the Main Divide in the central Southern Alps to $2200 \mathrm{~m}$ on the easternmost side (Lamont et al., 1999). The gradient is mainly due to precipitation, where prevailing westerlies and an orographic lift effect result in more snowfall (accumulation) on the western side of the mountains, thus lowering the ELA (Lamont et al., 1999). Glacier aspect influences the amount of surface melt, with findings suggesting that ELAs of glaciers with north-facing aspects were $\sim 200$ 
m higher than those of south-facing glaciers (Chinn and Whitehouse, 1980; Lamont et al., 1999). Rocky Top is on the eastern side of Fiordland, but unlike the central Southern Alps it has relatively low-elevation hills to the west so the ELA is less influenced by orographic effects. Rocky Top has a southeast facing aspect, so overall would be expected to be on the lower end of the range of mean ELAs of Southern Alps glaciers.

Figure 5.5 presents annual index glacier survey results from 1977-2016, showing a mean annual end-of-summer snowline (EOSS) ranging between $1704 \mathrm{~m}$ and 2024 $\mathrm{m}$ and averaging around $1849 \mathrm{~m}$. From 1977 to 2005 mean annual snowlines of index glaciers trended around average (excluding 1990 and 1991, which had limited data). There was some fluctuation of snowlines between 1998-2005, but since 2006 snowlines have trended at higher than average elevations. Based on the trend, the mean annual present-day ELA for Southern Alps glaciers is closer to $\sim 1900 \mathrm{~m}$.

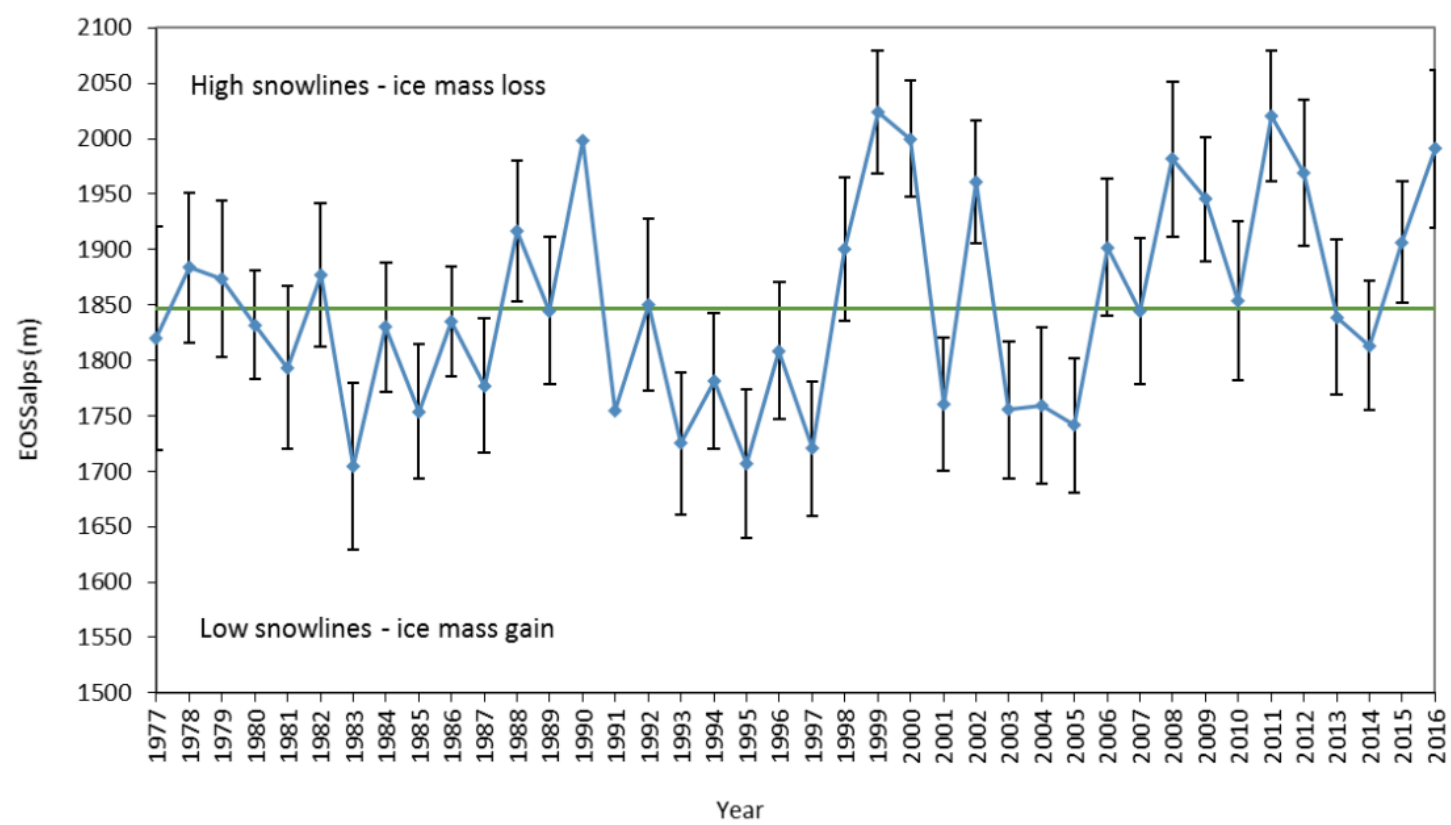

Figure 5.5: Annual index glacier survey results from 1977-2016. The green line $(1849 \mathrm{~m})$ denotes the average end of summer snowline elevation for the whole survey period. Figure from Willsman (2017).

I argue that the present-day ELA at Rocky Top is probably within the range 1600$2000 \mathrm{~m}$, but most likely around $1800 \mathrm{~m}$. The minimum value of this range (1600 $\mathrm{m}$ ) is based on observations of nearby modern glaciers and interpolation by Lamont et al. (1999). Of the 50 index glaciers in 2016, the three closest to Rocky 
Top have mean ELAs of 1567 m, 1518 m and 1365 m (Mt Irene, Merrie Ranges and Caroline Peak respectively) (Willsman, 2017). Based on these observations, the ELA would be expected to be similar (1350-1600 m) at Rocky Top. However other peaks near Rocky Top in the Hunter Mountains such as Flat Mount (1748 m) and unnamed (1804 m) are considerably higher than the index glacier ELA of 1600$1650 \mathrm{~m}$ but are not presently glaciated, indicating that this may not be suitable. The ELA for Rocky Top is expected to be below the mean ELA of all Southern Alps glaciers ( $1900 \mathrm{~m})$, due to the southern latitudinal location. Therefore the maximum estimate of ELA is $2000 \mathrm{~m}$ (to account for uncertainty) and the best estimate of ELA is $1800 \mathrm{~m}$, the mean of $1600 \mathrm{~m}$ and $2000 \mathrm{~m}$. Using the present-day ELA at Rocky Top of $1800 \mathrm{~m}$, the Monte Carlo algorithm was re-run using a mean ELA of $1800 \mathrm{~m}$ and standard deviation of $100 \mathrm{~m}$ (Section 4.3). Results returned average temperature anomalies of around $\sim-3.2$ to $-3.3^{\circ} \mathrm{C}$ cooler than present, $\sim 5^{\circ} \mathrm{C}$ warmer than those produced by the mean summer air temperature proxy (see Table 5.3 below). 
Table 5.3: Temperature anomalies (relative to present-day) produced by the algorithm for the former glacier terminating at each moraine extent. Paleotemperature significantly differs based on the present-day ELA inputs of $2907.7 \pm 602.4 \mathrm{~m}$ asl (mean air temperature proxy) and $1800 \pm 100$ m ("best estimate"; see Section 3.3).

\begin{tabular}{llllll}
\hline Moraine & Age (yr) & $\begin{array}{l}\text { Paleo-ELA } \\
\text { (present-day ELA }\end{array}$ & $\begin{array}{l}\text { Paleo-ELA } \\
\text { (present-day ELA } \\
\text { 2907 } \mathbf{~ a s l ) ~}\end{array}$ & $\begin{array}{l}\text { Temp. anomaly }{ }^{\circ} \mathbf{C} \\
\text { (present-day ELA }\end{array}$ & $\begin{array}{l}\text { Temp. anomaly }{ }^{\circ} \mathbf{C} \\
\text { (present-day ELA }\end{array}$ \\
& & & $1191 \pm 101$ & $-8.4 \pm 1.1$ & $-3.2 \pm 0.8$ \\
IN & $17342 \pm 172$ & $1207 \pm 599$ & $1184 \pm 101$ & $-8.5 \pm 1.1$ & $-3.3 \pm 0.8$ \\
L3 & $17196 \pm 220$ & $1184 \pm 609$ & $1183 \pm 101$ & $-8.5 \pm 1.1$ & $-3.3 \pm 0.8$ \\
R3 & $18709 \pm 237$ & $1183 \pm 584$ & $1176 \pm 98$ & $-8.6 \pm 1.1$ & $-3.3 \pm 0.8$ \\
\hline
\end{tabular}


The temperature anomaly reflects the difference between average present-day temperature and paleotemperature at the time of each moraine formation event. As such, the best estimate of paleotemperature based on the "present-day ELA = $1800 \mathrm{~m}$ " results has implications regarding climate at the time of moraine formation.

The local LGIT, beginning 18 ka (Barrell et al., 2013b), was a transitional period of warming and widespread glacial retreat following the LGM. Studies have suggested that during the LGM (28-18 ka) the average annual temperature in New Zealand was between $\sim 4-7^{\circ} \mathrm{C}$ cooler than present (Drost et al., 2007, Golledge et al., 2012, McCarthy et al., 2008; Putnam et al., 2013b). The Rocky Top paleotemperature results were compared to other paleotemperature records from the Southern Alps.

Surface exposure dating of moraines in the Rakaia Valley produced a similar chronology to that of Rocky Top cirque. In particular, the Rakaia Valley "Big Ben" moraine was dated at 17,840 \pm 240 yrs (Putnam et al., 2013b). Glaciological reconstruction for the Big Ben moraine produced a paleotemperature of $-6.25^{\circ} \mathrm{C}$ relative to present, a result that is indistinguishable from paleotemperature values for the LGM in the Southern Alps (Putnam et al., 2013a; Golledge et al., 2012). Reconstruction of paleotemperature for other moraine extents in the Rakaia Valley indicated net temperature increase from $-6.25^{\circ} \mathrm{C}$ to $-2.25^{\circ} \mathrm{C}$ between $\sim 17,840$ and $\sim 15,660$ yrs ago (Putnam et al., 2013b). Results from the Rakaia valley are also consistent with $\sim 3.6^{\circ} \mathrm{C}$ of warming between $\sim 17,700$ and $\sim 13,000$ yrs ago in the Lake Ohau catchment (Kaplan et al., 2010; Putnam et al., 2013a). The Rakaia Valley paleotemperature of $-2.25^{\circ} \mathrm{C}$ at $\sim 15,660$ yrs ago (Putnam et al., 2013b) is also consistent with paleotemperature reconstructions for the Misery moraines deposited by the former Otira Glacier (15.2 $\pm 0.8 \mathrm{ka})$, which produced a temperature anomaly of $-2.3 \pm 0.8^{\circ} \mathrm{C}(1 \mathrm{SD})$ relative to present (Eaves et al., 2017). The consistency across different studies and locations gives confidence to the robustness of paleotemperature results at Rocky Top.

As discussed, the best estimate of paleotemperature at Rocky Top (based on the present-day ELA $=1800 \mathrm{~m}$ proxy) is around $-3.3 \pm 0.8^{\circ} \mathrm{C}$ cooler than present. The best estimate is around $\sim 2-3^{\circ} \mathrm{C}$ warmer than paleotemperature estimates of other studies of a similar time period (e.g. $-6.25^{\circ} \mathrm{C}$; Putnam et al., 2013b). The 
dissimilarity between paleotemperature results could be real, if Rocky Top did experience a climate that was $\sim 2-3^{\circ} \mathrm{C}$ warmer on average for some reason. Alternatively the Rocky Top paleotemperature results could be compromised in some way. The next section explores these possibilities.

\subsubsection{Investigation into paleotemperature dissimilarities}

The paleotemperature dissimilarity could potentially have been caused by a regional climatic difference, resulting in a warmer climate at Rocky Top. However, Rocky Top is located $\sim 100 \mathrm{~km}$ further south than the Rakaia Valley (Putnam et al., 2013b), Lake Ohau (Putnam et al., 2013a) and Misery moraine (Eaves et al., 2017), so paleotemperature would be expected to be relatively colder due to the latitudinal gradient. Drost et al. (2007) described regional differences in LGM temperature and precipitation across the Southern Alps by empirical model simulation (Figure 5.6). Rocky Top cirque falls within the WSSI (West and South South Island) region. The WSSI region varies greatly in temperature, precipitation and topography so Drost et al. (2007) used sub-regions named "Southern OtagoSouthland" and "West Coast-Fiordland". Located on the eastern edge of Fiordland, Rocky Top is best represented by the West Coast-Fiordland sub-region, though is located somewhat near the boundary of the two subsets. The "West CoastFiordland" subset had a simulated LGM cooling of $\sim 8-10^{\circ} \mathrm{C}$, whereas the "Southern Otago-Southland" subset had simulated LGM cooling of only $\sim 2-4^{\circ} \mathrm{C}$. The pattern of cooling across sub-regions is suggested to be due to an enhanced orographic effect. Drost et al. (2007) modelled LGM orography in the Southern Alps relative to present day, finding that the addition of significant glacial ice increased land surface elevations by up to $1000 \mathrm{~m}$. The resulting enhanced orographic effect had an impact on regional climate, particularly by cooling in the mountains and 'sheltering' of the land to the east (Drost et al., 2007). Situated on the eastern margin of the main ice cover in Fiordland, Rocky Top would likely have experienced sheltering effects, so the cooling at Rocky Top cirque could be expected to be somewhere in between the temperatures of the two sub-regions, at around $5-7^{\circ} \mathrm{C}$. This is comparable to the estimated paleotemperature of $-6.25^{\circ} \mathrm{C}$ at Big Ben moraine (17,840 \pm 240 yrs), Rakaia Valley (Putnam et al., 2013b), 
suggesting that regional climatic differences is unlikely to be the cause of the paleotemperature dissimilarity between Rocky Top and other sites.

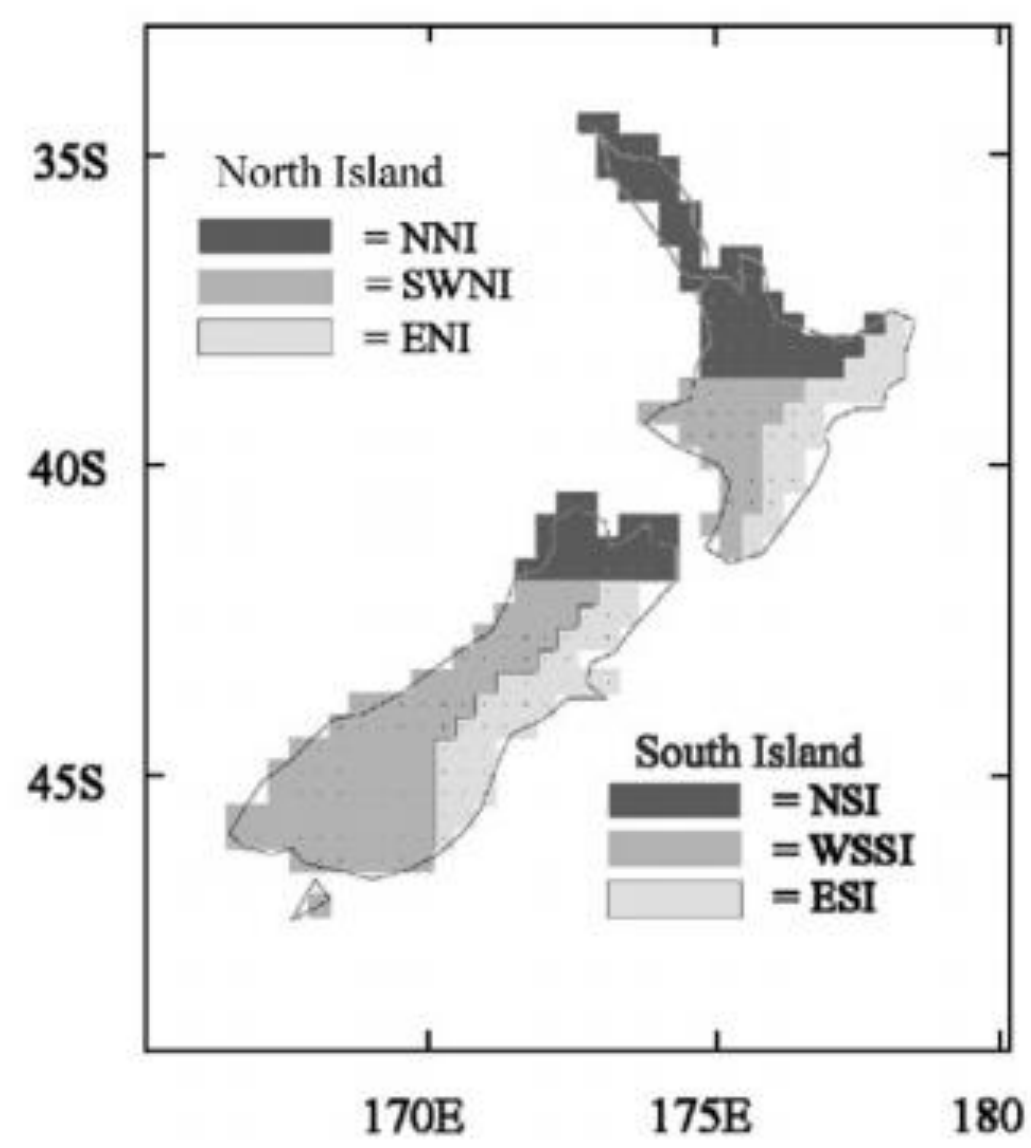

Figure 5.6: Major regions of New Zealand, as referred to by Drost et al. (2007). Abbreviations: $N N I=$ North North Island, SWNI = South-West North Island, ENI = East North Island, NSI = North South Island, WSSI = West and South South Island, ESI = East South Island. Rocky Top cirque falls within the WSSI region.

There is an assumption that the ELA change was all due to temperature change. If precipitation was increased or decreased at Rocky Top, the temperature required to model the former glacier to moraine extent would be different. As such, precipitation change could account for the paleotemperature discrepancy. There is some evidence for precipitation changes during the LGM, with studies suggesting a decrease in annual mean precipitation during the LGM of $\sim 25-30 \%$ relative to present (Golledge et al., 2012; Drost et al., 2007). Drost et al. (2007) identified regional and seasonal variations in precipitation during the LGM. The region surrounding Rocky Top cirque agreed with the trend of precipitation decrease, 
experiencing a $31.7 \%$ reduction in precipitation relative to present-day levels (Drost et al., 2007). A drier than present climate would mean thinner snowpacks, thus requiring extra cooling beyond the estimate presented here $\left(\sim-3.2^{\circ} \mathrm{C}\right)$, to explain the paleo-ELA depression. Seasonality of precipitation during the LGM followed a similar pattern to the present-day seasonal trend. The eastern North Island was the only region that clearly showed an increase in seasonality in precipitation. The implication of this is that variation in precipitation seasonality wouldn't have had a significant impact on the Rocky Top paleotemperature results.

The Irishman Stream moraines $(13,000 \pm 500 \mathrm{yr}$ ago $)$ had a modelled temperature change of $-2.7 \pm 0.6^{\circ} \mathrm{C}$, assuming no precipitation change from present (Doughty et al., 2013). A $20 \%$ decrease in precipitation changed this value to $-2.3^{\circ} \mathrm{C}$, and a $20 \%$ increase in precipitation made it $-3.2^{\circ} \mathrm{C}$ (Doughty et al., 2013). The impact of precipitation on temperature is similar to findings by Anderson and Mackintosh (2006) which indicated that a $37 \%$ increase in precipitation is required to balance $1^{\circ} \mathrm{C}$ of warming. If a $37 \%$ precipitation change has the same impact on ELA as $1^{\circ} \mathrm{C}$ of temperature change, then a $37 \%$ change in precipitation is equivalent to 188.68 m of ELA change.. As such, a moderate ( $20-30 \%)$ change in levels of precipitation since present day (similar to LGM precipitation change) would probably not be enough to significantly alter the estimated Rocky Top paleotemperature estimate of $\sim-3^{\circ} \mathrm{C}$.

Paleotemperature results at Rocky Top could be compromised by the poorlyconstrained temperature lapse rate. The temperature lapse rate of $5.3^{\circ} \mathrm{C} \mathrm{km}^{-1}$ (Norton, 1985) was applied to the paleoELA reconstruction to estimate the temperature required to match the former glacial extent. The lapse rate varies due to factors such as season, altitude, and the amount of moisture in the atmosphere (Norton, 1985). Lapse rate has a strong seasonal cycle, being lowest in winter and greatest in summer (Norton, 1985). The summer lapse rate was selected as summer ablation has the biggest impact on mass balance (Anderson and Mackintosh, 2006). Norton (1985) derived lapse rates for altitudes above and below $300 \mathrm{~m}$. A higher elevation threshold could not be used due to a low number of temperature stations at high altitudes. There were pronounced differences between lapse rates at different altitudes, with altitudes below $300 \mathrm{~m}$ exhibiting lower lapse rates. In other words, the lapse rate has a non-linear trend with 
greater cooling at high elevations (Norton, 1985). As lapse rate observations were mainly from low elevations, the lapse rate is poorly constrained at higher elevations and is not simply predicted by the non-linear trend. Rocky Top is well above $300 \mathrm{~m}(\sim 1430 \mathrm{~m})$ so the lapse rate may be inappropriate for use at this site. Moisture in the atmosphere also affects the temperature lapse rate. In dry air, the dry adiabatic lapse rate has a constant value of $9.8^{\circ} \mathrm{C}$ per $1000 \mathrm{~m}$ (Norton, 1985). If the atmosphere is saturated, condensing water vapour releases latent heat which reduces the rate of cooling so rising air follows the moist adiabatic lapse rate. Situated within the Southern Alps, Rocky Top experiences a variety of circulation and moisture conditions, so a single lapse rate may not be appropriate. Though a single lapse rate such as the value of $5.3^{\circ} \mathrm{C} \mathrm{km}^{-1}$ used may not account for all variation of the lapse rate, the Monte Carlo method captured a wide range of uncertainty in the lapse rates (see Section 3.3).

Paleotemperature results at Rocky Top could also be compromised by the possibility that the present-day ELA estimation of $\sim 1800 \mathrm{~m}$ is still too low. The ELA is difficult to constrain due to the lack of suitable present-day evidence in the region. Of the 50 index glaciers in 2016, the three index glaciers closest to Rocky Top have mean 2016 ELAs of 1567 m, 1518 m and 1365 m (Mt Irene, Merrie Ranges and Caroline Peak respectively) (Willsman, 2017). Figure 5.7 shows images of the three glaciers in March (end of summer) 2010. Willsman et al. (2010) describes Mt Irene as a 'glacierette' and Merrie Range and Caroline Peak as 'patchy glacierettes'. Glacierettes, or very small glaciers, tend to have a large thickness to length ratio (H/L $\sim 0.1$ Kuhn 1995) and the existence of many glacierettes is due to non-climatic processes. These glaciers may be unsuitable for climatic analyses if their existence is ensured more by topography than by climatic conditions (Kuhn, 1995). Particular topographic conditions may favour processes that contribute to winter accumulation, such as avalanches, shading and wind-focusing of snow (Kuhn, 1995). The enhanced winter mass balance is non-temperature controlled, resulting in an artificially depressed snowline. The depressed snowline would not be representative of the regional present-day ELA, which would be higher. The present-day ELA estimation of $\sim 1800 \mathrm{~m}$ is a mean of $1600-2000 \mathrm{~m}$, the lower range of which should perhaps be higher. 
Overall it seems most likely that the dissimilarity in estimated paleotemperature between Rocky Top and other Southern Alps was most likely due to the assumptions and limitations discussed. However, there is still a real possibility that the temperature at Rocky Top during the LGM/LGIT was different to other regions of New Zealand/ Glacier modelling, which explicitly calculates glacier mass balance, may be more informative regarding the causes of the paleotemperature dissimilarity. 


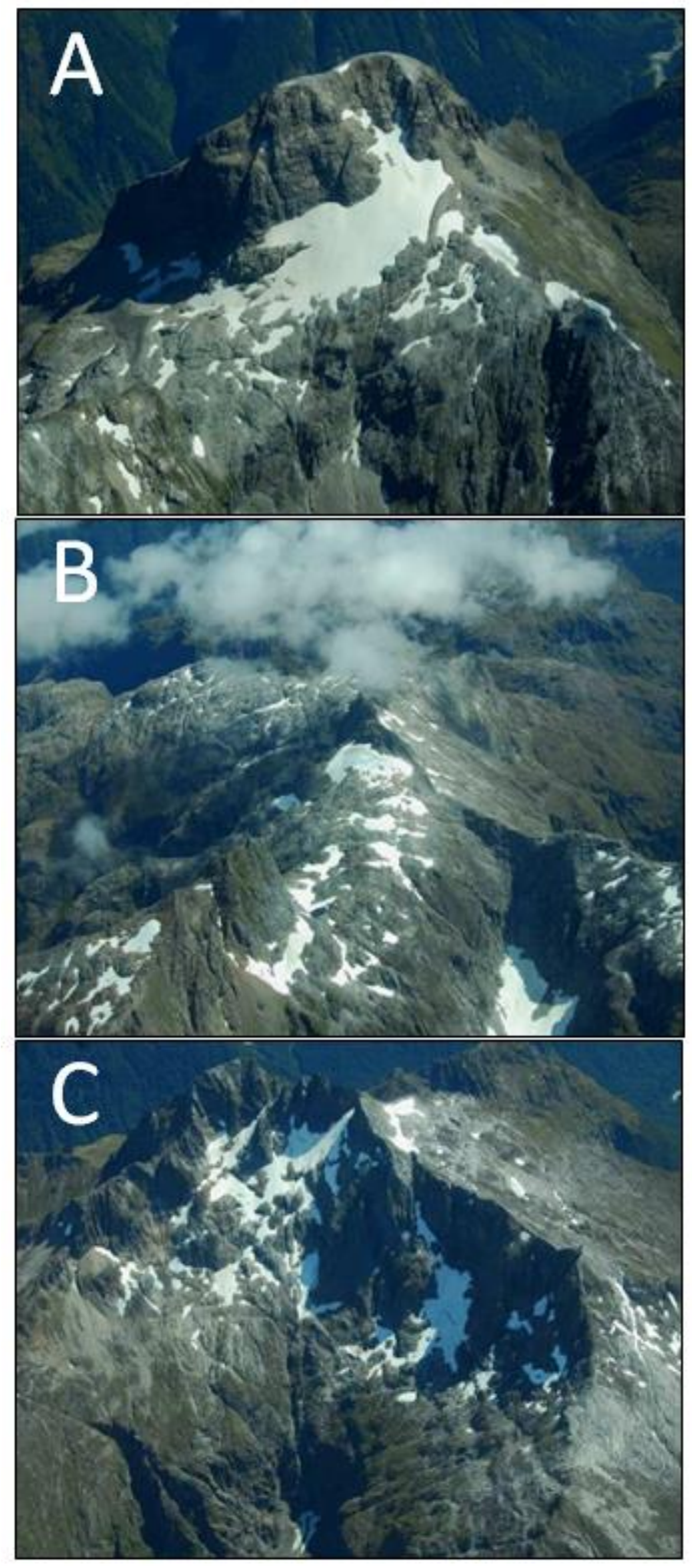

Figure 5.7: Photographs of the three index glaciers closest to Rocky Top: (A) Mt Irene, (B) Merrie Range, and (C) Caroline Peak. Glaciers are very small and their existence may be due to dominantly non-climatic processes. All photographs taken on $6^{\text {th }}$ March 2010. Photographs from Willsman et al. (2010). 


\section{CHAPTER 6: CONCLUSION}

In summary, this study constrains the timing and magnitude of glacier length changes at Rocky Top cirque in the Southern Alps, New Zealand. This aim was achieved by geomorphological mapping of glacial landforms at the Rocky Top cirque and through cosmogenic ${ }^{10} \mathrm{Be}$ surface exposure dating of moraine landforms. This study also successfully made a quantitative reconstruction of paleoclimate at identified former glacier extents, as constrained by well-preserved moraines.

Geomorphological mapping of the glacial landforms identified a total of ten moraines that clearly delineated former glacier geometries at certain extents. Some moraines were later grouped to represent a single landform due to their close proximity, very similar ages and similar expression, resulting in a total of five discrete moraine landforms. Surface exposure dating of in situ cosmogenic ${ }^{10} \mathrm{Be}$ yielded a consistent pattern of overall glacier retreat of the moraine sequence. A chi squared outlier detection routine identified a total of three outliers, which were pruned from the final error-weighted means reported. The two youngest moraines, IN and L3, produced indistinguishable exposure ages of $17342 \pm 172 \mathrm{yrs}$ and $17196 \pm 220$ yrs respectively. Progressively older moraines, R3, L4/L5 and R4, produced respective surface exposure ages of $18709 \pm 237,19629 \pm 308$ and $34608 \pm 8437$.

A quantitative reconstruction of paleoclimate was made for the former glacier extents. Each former glacier extent was constrained by moraine evidence around the lower margin and the 'larger-volume ice model approach' of Kaplan et al. (2010) at the upper margin. Manual glacier surface reconstruction was used to calculate the former equilibrium-line altitude (paleo-ELA) for each former glacier extent. Moraines IN and L3 produced respective local ELA values of $1190 \pm \sim 15$ and $1187 \pm \sim 16$, implying rapid glacier retreat when combined with surface exposure dating results. Moraines R3 and L4/L5 had respective local ELA values of $1186 \pm \sim 16$ and $1179 \pm \sim 18$. Overall paleo-ELA values were $\sim 610-620 \mathrm{~m}$ lower then present-day, based on the best estimate for present-day ELA as discussed in Section 5.3. The paleo- and present-day ELA difference equates to a best-estimate 
temperature depression of $\sim-3.2 \pm 0.8^{\circ} \mathrm{C}$ to $-3.3 \pm 0.8^{\circ} \mathrm{C}$, when uncertainties in the ELA reconstruction and temperature lapse rate are considered.

The overall pattern of retreat of the former Rocky Top glacier is consistent with other moraine chronologies from the Southern Alps, suggesting that glaciers in the Southern Alps responded to common climatic forcings between $~ 19-17 \mathrm{ka}$. In particular, the moraine sequence at Rocky Top exhibits a period of rapid retreat around $\sim 17 \mathrm{ka}$ which has been observed at other Southern Alps sites (Barrows et al., 2013; Putnam et al., 2013a; Putnam et al., 2013b).

The best-estimate of paleotemperature at Rocky Top $\left(-3.3 \pm 0.8^{\circ} \mathrm{C}\right)$ is around $\sim 2$ $3^{\circ} \mathrm{C}$ warmer than paleotemperature estimates of other studies of a similar time period (e.g. $-6.25^{\circ} \mathrm{C}$; Putnam et al., 2013b). Section 5.3.3 investigate potential reasons for the dissimilarities in paleotemperature. The dissimilarity could potentially have been caused by a regional climatic difference, resulting in a warmer climate at Rocky Top, but a number of consistent paleoclimate reconstruction studies (e.g. Drost et al., 2007; Golledge et al., 2012; Putnam et al., $2013 b)$ suggest this is unlikely. The Rocky Top paleotemperature results are potentially compromised in some way by limitations such as the poorly constrained temperature lapse rate, precipitation effects and/or inaccurate present-day ELA based on 'glacierette' measurements.

Future research at Rocky Top cirque could involve the processing of more boulder samples. Only two samples were successfully processed for Moraine R4, but as stated in the literature a minimum of 3-5 samples is required to account for outliers and ensure a high-precision chronology (Ivy-Ochs, 2008). If time and monetary constraints permitted, it would also be interesting to see surface exposure age results from Moraine L6 which is currently undated.

In the future, glacier-climate studies could attempt to improve quantification of variables involved in the derivation of paleotemperature. One such variable that could be better constrained is the present-day temperature lapse rates. The variation of lapse rate at high altitudes ( $>1000 \mathrm{~m}$ asl) is applicable to many glacierclimate studies and may have a profound effect on paleotemperature results. One might also use models to examine any changes in past temperature lapse rate. For certain sites, the present-day ELA could also be better constrained. As the mean summer air temperature method was shown to be a poor proxy (Section 5.3), 
perhaps another method could be developed that would be widely applicable to many non-glacierised sites.

The generation of additional moraine sequence chronologies will potentially confirm and give confidence to the emerging pattern of glacier length changes in the Southern Alps. In particular, additional records from the southern end of the Southern Alps will help to examine the regional climatic pattern and fill gaps in the climatic record. Further paleoclimate reconstructions pertaining to moraine chronologies could help to predict the impact of modern global warming on glacier length and mass balance.

To conclude, the glacier-climate reconstruction of the moraine sequence at Rocky Top cirque presented in this study adds to the limited number of existing Southern Hemisphere paleoclimate records, contributing to understanding of glacier and climate variability. Further studies in the Southern Hemisphere should continue to investigate glacier-climate interactions in order to improve understanding of natural climate variability during pre-industrial times, contributing to the overall goal to determine the extent of anthropogenic climate change. 


\section{REFERENCES}

Allibone, A., Jongens, R., Scott, J., Tulloch, A., Turnbull, I., Cooper, A., . . Rattenbury, M. (2009). Plutonic rocks of the Median Batholith in eastern and central Fiordland, New Zealand: Field relations, geochemistry, correlation, and nomenclature. New Zealand Journal of Geology and Geophysics, 52(2), 101148.

Anderson, B., \& Mackintosh, A. (2006). Temperature change is the major driver of lateglacial. Geology, 34(2), 121-124.

Anderson, L., Roe, G., \& Anderson, R. (2013). The effects of interannual climate variability on the moraine record. Geology (Boulder), 42(1), 55-58.

Bahr, D. B., Pfeffer, W. T., Sassolas, C., \& Meier, M. F. (n.d.). Response time of glaciers as a function of size and mass balance: 1 . Theory. Journal of Geophysical Research, 103(B5), 9777-9782.

Balco, G. (2006). Converting Al and Be isotope ratio measurements to nuclide concentrations in quartz. Retrieved from http://hess.ess.washington.edu/math/docs/common/ams_data_reduction/

Balco, G. (2017). The online exposure age calculator formerly known as the CRONUSEarth online exposure age calculator. Retrieved from https://hess.ess.washington.edu/math/v3/v3_age_in.html

Balco, G. (2020). Glacier Change and Paleoclimate Applications of CosmogenicNuclide Exposure Dating. Annual Review of Earth and Planetary Sciences, 48(1), 21-48.

Balco, G., Stone, J. O., Lifton, N. A., \& Dunai, T. J. (2008). A complete and easily accessible means of calculating surface exposure ages or erosion rates from 10Be and 26Al measurements. Quaternary Geochronology, 3(3), 174-195.

Barr, I. D., \& Lovell, H. (2014). A review of topographic controls on moraine distribution. Geomorphology, 226, 44-64.

Barrell, D. J. (2011a). Quaternary glaciers of New Zealand. In Developments in Quaternary Science (Vol. 15, pp. 1047-1064). Elsevier Science \& Technology.

Barrell, D., Andersen, B., \& Denton, G. (2011b). Glacial geomorphology of the central South Island, New Zealand. GNS Science Monography, 27.

Barrell, D. J. (2013a). Late Quaternary of the Southwest Pacific Region. In S. A. Elias, The Encyclopedia of Quaternary Science (Vol. 2, pp. 202-215). Amsterdam: Elsevier.

Barrell, D., Almond, P., Vandergoes, M., Lowe, D., \& Newnham, R. (2013b). A composite pollen-based stratotype for inter-regional evaluation of climatic 
events in New Zealand over the past 30,000 years (NZ-INTIMATE project). Quaternary Science Reviews, 74, 4-20.

Barrows, T. T., Almond, P., Rose, R., Fifield, L. K., Mills, S. C., \& Tims, S. G. (2013). Late Pleistocene glacial stratigraphy of the Kumara-Moana region, west coast of South Island, New Zealand. Quaternary Science Reviews, 74, 139159.

Bate, S. (2008). A reconstruction of equilibrium line altitudes of the Little Ice Age glaciers in Linnédalen, Western Spitsbergen, Svalbard. Term Project AG-212. Svalbard: University Centre in Svalbard.

Batt, G. E., \& Braun, J. (1999). The tectonic evolution of the Southern Alps, New Zealand: insights from fully thermally coupled dynamical modelling. Geophysical Journal International, 136(2), 403-420.

Blard, P., Bourlès, D., Pik, R., \& Lavé, J. (2008). In situ cosmogenic 10Be in olivines and pyroxenes. Quaternary geochronology, 3(3), 196-205.

Brook, M. (2009). Glaciation of Mt Allen, Stewart Island (Rakiura): The southern margin of LGM glaciation in New Zealand. Geografiska Annaler. Series A, Physical Geography, 91(2), 71-81.

Byrnes, G. (2015). Boundary markers : land surveying and the colonisation of New Zealand. Bridget Williams Books.

Carrivick, J., James, W., Grimes, M., Sutherland, J., \& Lorrey, A. (2020). Ice thickness and volume changes across the Southern Alps, New Zealand, from the little ice age to present. Scientific Reports, 10(1), 13392-13392.

Cerling, T., \& Craig, H. (1994). Geomorphology and In-Situ Cosmogenic Isotopes. Annual Review of Earth and Planetary Sciences, 22(1), 273-317.

Chandler, B., Lovell, H., Boston, C., Lukas, S., Barr, I., B. Í., . . Stroeven, A. (2018). Glacial geomorphological mapping: A review of approaches and frameworks for best practice. Earth-Science Reviews, 185, 806-846.

Chinn, T. J., \& Whitehouse, I. E. (1980). Glacier snow line variations in the Southern Alps, New Zealand. International Association of Hydrological Sciences Publication 126 (Riederalp Workshop 1978 - World Glacier Inventory),, 219228.

Chinn, T., Fitzharris, B. B., Willsman, A., \& Salinger, M. J. (2012). Annual ice volume changes 1976-2008 for the New Zealand Southern Alps. Global and Planetary Change, 92-93, 105-118.

Clark, P. U., Dyke, A. S., Shakun, J. D., Carlson, A. E., Clark, J., Wohlfarth, B., . . McCabe, A. M. (2009). The Last Glacial Maximum. Science, 325(5941), 710714.

Corbett, L. B., Bierman, P. R., \& Rood, D. H. (2016). An approach for optimizing in situ cosmogenic 10Be sample preparation. Quaternary Geochronology, 33, 24-34. 
Cullen, N., \& Conway, J. (2015). A 22 month record of surface meteorology and energy balance from the ablation zone of Brewster Glacier, New Zealand. Journal of Glaciology, 61(229), 931-946.

Darvill, C. M. (2013). Cosmogenic Nuclide Analysis. In L. E. Clarke, \& J. M. Nield, Geomorphological Techniques (pp. 1-25). London: British Society for Geomorphology.

Denton, G. H., Anderson, R. F., Toggweiler, J. R., Edwards, R. L., Schaefer, J. M., \& Putnam, A. E. (2010). The last glacial termination. Science, 328(5986), 16521656.

Desilets, D., \& Zreda, M. (2003). Spatial and temporal distribution of secondary cosmic-ray nucleon intensities and applications to in situ cosmogenic dating. Earth and Planetary Science Letters, 206(1-2), 21-42.

Doughty, A., Anderson, B., Mackintosh, A., Kaplan, M., Vandergoes, M., Barrell, D., ... Putnam, A. (2013). Evaluation of Lateglacial temperatures in the Southern Alps of New Zealand based on glacier modelling at Irishman Stream, Ben Ohau Range. Quaternary Science Reviews, 74, 160-169.

Dowdeswell, J., Hagen, J., Björnsson, H., Glazovsky, A., Harrison, W., Holmlund, P., . . . Thomas, R. (1997). The Mass Balance of Circum-Arctic Glaciers and Recent Climate Change. Quaternary Research, 48(1), 1-14.

Dowling, L. (2019). The Holocene Glacial History of Dart Glacier, Southern Alps, New Zealand. Victoria University of Wellington.

Drost, F., Renwick, J., Bhaskaran, B., Oliver, H., \& McGregor, J. (2007). Simulation of New Zealand's climate using a high-resolution nested regional climate model. International Journal of Climatology, 27(9), 1153-1169.

Dunai, T. J. (2001). Influence of secular variation of the geomagnetic field on production rates of in situ produced cosmogenic nuclides. Earth and Planetary Science Letters, 193(1), 197-212.

Dunai, T. J. (2010). Cosmogenic Nuclides. United Kingdom: Cambridge University Press.

Dunai, T. J., \& Lifton, N. A. (2014). The Nuts and Bolts of Cosmogenic Nuclide Production. Elements, 10(5), 347-350.

Dunne, J., Elmore, D., \& Muzikar, P. (1999). Scaling factors for the rates of production of cosmogenic nuclides for geometric shielding and attenuation at depth on sloped surfaces. Geomorphology, 27(1), 3-11.

Eaves, S. R., Anderson, B. M., \& Mackintosh, A. N. (2017). Glacier-based climate reconstructions for the last glacial-interglacial transition: Arthur's Pass, New Zealand (43ㅇ). Journal of Quaternary Science, 32(6), 877-887.

Eaves, S., \& Brook, M. (2021). Glaciers and glaciation of North Island, New Zealand. New Zealand Journal of Geology and Geophysics, 64(1), 1-20. 
Eaves, S., Mackintosh, A., Anderson, B., Doughty, A., Townsend, D., Conway, C., ... Calvert, A. (2016). The Last Glacial Maximum in the central North Island, New Zealand: palaeoclimate inferences from glacier modelling. Climate of the Past, 12(4), 943-960.

Fitzharris, B., Chinn, T., \& Lamont, G. (1997). Glacier balance fluctuations and atmospheric circulation patterns over the SOuthern Alps, New Zealand. International Journal of Climatology, 17(7), 745-763.

Forster, P., Ramaswamy, V., Artaxo, P., Berntsen, T., Betts, R., Fahey, D., ... Van Dorland, R. M. (2007). Changes in Atmospheric Constituents and in Radiative Forcing. United Kingdom: Cambridge University Press.

Gardner, A. S., \& Sharp, M. J. (2010). A review of snow and ice albedo and the development of a new physically based broadband albedo parameterization. Journal of Geophysical Research. Earth Surface, 115(1).

Gibbons, A., Megeath, J., \& Pierce, K. (1984). Probability of moraine survival in a succession of glacial advances. Geology (Boulder), 12(6), 327-330.

Golledge, N. R., Mackintosh, A. N., Anderson, B. M., Buckley, K. M., Doughty, A. M., Barrell, D. J., ... Schaefer, J. M. (2012). Last Glacial Maximum climate in New Zealand inferred from a modelled Southern Alps icefield. Quaternary Science Reviews, 46, 30-45.

Gosse, J. C., \& Phillips, F. M. (2001). Terrestrial in situ cosmogenic nuclides: theory and application. Quaternary Science Reviews, 20(14), 1475-1560.

Hancox, G., \& Perrin, N. (2009). Green Lake Landslide and other giant and very large postglacial landslides in Fiordland, New Zealand. Quaternary Science Reviews, 28(11), 1020-1036.

Hatherton, T., \& Leopard, A. (1967). The densitites of New Zealand rocks. New Zealand Journal of Geology and Geophysics, 7(3), 605-625.

Heyman, J., Stroeven, A., Harbor, J., \& Caffee, M. (2011). Too young or too old: Evaluating cosmogenic exposure dating based on an analysis of compiled boulder exposure ages. Earth and Planetary Science Letters, 302(1-2), 71-80.

IPCC. (2013). Climate Change 2013: The Physical Science Basis. Contribution of Working Group I to the Fifth Assessment Report of the Intergovernmental Panel on Climate Change (T. F. Stocker, D. Qin, G.-K. Plattner, M. Tignor, S. K. Allen, J. Boschung, A. Nauels, Y. Xia, V. Bex, \& P. M. Midgley Eds.). Cambridge, United Kingdom and New York, NY, USA: Cambridge University Press.

Ivy-Ochs, S., \& Briner, J. P. (2014). Dating Disappearing Ice with Cosmogenic Nuclides. Elements, 10(5), 351-356.

Ivy-Ochs, S., \& Kober, F. (2008). Surface exposure dating with cosmogenic nuclides. Quaternary Science Journal, 57(1-2), 179-208. 
Ivy-Ochs, S., Kerschner, H., \& Schlüchter, C. (2007). Cosmogenic nuclides and the dating of Lateglacial and Early Holocene glacier variations: The Alpine perspective. Quaternary International, 164, 53-63.

Jiang, N., Griffiths, G., \& Lorrey, A. (2013). Influence of large-scale climate modes on daily synoptic weather types over New Zealand. International Journal of Climatology, 33(2), 499-519.

Kaplan, M. R., Hein, A. S., Hubbard, A., \& Lax, S. M. (2009). Can glacial erosion limit the extent of glaciation? Geomorphology, 103(2), 172-179.

Kaplan, M. R., Schaefer, J. M., Denton, G. H., Barrell, D. J., Chinn, T. J., Putnam, A. E., . . Doughty, A. M. (2010). Glacier retreat in New Zealand during the Younger Dryas stadial. Nature, 467, 194.

Kaplan, M. R., Schaefer, J. M., Denton, G. H., Doughty, A. M., Barrell, D. J., Chinn, T., ... Finkel, R. C. (2013). The anatomy of long-term warming since $15 \mathrm{ka}$ in New Zealand based on net glacier snowline rise. Geology, 41(8), 887-890.

Kaplan, M., Ackert, J., Singer, B., Douglass, D., \& Kurz, M. (2004). Cosmogenic nuclide chronology of millennial-scale glacial advances during 0-isotope Stage 2 in Patagonia. Geological Society of America Bulletin, 116(3-4), 308321.

Kirkbride, M., \& Winkler, S. (2012). Correlation of Late Quaternary moraines: impact of climate variability, glacier response, and chronological resolution. Quaternary Science Reviews, 46, 1-29.

Koltai, G., Cheng, H., \& Spötl, C. (2018). Palaeoclimate significance of speleothems in crystalline rocks: a test case from the Late Glacial and early Holocene (Vinschgau, northern Italy). Climate of the Past, 14(3), 369-381.

Kuhn, M. (1995). The mass balance of very small glaciers. Zeitschrift für Gletscherkunde und Glazialgeologie, 31, 171-179.

Lal, D. (1991). Cosmic ray labeling of erosion surfaces: in situ nuclide production rates. Earth and Planetary Science Letters, 104(2-4), 424-439.

Lamont, G., Chinn, T., \& Fitzharris, B. (1999). Slopes of glacier ELAs in the Southern Alps of New Zealand in relation to atmospheric circulation patterns. Global and Planetary Change, 22(1), 209-219.

Lifton, N., Bieber, J. W., Clem, J. M., Duldig, M. L., Evenson, P., Humble, J. E., \& Pyle, R. (2005). Addressing solar modulation and long-term uncertainties in scaling secondary cosmic rays for in situ cosmogenic nuclide applications. Earth and Planetary Science Letters, 239(1), 140-161.

Lifton, N., Sato, T., \& Dunai, T. J. (2014). Scaling in situ cosmogenic nuclide production rates using analytical approximations to atmospheric cosmicray fluxes. Earth and Planetary Science Letters, 386, 149-160. 
Lifton, N., Smart, D., \& Shea, M. (2008). Scaling time-integrated in situ cosmogenic nuclide production rates using a continuous geomagnetic model. Earth and Planetary Science Letters, 268(1), 190-201.

Lorrey, A., Brookman, T., Evans, M., Fauchereau, N., Macinnis-Ng, C., Barbour, M., ... Schrag, D. (2016). Stable oxygen isotope signatures of early season wood in New Zealand kauri (Agathis australis) tree rings: Prospects for palaeoclimate reconstruction. Dendrochronologia (Verona), 40, 50-63.

Macara, G. R. (2013). The climate and weather of Southland. NIWA Science and Technology Series 63.

Mackintosh, A., Anderson, B., Lorrey, A., Renwick, J., Frei, P., \& Dean, S. (2017a). Regional cooling caused recent New Zealand glacier advances in a period of global warming. Nature Communications, 8(1), 14202-14202.

Mackintosh, A. N., Anderson, B. M., \& Pierrehumbert, R. T. (2017b). Reconstructing Climate from Glaciers. Annual Review of Earth and Planetary Sciences, 45(1), 649-680.

Marrero, S. M., Phillips, F. M., Borchers, B., Lifton, N., Aumer, R., \& Balco, G. (2016). Cosmogenic nuclide systematics and the CRONUScalc program. Quaternary Geochronology, 31, 160-187.

Masarik, J., \& Reedy, R. C. (1995). Terrestrial cosmogenic-nuclide production systematics calculated from numerical simulations. Earth and Planetary Science Letters, 136(3-4), 381-395.

McCarthy, A., Mackintosh, A., Rieser, U., \& Fink, D. (2008). Mountain Glacier Chronology from Boulder Lake, New Zealand, Indicates MIS 4 and MIS 2 Ice Advances of Similar Extent. Arctic, Antarctic, and Alpine Research, 40(4), 695-708.

McKinnon, K., Mackintosh, A., Anderson, B., \& Barrell, D. (2012). The influence of sub-glacial bed evolution on ice extent: a model-based evaluation of the Last Glacial Maximum Pukaki glacier, New Zealand. Quaternary Science Reviews, 57, 46-57.

Meier, M. F., \& Post, A. S. (1969). What are glacer surges? Canadian Journal of Earth Sciences, 6, 807-817.

Milankovich, M. (1941). Kanon der Erdbestrahlung und seine Anwendung auf das Eiszeitenproblem. Royal Serbian Academy Special Publication, 133, 1-633.

Nesje, A. (2014). Reconstructing Paleo ELAs on Glaciated Landscapes. Earth Sysems and Environmental Sciences, 909-917.

Nesje, A., \& Dahl, S. O. (2000). Glaciers and Environmental Change. London: Routledge.

Nishiizumi, K., Imamura, M., Caffee, M. W., Southon, J. R., Finkel, R. C., \& McAninch, J. (2007). Absolute calibration of 10Be AMS standards. Nuclear Instruments 
and Methods in Physics Research Section B: Beam Interactions with Materials and Atoms, 258(2), 403-413.

Norton, D. A. (1985). A multivariate technique for estimating New Zealand temperature normals. Weather and Climate, 5, 64-74.

Norton, K. P., von Blanckenburg, F., Schlunegger, F., Schwab, M., \& Kubik, P. W. (2008). Cosmogenic nuclide-based investigation of spatial erosion and hillslope channel coupling in the transient foreland of the Swiss Alps. Geomorphology, 95(3), 474-486.

Oerlemans, J. (1997). Climate sensitivity of Franz Josef Glacier, New Zealand as revealed by climatic modelling. Arctic \& Alpine Research, 29(2), 233-239.

Oerlemans, J. (2001). Glaciers and climate change. Lisse: A. A. Balkema.

Oerlemans, J., \& Fortuin, J. P. (1992). Sensitivity of Glaciers and Small Ice Caps to Greenhouse Warming. Science, 258(5079), 115-117.

Oerlemans, J., \& Knap, W. (1998). A 1 year record of global radiation and albedo in the ablation zone of Morteratschgletscher, Switzerland. Journal of Glaciology, 44(147), 231-238.

Porter, S. (2000). Snowline depression in the tropics during the Last Glaciation. Quaternary Science Reviews, 20(10), 1067-1091.

Porter, S. C. (1975). Equilibrium-line altitudes of late Quaternary glaciers in the Southern Alps, New Zealand. Quaternary Research, 5(1), 27-47.

Putnam, A. E., Denton, G. H., Schaefer, J. M., Barrell, D. J., Andersen, B. G., Finkel, R. C., ... Schlüchter, C. (2010a). Glacier advance in southern middle-latitudes during the Antarctic Cold Reversal. Nature Geoscience, 3, 700.

Putnam, A. E., Schaefer, J. M., Barrell, D. J., Vandergoes, M., Denton, G. H., Kaplan, M. R., ... Kelley, S. E. (2010b). In situ cosmogenic 10Be production-rate calibration from the Southern Alps, New Zealand. Quaternary Geochronology, 5(4), 392-409.

Putnam, A. E., Schaefer, J. M., Denton, G. H., Barrell, D. J., Birkel, S. D., Andersen, B. G., ... Doughty, A. M. (2013a). The Last Glacial Maximum at $44^{\circ} \mathrm{S}$ documented by a 10 Be moraine chronology at Lake Ohau, Southern Alps of New Zealand. Quaternary Science Reviews, 62, 114-141.

Putnam, A., Schaefer, J., Denton, G., Barrell, D., Andersen, B., Koffman, T., ... Ladig, K. (2013b). Warming and glacier recession in the Rakaia valley, Southern Alps of New Zealand, during Heinrich Stadial 1. Earth and Planetary Science Letters, 382, 98-110.

Putnam, A. E., Schaefer, J. M., Denton, G. H., Barrell, D. J., Finkel, R. C., Andersen, B. G., ... Doughty, A. M. (2012). Regional climate control of glaciers in New Zealand and Europe during the pre-industrial Holocene. Nature Geoscience, 5,627 . 
Ryan, J. C., Hubbard, A. L., \& Box, J. E. (2015). UAV photogrammetry and structure from motion to assess calving dynamics at Store Glacier, a large outlet draining the Greenland ice sheet. The Cryosphere, 9(1), 1-11.

Salinger, M. J., \& Mullan, A. B. (1999). New Zealand climate: temperature and precipitation variations and their links with atmospheric circulation. International Journal of Climatology, 19, 1049-1071.

Schaefer, J. M., Denton, G. H., Kaplan, M., Putnam, A., Finkel, R. C., Barrell, D. J., . . . Schlüchter, C. (2009). High-Frequency Holocene Glacier Fluctuations in New Zealand Differ from the Northern Signatur. Science, 324(5927), 622-625.

Sharp, M. (1988). Surging glaciers: behaviour and mechanisms. Progress in Physical Geography, 12(3), 349-370.

Shulmeister, J., Davies, T. R., Evans, D. J., Hyatt, O. M., \& Tovar, D. S. (2009). Catastrophic landslides, glacier behaviour and moraine formation - A view from. Quaternary Science Reviews, 28(11), 1085-1096.

Stone, J. (2000). Air pressure and cosmogenic isotope production. Journal of Geophyiscal Research: Solid Earth, 105(B10), 23753-23759.

Streckeisen, A. (1974). Classification and Nomenclature of Plutonic Rocks: Recommendations of the IUGS Subcommission on the Systematics of Igneous Rocks. Geologische Rundschau, 63(2), 773-786.

Tielidze, L., Eaves, S., Norton, K., \& Mackintosh, A. (2021). Glacial geomorphology of the Ahuriri River valley, central Southern Alps, New Zealand. Journal of Maps, 17(2), 73-86.

Tovar, D. S., Shulmeister, J., \& Davies, T. (2008). Evidence for a landslide origin of New Zealand's Waiho Loop moraine. Nature Geoscience, 1(8), 524.

Turnbull, I. M., Allibone, A. H., \& Jongens, R. (2010). Geology of the Fiordland area: scale 1:250,000. Institute of Geological \& Nuclear Sciences 1:250,000 geological map.

Ummenhofer, C. C., Gupta, A. S., \& England, M. H. (2009). Causes of Late TwentiethCentury Trends in New Zealand Precipitation. Journal of Climate, 22(1), 319.

Vacco, D., Alley, R., \& Pollard, D. (2010). Glacial advance and stagnation caused by rock avalanches. Earth and Planetary Science Letters, 294(1), 123-130.

von Blanckenburg, F., \& Willenbring, J. (2014). Cosmogenic nuclides; dates and rates of earth-surface change. Elements, 10(5), 341-346.

von Blanckenburg, F., Belshaw, N., \& O'Nions, R. (1996). Separation of 9Be and cosmogenic $10 \mathrm{Be}$ from environmental materials and SIMS isotope dilution analysis. Chemical Geology, 129(1-2), 93-99.

von Blanckenburg, F., Hewawasam, T., \& Kubik, P. (2004). Cosmogenic nuclide evidence for low weathering and denudation in the wet, tropical highlands of Sri Lanka. Journal of Geophysical Research: Earth Surface, 109(F3). 
Willsman, A. (2017). Annual glacier ice volumes, 1977-2016. Dunedin: National Institute of Water \& Atmospheric Research Ltd.

Willsman, A. P., CHinn, T., Hendrikx, J., \& Lorrey, A. (2010). New Zealand Glacier Monitoring: End of Summer Snowline Survey 2010. Christchurch: National Institute of Water \& Atmospheric Research Ltd.

Wirsig, C., Ivy-Ochs, S., Reitner, J., Christl, M., Vockenhuber, C., Bichler, M., \& Reindl, M. (2017). Subglacial abrasion rates at Goldbergkees, Hohe Tauern, Austria, determined from cosmogenic $10 \mathrm{Be}$ and $36 \mathrm{Cl}$ concentrations. Earth Surface Processes and Landforms, 42(7), 1119-1131.

Zekollari, H., Huss, M., \& Farinotti, D. (2020). On the Imbalance and Response Time of Glaciers in the European Alps. Geophysical Research Letters, 47(2), e2019GL085578. 